Official Cover and Approval pages include the Dean's signature, to be completed at the final exam or after required corrections are complete. No faculty/committee signatures are needed for these pages which become the first two pages of the thesis/dissertation (one consolidated document to be uploaded to Libra).

\title{
Anti-coking Materials for Steam Crackers
}

\author{
A Dissertation \\ Presented to
}

the faculty of the School of Engineering and Applied Science

University of Virginia

\author{
in partial fulfillment \\ of the requirements for the degree \\ Doctor of Philosophy \\ by \\ Kehua Yin
}

December 2016 


\title{
APPROVAL SHEET
}

\author{
This Dissertation \\ is submitted in partial fulfillment of the requirements \\ for the degree of \\ Doctor of Philosophy
}

Author Signature: Kehua Yin

This Dissertation has been read and approved by the examining committee:

Advisor: Robert J. Davis

Committee Member: William Epling

Committee Member: Joshua Choi

Committee Member: T. Brent Gunnoe

Committee Member: Sen Zhang

Committee Member:

Accepted for the School of Engineering and Applied Science:

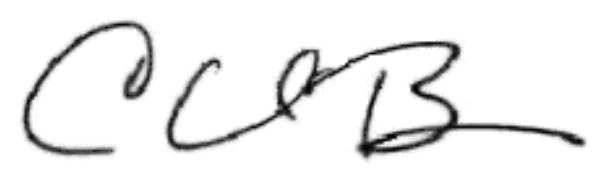

Craig H. Benson, School of Engineering and Applied Science

December 2016 


\title{
Anti-coking Materials for Steam Crackers
}

\author{
A Dissertation
}

Presented to

The faculty of the School of Engineering and Applied Science

University of Virginia

\author{
In Partial Fulfillment \\ of the requirement for the Degree \\ Doctor of Philosophy in Chemical Engineering
}

\author{
By \\ Kehua Yin \\ December 2016
}




\section{Abstract}

Steam cracking is one of the most important chemical processes in the world, which provides olefin monomers ethylene and propylene for the chemical industry. The boom of shale gas in the past decade has spurred the investment in steam cracking, with construction of new crackers and expansions of existing crackers planned. There has been growing interest in improving the operational profits of steam crackers by applying a catalytic coating on the internal wall of cracker tubes to reduce coke formation and increase the on-line production time. Ceria-based oxides have been widely used in the three way catalysts for gasoline car emission control and have shown excellent activity in carbon oxidation due to their redox property. The addition of cerium oxide has also been shown to reduce the coke formation over catalysts used for steam reforming of hydrocarbons. Therefore, ceria-based oxides are promising anti-coking coating materials for steam crackers. Moreover, a methodology for reaction of carbon needs to be developed to obtain reproducible kinetics.

In this study, a methodology has been developed by using coke oxidation with dioxygen over cerium-zirconium mixed oxides as a model reaction and was validated with classic gas phase $\mathrm{CO}$ oxidation. The surface-area-based reaction rates were obtained by evaluating the active catalyst surface area in the mixture of catalyst and coke, which correlated with the reaction rates of $\mathrm{CO}$ oxidation. The composition $\mathrm{Ce}_{0.8} \mathrm{Zr}_{0.2} \mathrm{O}_{2}$ was found to be the most active catalyst for coke oxidation. Detailed kinetic studies of both coke and $\mathrm{CO}$ oxidation revealed the important role of lattice oxygen.

The developed method was then used to study coke gasification with dioxygen and steam over alkaline-earth-metal-doped $\mathrm{Ce}_{0.8} \mathrm{Zr}_{0.2} \mathrm{O}_{2}$. The alkaline earth metal compounds were highly 
dispersed on the surface of $\mathrm{Ce}_{0.8} \mathrm{Zr}_{0.2} \mathrm{O}_{2}$. The presence of alkaline earth metals promoted the catalytic activity of coke gasification with steam but decreased the rate of coke gasification with dioxygen. 


\section{Acknowledgements}

I would like to thank the many people who have helped me in the past five years and contributed to my successful completion of this degree. First and foremost, I would like to express my deepest gratitude to my advisor, Prof. Robert Davis, for providing invaluable guidance, support, encouragement and help throughout my study, research and career development. The financial support from the Dow Chemical Company is appreciated. I am so grateful to collaborate with the researchers at the Dow Chemical Company and the Georgia Institute of Technology: Dr. Hirokazu Shibata, Dr. Andrzej Malek, Prof. Christopher Jones, Prof. Pradeep Agrawal and Ms. Shilpa Mahamulkar.

I would like to thank my $\mathrm{PhD}$ committee members for all of their insightful comments: Dr. Gary Koenig, Dr. Joshua Choi and Dr. Ian Harrison. Best regards go to the staff members in the department, Ms. Vickie Faulconer, Ms. Teresa Morris, Ms. Jennifer Davis and Mr. Ricky Buchanan. Many thanks go to all past and present Davis Lab members for their support and technical assistance, Dr. Heng Shou, Dr. Matthew Ide, Dr. Juan Lopez, Dr. Derek Falcone, Dr. Sabra Hanspal, Benjamin Huang, Jiahan Xie, Nicholas Kaylor, James Kammert, Gordon Brezicki and Tyler Prillaman.

I also want to thank my dear friends from Peking University and University of Virginia for their support. I enjoy the friendship and the happy time spending together with them. Many thanks goes to my girlfriend, Qitong Guo, whom I met at the University of Virginia. Those

memories with you will be my lifetime treasure. Thank you for teaching me how to have "common sense" and helping me get through the tough job search process. 
Last but not least, my sincerest gratitude to my family, my father Lvlong Yin, my mother Feng'e Li and my little brother Huajun Yin. Your everlasting support and love help me go through the difficult times and frustrations in the past five years. I will do my best to make you proud. 


\section{Table of Contents}

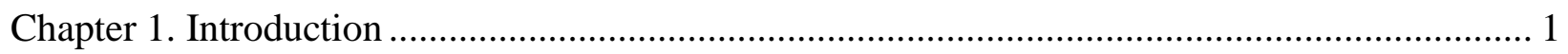

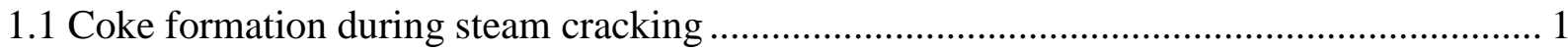

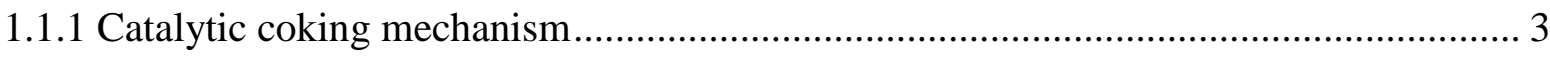

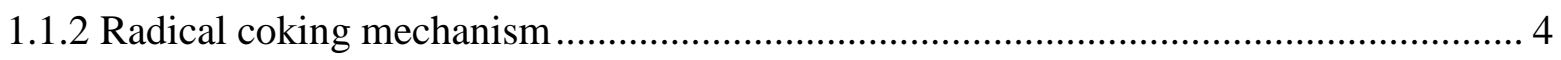

1.1.3 Droplet condensation coke ……….......................................................................... 5

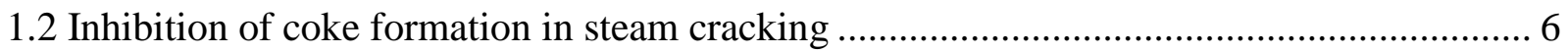

1.3 Cerium-based oxides: Promising Anti-coking coating materials for steam crackers ......... 10

1.3.1 Ceria-based materials for soot oxidation with dioxygen .......................................... 10

1.3.2 Effect of cerium addition during steam reforming reactions: Inhibition of coke

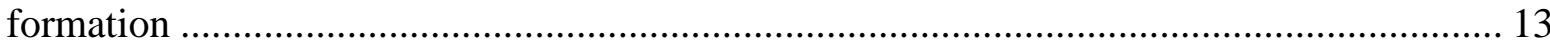

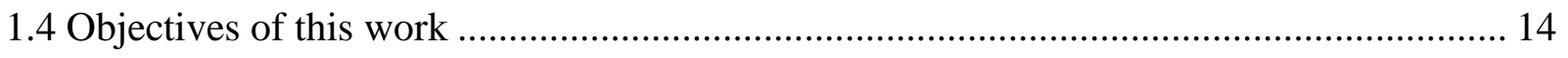

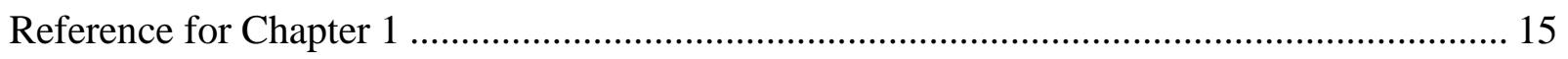

Chapter 2. Catalytic Oxidation of Solid Carbon and Carbon Monoxide over Cerium-Zirconium

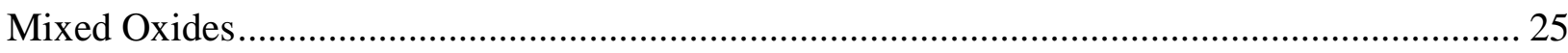

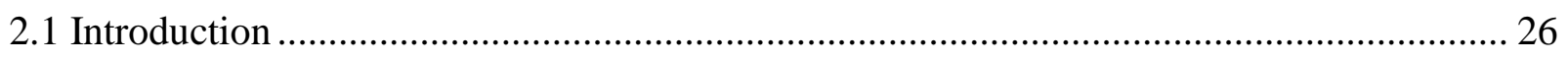

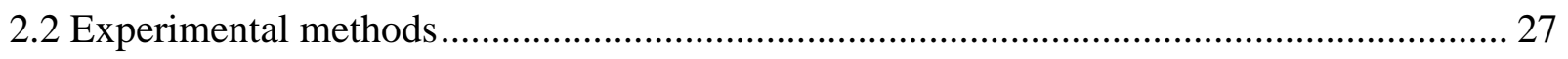

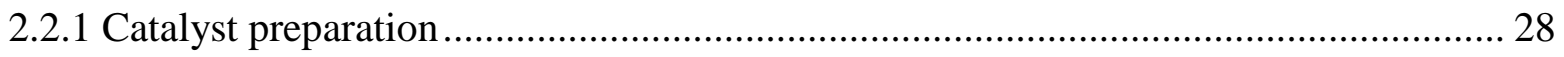

2.2.2 Coke formation from thermal reaction of ethylene ................................................... 28

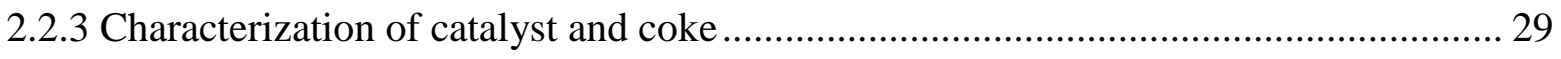


2.2.4 Coke oxidation by $\mathrm{O}_{2}$

2.2.5 $\mathrm{CO}$ oxidation by $\mathrm{O}_{2}$ 31

2.3 Results 32

2.3.1 Characterization of $\mathrm{CeO}_{2}, \mathrm{ZrO}_{2}$ and $\mathrm{Ce}-\mathrm{Zr}$ mixed oxides 32

2.3.2 Characterization of coke 40

2.3.3 Kinetics of coke oxidation in the presence of $\mathrm{CeO}_{2}$ and $\mathrm{Ce}-\mathrm{Zr}$ mixed oxides 44

2.3.4 $\mathrm{CO}$ oxidation over $\mathrm{CeO}_{2}$ and $\mathrm{Ce}-\mathrm{Zr}$ mixed oxides 51

2.4 Discussion 56

2.5 Conclusions 61

References for Chapter 2 62

Chapter 3. Catalytic Gasification of Coke with Dioxygen and Steam over Alkaline-earth-metaldoped Cerium-Zirconium Mixed Oxides 69

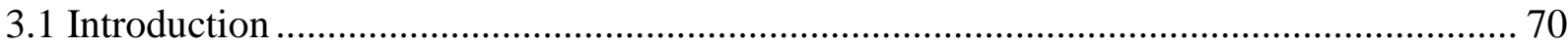

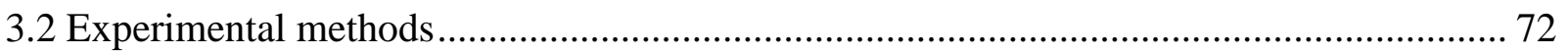

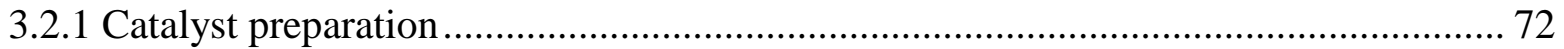

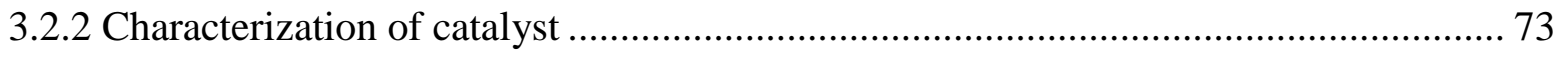

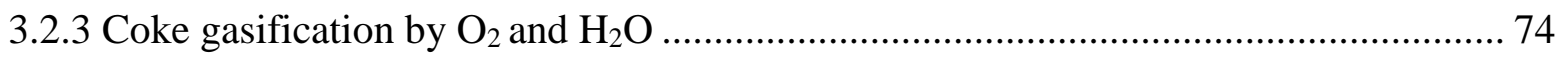

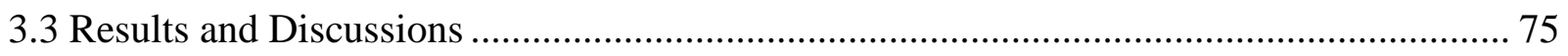

3.3.1 Characterization of undoped and alkaline-earth-metal-doped $\mathrm{Ce}_{0.8} \mathrm{Zr}_{0.2} \mathrm{O}_{2} \ldots \ldots \ldots \ldots \ldots .75$ 
3.3.2 Coke gasification with $\mathrm{O}_{2}$ and $\mathrm{H}_{2} \mathrm{O}$ in the presence of undoped and alkaline-earth-

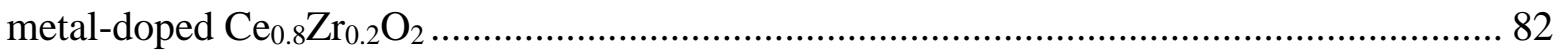

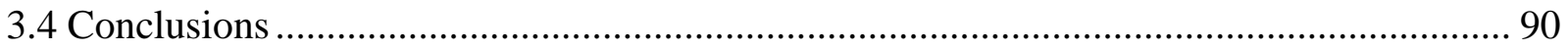

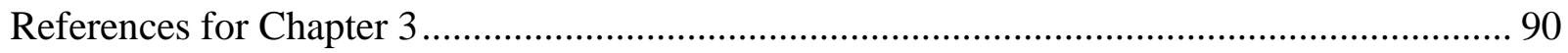

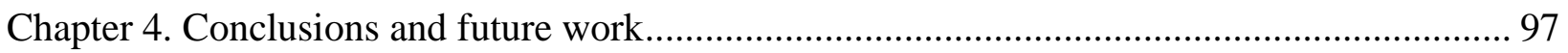

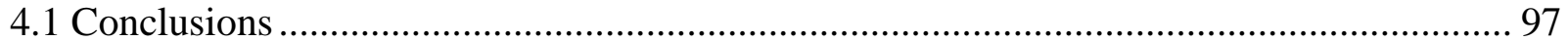

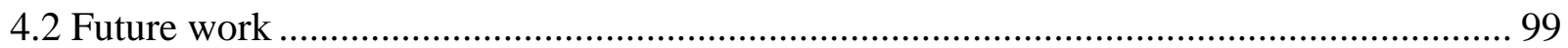

4.2.1 In-situ coke deposition and gasification over catalysts ...................................... 99

4.2.2 Water gas shift reaction: A possible probe reaction for steam gasification of coke .. 100

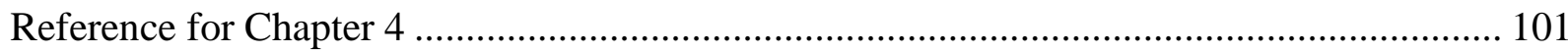

Appendix A. List of Publications at University of Virginia .................................................. 116 


\section{List of Tables}

Table 2.1 Physical properties of $\mathrm{CeO}_{2}, \mathrm{ZrO}_{2}$ and $\mathrm{Ce}-\mathrm{Zr}$ mixed oxides .................................. 32

Table 2.2 Surface compositions of $\mathrm{CeO}_{2}, \mathrm{CeO}_{2}$ and $\mathrm{Ce}-\mathrm{Zr}$ mixed oxides derived from XPS.... 37

Table 2.3 Oxygen storage capacity of $\mathrm{CeO}_{2}$ and $\mathrm{Ce}-\mathrm{Zr}$ mixed oxides.................................. 39

Table 2.4 Deconvolution of Raman features associated with synthetic coke........................... 43

Table 2.5 Active catalyst surface area and coke oxidation rates at $673 \mathrm{~K}$ for $\mathrm{CeO}_{2}$ and $\mathrm{Ce}-\mathrm{Zr}$

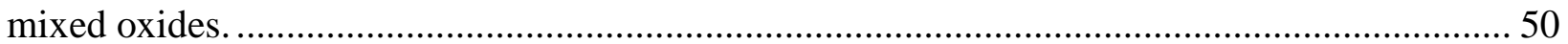

Table 2.6 Order of reaction with respect to dioxygen during coke oxidation with $\mathrm{Ce}_{0.8} \mathrm{Zr}_{0.2} \mathrm{O}_{2}$. ${ }^{\text {a }} 50$

Table 2.7 Order of reaction with respect to $\mathrm{O}_{2}$ during coke oxidation over Ce-based catalysts. ${ }^{\text {a }} 51$

Table 2.8 Apparent activation energy of coke oxidation in the presence of Ce-based catalysts. ${ }^{\text {a }} 51$

Table 2.9 Rate of $\mathrm{CO}$ oxidation at $5 \% \mathrm{CO}$ conversion over $\mathrm{CeO}_{2}$ and $\mathrm{Ce}-\mathrm{Zr}$ mixed oxides. ${ }^{\mathrm{a}}$..... 52

Table 2.10 Apparent activation energy of $\mathrm{CO}$ oxidation over Ce-based catalysts. ${ }^{\mathrm{a}} . . . . . . . . . . . . . . . . .55$

Table 2.11 Coke oxidation rates and its reaction conditions for cerium zirconium mixed oxides in

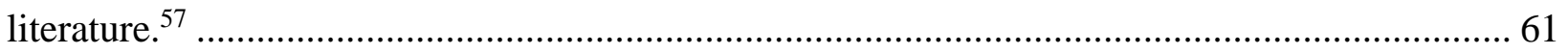

Table 3.1 Physical properties of undoped and alkaline-earth-metal-doped Ce-Zr mixed oxides. 75

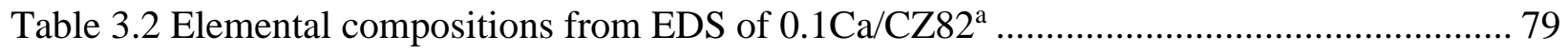

Table 3.3 Oxygen storage capacity of undoped and alkaline-earth-metal-doped $\mathrm{Ce}_{0.8} \mathrm{Zr}_{0.2} \mathrm{O}_{2} \ldots . .81$

Table 3.4 Coke gasification rate with dioxygen and steam over undoped and alkaline-earth-

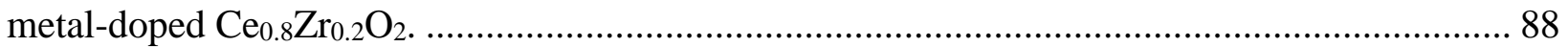




\section{List of Figures}

Figure 1.1 Catalytic coke formation schematic, ${ }^{11}$ Copyright The Society of Chemical Engineers,

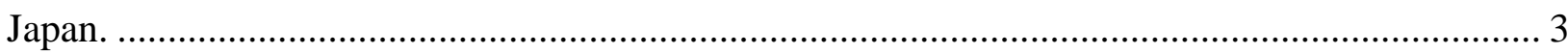

Figure 1.2 Radical mechanism for coke formation, ${ }^{8}$ Copyright The Society of Chemical

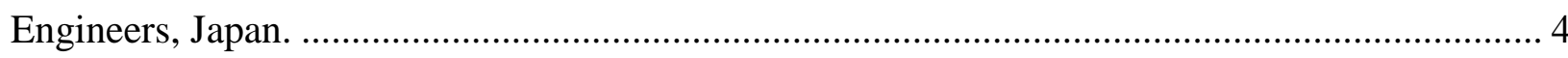

Figure 1.3 Droplet condensation mechanism, ${ }^{8}$ Copyright The Society of Chemical Engineers,

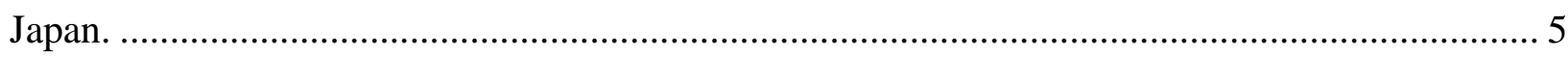

Figure 1.4 Rate of coke formation and weight content on a metallic cylinder. ${ }^{7} \ldots \ldots \ldots \ldots \ldots \ldots \ldots \ldots . . . . . . . . . . .6$

Figure 1.5 Scheme of active oxygen mechanism for $\mathrm{CeO}_{2}$ catalyzed carbon oxidation, ${ }^{28}$

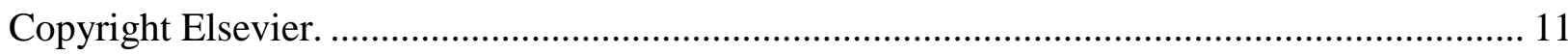

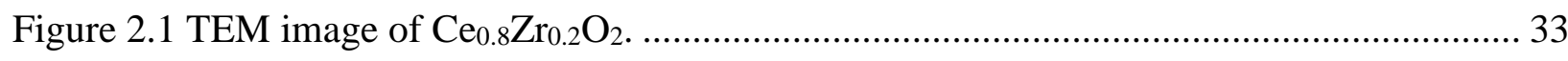

Figure 2.2 X-ray diffraction patterns of $\mathrm{CeO}_{2}$ and $\mathrm{ZrO}_{2}$, and $\mathrm{Ce}-\mathrm{Zr}$ mixed oxides. $\mathrm{C}$ : cubic, m:

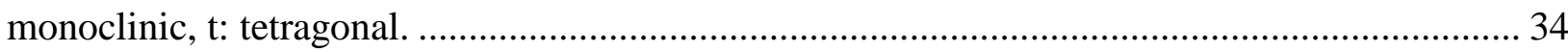

Figure 2.3 Raman spectra of $\mathrm{CeO}_{2}, \mathrm{ZrO}_{2}$ and $\mathrm{Ce}-\mathrm{Zr}$ mixed oxides. C: cubic, t: tetragonal, m:

monoclinic

Figure 2.4 X-ray photoelectron spectra of $\mathrm{Ce} 3 \mathrm{~d}$ core electrons of $\mathrm{CeO}_{2}$ and $\mathrm{Ce}-\mathrm{Zr}$ mixed oxides.

Figure $2.5 \mathrm{H}_{2}-\mathrm{TPR}$ of $\mathrm{CeO}_{2}$ and $\mathrm{Ce}-\mathrm{Zr}$ mixed oxide. Surface area of the oxide sample, provided

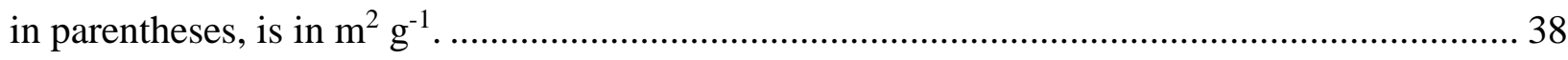

Figure 2.6 SEM image of synthetic coke after 64 hours milling. ....................................... 40

Figure 2.7 X-ray diffraction pattern of synthetic coke. ................................................. 41

Figure 2.8 HRTEM image of synthetic coke. .................................................................. 42

Figure 2.9 Raman spectrum of synthetic coke evaluated with an excitation $\lambda_{0}=514 \mathrm{~nm}$. Colors associated with various components can be found in the on-line version of the article. 
Figure 2.10 Temperature-programmed oxidation of synthetic coke with and without 20 wt.\% $\mathrm{Ce}_{0.8} \mathrm{Zr}_{0.2} \mathrm{O}_{2}$. Reaction conditions: $1 \mathrm{~K} \mathrm{~min}^{-1}, 100 \mathrm{~cm}^{3} \mathrm{~min}^{-1} 10$ vol. $\% \mathrm{O}_{2} / \mathrm{He}$, tight contact sample.

Figure 2.11 Weight loss profile of coke during coke oxidation catalyzed by $\mathrm{Ce}_{0.8} \mathrm{Zr}_{0.2} \mathrm{O}_{2}$ at $673 \mathrm{~K}$. Reaction conditions: 20 wt. $\% \mathrm{Ce}_{0.8} \mathrm{Zr}_{0.2} \mathrm{O}_{2}, 100 \mathrm{~cm}^{3} \mathrm{~min}^{-1} 10$ vol.\% $\mathrm{O}_{2} / \mathrm{He}$, tight contact sample.

Figure 2.12 Effect of grinding time on the rate constant of coke oxidation catalyzed by

$\mathrm{Ce}_{0.8} \mathrm{Zr}_{0.2} \mathrm{O}_{2}$. Reaction conditions: 20 wt. $\% \mathrm{Ce}_{0.8} \mathrm{Zr}_{0.2} \mathrm{O}_{2}, 100 \mathrm{~cm}^{3} \mathrm{~min}^{-1} 10$ vol.\% $\mathrm{O}_{2} / \mathrm{He}$.

Figure 2.13 SEM images of a mixture of $20 \mathrm{wt} . \% \mathrm{Ce}_{0.8} \mathrm{Zr}_{0.2} \mathrm{O}_{2}$ and $80 \mathrm{wt} . \%$ synthetic coke at tight contact (a and c) and loose contact (b and d) conditions.......

Figure 2.14 Relationship between measured first order rate constant and normalized catalyst loading for $\mathrm{CeO} 2$ and Ce-Zr mixed oxides. Reaction conditions: 673 K, 100 cm3 min-1 10 vol.\% $\mathrm{O} 2 / \mathrm{He}$, tight contact samples. 49

Figure 2.15 Influence of (a) $\mathrm{O}_{2}$ and (b) $\mathrm{CO}$ concentration on $\mathrm{CO}$ oxidation rate over $\mathrm{CeO}_{2}$ at 513

$\mathrm{K}$. While varying the concentration of one gas, the other gas was kept at 2 vol. $\%$. 53

Figure 2.16 Influence of (a) $\mathrm{O}_{2}$ and (b) $\mathrm{CO}$ concentration on $\mathrm{CO}$ oxidation rate over $\mathrm{Ce}_{0.8} \mathrm{Zr}_{0.2} \mathrm{O}_{2}$

at $513 \mathrm{~K}$. While varying the concentration of one gas, the other gas was kept at 2 vol.\%. 54

Figure 2.17 Correlation of coke oxidation rates at $673 \mathrm{~K}$ and $\mathrm{CO}$ oxidation rates at $573 \mathrm{~K}$ over

Ce-based materials. 57

Figure 2.18 Scheme of the CO oxidation mechanism over Ce-based catalysts. 58 Figure 2.19 Scheme of the mechanism of coke oxidation over Ce-based materials: 1. redox path, 2. spill-over of active oxygen path. Colors associated with various components can be found in the on-line version of the article. 59 
Figure 2.20 SEM image of coke- $\mathrm{Ce}_{0.8} \mathrm{Zr}_{0.2} \mathrm{O}_{2}$ mixture at $50 \%$ coke conversion. 60

Figure 3.1 X-ray diffraction patterns of undoped and alkaline-earth-metal-doped $\mathrm{Ce}_{0.8} \mathrm{Zr}_{0.2} \mathrm{O}_{2 .} .76$

Figure 3.2 Raman spectra of undoped and alkaline-earth-metal-doped $\mathrm{Ce}_{0.8} \mathrm{Zr}_{0.2} \mathrm{O}_{2}$. 77

Figure 3.3 Dark-field STEM image of 0.1Ca/Ce0.8Zr0.2O2. The corresponding compositions of analysis region are shown in Table 3.2 78

Figure 3.4 Uptake of $\mathrm{H} 2$ during temperature programmed reduction of undoped and alkalineearth-metal-doped $\mathrm{Ce}_{0.8} \mathrm{Zr}_{0.2} \mathrm{O}_{2}$.

Figure 3.5 Temperature-programmed oxidation of synthetic coke with and without catalyst.

Reaction conditions: $80 \mathrm{wt} . \%$ catalyst in the mixture, $5 \mathrm{~K} \mathrm{~min}^{-1}, 100 \mathrm{~cm}^{3} \mathrm{~min}^{-1} 10 \mathrm{vol} . \% \mathrm{O}_{2} / \mathrm{He}$, tight contact sample. The peak oxidation temperature are listed in the parenthes. 83

Figure 3.6 Weight loss profile of coke during coke oxidation catalyzed by $\mathrm{Ce}_{0.8} \mathrm{Zr}_{0.2} \mathrm{O}_{2}$ at $693 \mathrm{~K}$. Reaction conditions: 50 wt. $\% \mathrm{Ce}_{0.8} \mathrm{Zr}_{0.2} \mathrm{O}_{2}, 100 \mathrm{~cm}^{3} \mathrm{~min}^{-1} 10$ vol. $\% \mathrm{O}_{2} / \mathrm{He}$, tight contact sample.

Figure 3.7 Relationship between measured first order rate constant and normalized catalyst loading for (a) $\mathbf{~ : ~ C Z 8 2 , ~ \bullet : ~} 0.1 \mathrm{Mg} / \mathrm{CZ} 82, \boldsymbol{\Delta}: 0.1 \mathrm{Ca} / \mathrm{CZ} 82, \boldsymbol{\nabla}: 0.1 \mathrm{Sr} / \mathrm{CZ} 82, \quad 4: 0.1 \mathrm{Ba} / \mathrm{CZ} 82$; and (b) $\mathrm{Ce}_{0.8} \mathrm{Zr}_{0.2} \mathrm{O}_{2}$ doped with different amount of $\mathrm{Ca}$. 85 Figure 3.8 Temperature-programmed oxidation of synthetic coke with and without catalyst. Reaction conditions: 80 wt. $\%$ catalyst in the mixture, $5 \mathrm{~K} \mathrm{~min}^{-1}, 100 \mathrm{~cm}^{3} \mathrm{~min}^{-1} 100$ vol. $\% \mathrm{H}_{2} \mathrm{O}$, tight contact sample. The peak gasification temperatures are listed in the parenthesis 86 Figure 3.9 Weight loss profile of coke during coke oxidation catalyzed by $0.1 \mathrm{Ba} / \mathrm{Ce}_{0.8} \mathrm{Zr}_{0.2} \mathrm{O}_{2}$ at 993 K. Reaction conditions: 80 wt.\% $0.1 \mathrm{Ba} / \mathrm{Ce}_{0.8} \mathrm{Zr}_{0.2} \mathrm{O}_{2}, 100 \mathrm{~cm}^{3} \mathrm{~min}^{-1} 100$ vol.\% $\mathrm{H}_{2} \mathrm{O}$, tight contact samples 
Figure 3.10 Relationship between measured reaction rate and normalized catalyst loading for Undoped and alkaline earth metal doped $\mathrm{Ce}_{0.8} \mathrm{Zr}_{0.2} \mathrm{O}_{2}(\boldsymbol{\bullet}: \mathrm{CZ82}, \bullet: 0.05 \mathrm{Ca} / \mathrm{CZ} 82, \boldsymbol{\Delta}$ :

0.1Ca/CZ82, $\boldsymbol{\nabla}: 0.2 \mathrm{Ca} / \mathrm{CZ} 82,4: 0.1 \mathrm{Ba} / \mathrm{CZ82})$. Reaction conditions: $993 \mathrm{~K}, 100 \mathrm{~cm}^{3} \mathrm{~min}^{-1} 100$

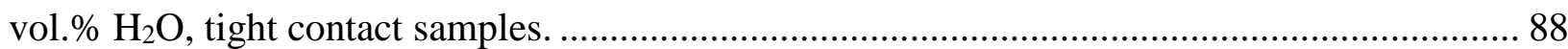




\section{Chapter 1. Introduction}

Adapted from Industry Engineering \& Chemistry Research, Shilpa Mahamulkar, ${ }^{[+]}$Kehua Yin, ${ }^{[+]}$ Pradeep K. Agrawal, Robert J. Davis, Christopher W. Jones, Andrzej Malek and Hirohazu Shibata, "Formation and oxidation/gasification of carbonaceous deposits: A review", 2016, 55 (37), 9760-9818, with permission from ACS Publisher. ${ }^{[+]}$Equal contribution

\subsection{Coke formation during steam cracking}

Ethylene is one of the most important building blocks for the chemical industry, with its production exceeding any other organic compound. The global ethylene production was about 167 million tons in 2014, while the production in the US was about 36 million tons. Around $60 \%$ of the ethylene produced is utilized in the production of polyethylene. Other important ethylene derivatives are ethylene oxide (13\%), ethylene dichloride (13\%) and ethylbenzene (7\%). At these high temperatures, radical reactions play an important role in the formation of a wide range of hydrocarbons. The major reaction for cracking of ethane involves dehydrogenation as shown in the following equation:

$$
\mathrm{H}_{3} \mathrm{C}-\mathrm{CH}_{3} \rightarrow \mathrm{H}_{2} \mathrm{C}=\mathrm{CH}_{2}+\mathrm{H}_{2}
$$

The cracking units are typically made of alloys containing $\mathrm{Ni}, \mathrm{Fe}, \mathrm{Cr}$, that are capable of withstanding very high temperatures. ${ }^{1}$ The residence time for these reactions is around $0.5-1 \mathrm{~s}$. At these high temperatures, radical reactions play an important role in the formation of a wide range of hydrocarbons. One of the major by-products of the steam cracking process is the formation of carbonaceous deposits (coke) on the walls of the reactor. The amount and type of coke formed depends on the operating conditions, nature of the feed, and nature of the reactor surface. Steam dilution of the feed has been observed to reduce coke formation. ${ }^{2}$ Coke formation affects the production efficiency in a number of ways, as mentioned below: , $^{3,4}$ 
- Increases pressure drop in the reactor ${ }^{5}$

- Reduces the reactor volume

- Increases the temperature of the reactor tube by affecting heat transfer from tube to gas

- Leads to expensive shutdowns

- Causes carburization of steel

- Influences the flow in the reactor

- Decreases the production capacity ${ }^{6}$

Coke formed in the cracking reactor is typically combusted by passing a mixture of steam and air at very high temperatures through the reactor in regeneration mode. The plant typically requires a shutdown for decoking every 20-60 days, depending on the type of feed used. ${ }^{7}$ These shutdowns are usually expensive and efforts are directed towards increasing the run length of steam crackers.

Coke deposition in steam cracking reactions is a combination of the following mechanisms namely: radical reactions in the gas phase, droplet condensation and coke formed on metallic particles. 


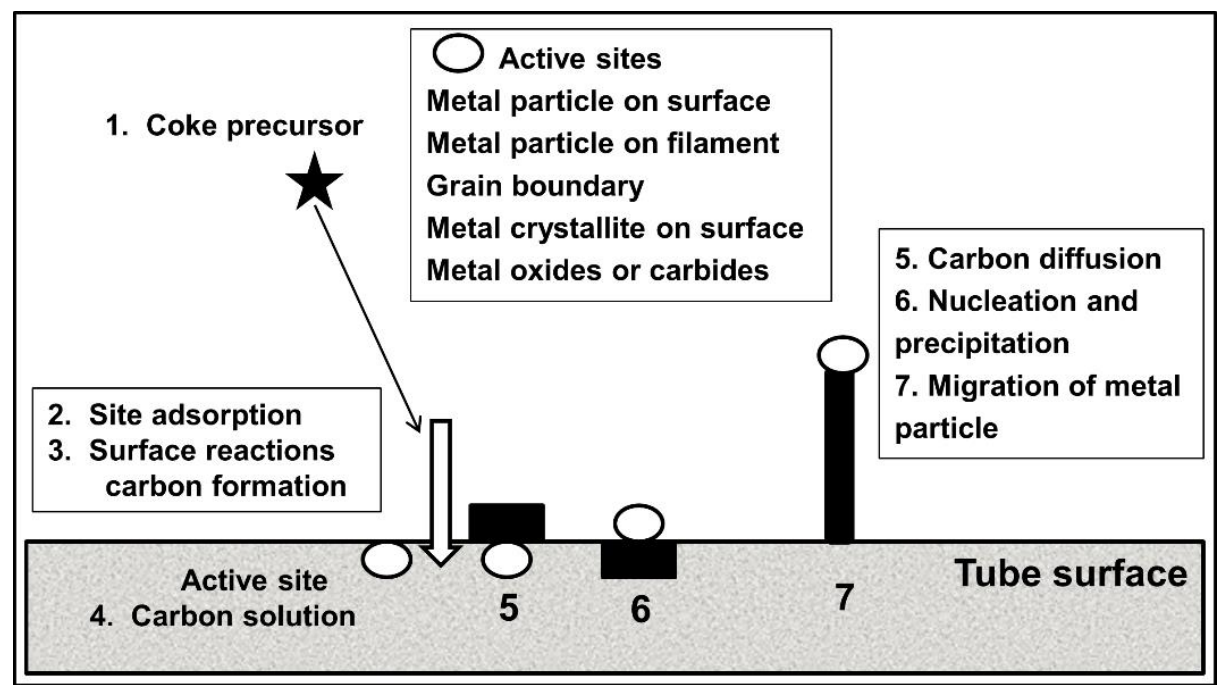

Figure 1.1 Catalytic coke formation schematic, ${ }^{11}$ Copyright The Society of Chemical Engineers, Japan.

\subsubsection{Catalytic coking mechanism}

In a steam cracker, catalytic coke formation takes place in the presence of catalytic sites, which can be the metallic walls of the reactor, more likely at grain boundaries. ${ }^{3,8}$ Since most industrial cracking units are made of alloys of $\mathrm{Ni}, \mathrm{Fe}$, and $\mathrm{Cr}$, many types of metallic sites are present on the reactor surface. These sites can catalyze coke formation at temperatures as low as $500{ }^{\circ} \mathrm{C}$. Although the catalytic coking rate increases significantly with increasing reaction temperatures, the coking rate is also highly dependent on the reactor surface used. Due to the presence of metallic sites, coking rates are higher in reactors made of materials like stainless steels or Incoloy (superalloys made of iron-nickel-chromium having good corrosion resistance and stability at high temperatures), compared to more inert oxide materials such as quartz..$^{3,4,9,10}$ Figure $1.1^{11}$ shows a schematic of the catalytic coking process taking place on a reactor wall. Hydrocarbons adsorb on the metallic surface and form coke. This coke further dissolves and diffuses through the metallic particle. With time, carbon deposits at the end of the metal particle, 
raising the metal from the reactor surface. This mechanism is most important after the decoking step when the reactor wall is clean, devoid of any coke exposing the metallic sites on the surface for reaction. ${ }^{12}$

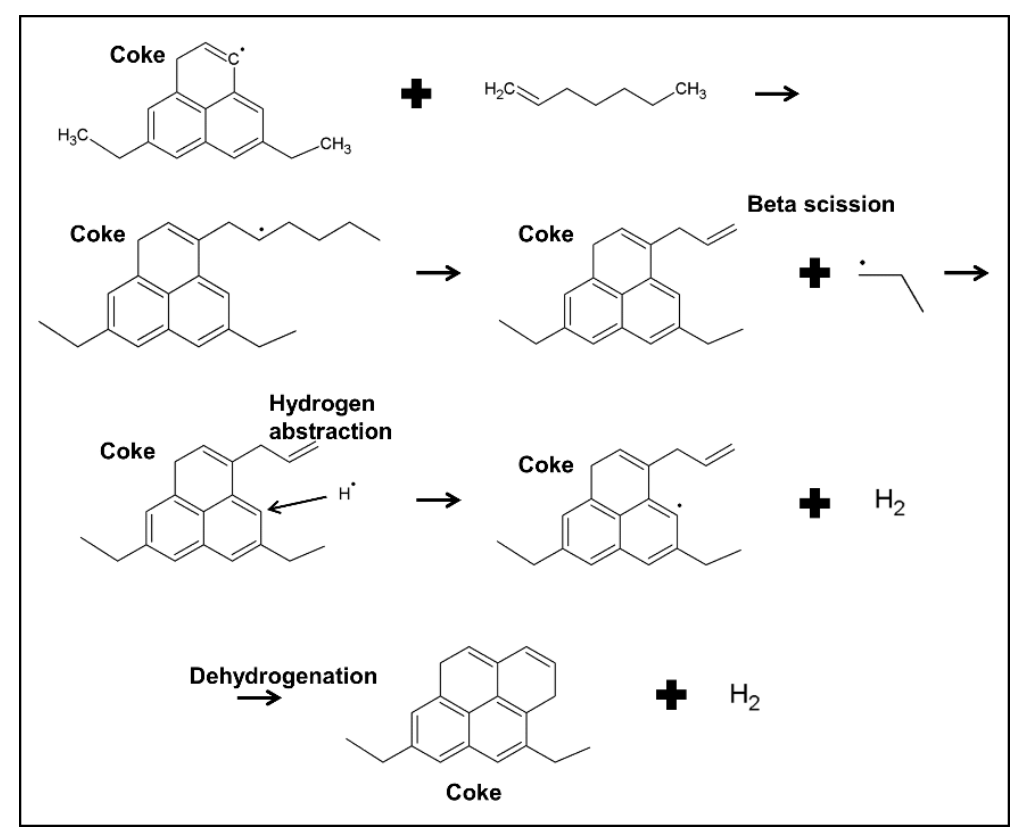

Figure 1.2 Radical mechanism for coke formation, ${ }^{8}$ Copyright The Society of Chemical Engineers, Japan.

\subsubsection{Radical coking mechanism}

At very high temperatures in the steam cracker, radicals are formed in the gas phase producing pyrolytic coke, which deposits on the reactor surface. ${ }^{3,8}$ These endothermic reactions require significant energy input to form the radical intermediates and hence take place only at high temperatures. Figure 1.2 shows a pathway for the formation of coke by the radical mechanism. ${ }^{8}$ Coke radicals in the gas phase react with the hydrogen present in unsaturated hydrocarbons. Decomposition of the aliphatic chain gives rise to new radicals. Further dehydrogenation of such molecules results in increase in the aromatic nature of the coke and also regeneration of radicals. Coke formed by this mechanism has very low hydrogen content because 
of the dehydrogenation of molecules during the coking reactions. The coke formed is typically very hard (graphitic) due to the cross-linking of aromatic molecules under the reaction conditions.

The rate of coke formation is highest for acetylene and lowest for paraffins and follows

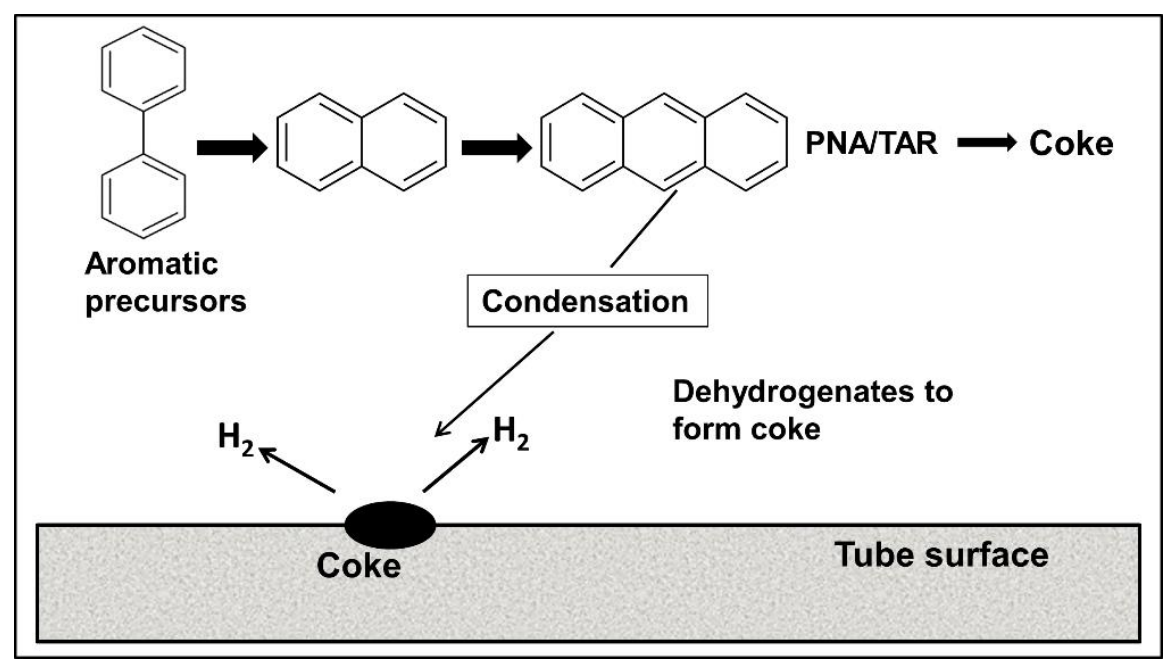

Figure 1.3 Droplet condensation mechanism, ${ }^{8}$ Copyright The Society of Chemical Engineers, Japan.

the order: acetylene $>$ olefins $>$ aromatics $>$ paraffins.

\subsubsection{Droplet condensation coke}

Aromatics with one or two rings act as coke precursors and condense by dehydrogenation to form tar-like particles after striking the reactor surface. ${ }^{13}$ This condensation takes place downstream of the cracking reactor where the temperature is lower than that in the reactor furnace.

A schematic of the droplet condensation mechanism is shown in Figure 1.3. At elevated temperatures, molecules undergo dehydrogenation, aided by radicals. This mechanism helps in 
further growth of the coke layer. Some molecules undergo hydrogen abstraction in the gas phase itself and are deposited on the reactor surface. The coke formed in the transfer line exchanger

results from the condensation of polyaromatics. ${ }^{10}$ Since the mechanism involves condensation of aromatic molecules at lower temperature, the coking rate is independent of the

chemical characteristics of the reactor surface. ${ }^{10}$

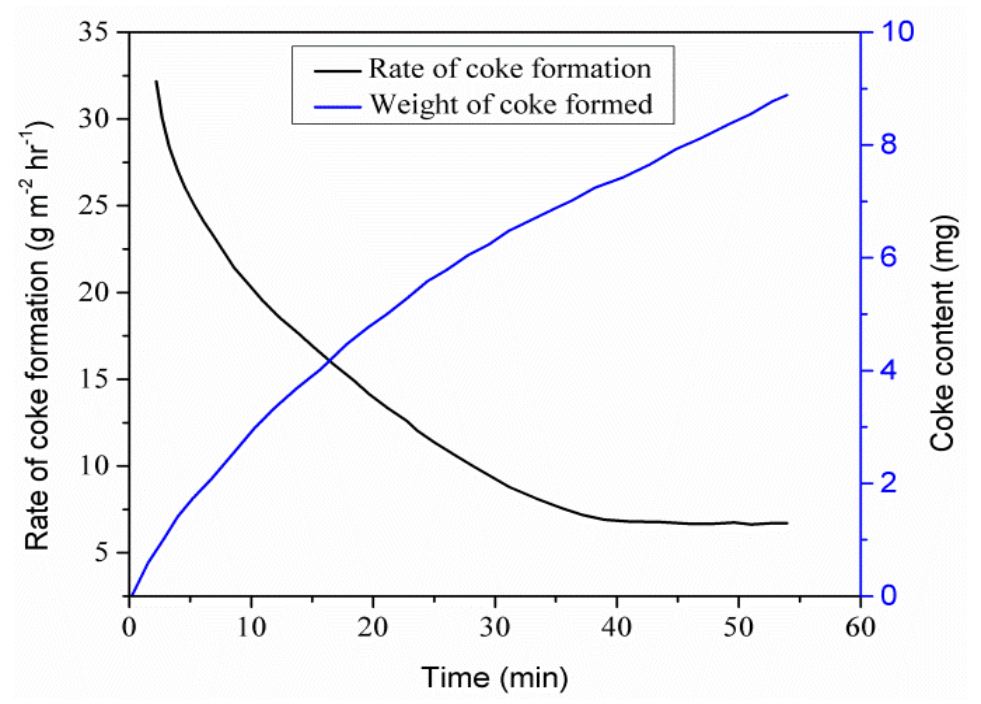

Figure 1.4 Rate of coke formation and weight content on a metallic cylinder. ${ }^{7}$

Figure 1.4 shows the rate of coke formation on a stainless steel surface as a function of time. The rate is initially high and decreases with time. ${ }^{7}$ Coke formation takes place both by catalytic and radical mechanism in the region where the coking rate changes with time. Deposition of coke on the metal surface decreases the rate of catalytic coke formation until all of the sites are blocked. At this point, the rate of coke formation becomes approximately constant and only radical coke is formed.

\subsection{Inhibition of coke formation in steam cracking}


Various researchers have undertaken different routes to reduce the coke formed due to the catalytic mechanism. The main approach to reduce the coke formed by this method is to create a barrier between the metallic reactor surface and the gas phase in the reactor.

For example, an aluminum coating has been used to passivate the cracking reactor surface before the reaction began, which reduced the amount of catalytic coking. ${ }^{6,14}$ Addition of magnesium to aluminum further reduced the coking rate. It was observed that the coke deposition reduced significantly due to these coatings, as the metal reactor surface sites were blocked. Zinc coatings were found to be effective in the oxidation of the coke formed on the reactor surface. ${ }^{6}$ Thermal spraying, ${ }^{14}$ plasma spraying, ${ }^{6}$ packed cementation ${ }^{6,14}$ and chemical vapor deposition (CVD) techniques have been used for coating of ceramic powders on the cracking furnace. ${ }^{1} \mathrm{TiC}$ and $\mathrm{SiC}$ coatings proved to be effective in reducing the rate of coke formation for n-hexane cracking. ${ }^{1}$

A coating of sulfur or phosphorous on the cracking furnace has also been shown to passivate the reactor surface, leading to decreased coke formation. This involved formation of metallic sulfides or metal phosphorous complexes that coordinated with the metal sites and reduced their catalytic activity. Addition of $\mathrm{SiO}_{2} / \mathrm{S}$ to the $\mathrm{S} / \mathrm{P}$ coating further enhanced the coke reduction. ${ }^{15-17}$ Dimethyl disulfide and carbon disulfide are other sulfur compounds used as coke inhibitors. ${ }^{6}$ Annealing of the cracking furnace in the presence of a $\mathrm{H}_{2} / \mathrm{H}_{2} \mathrm{O}$ mixture has been applied at higher temperatures to reduce the presence of metallic sites ( $\mathrm{Ni}, \mathrm{Fe})$ and enrich the surface with chromia. ${ }^{18}$

Westaim Surface Engineered Products Inc. developed a coating called CoatAlloy ${ }^{\mathrm{TM}}$ for use in ethylene pyrolysis furnaces. The coating consists of three layers: to prevent catalytic coking, gasify radical coke and stop carbon deposits from penetrating the metal surface to cause 
carburization. After one year of service, no carburization was observed on the surface of the coating. ${ }^{19}$ SK Corporation developed a coating called PY-Coat that serves similar purposes. ${ }^{20}$ The coating formulation is immediately injected into the hot furnace after the decoking step. The formulation vaporizes and deposits on the reactor inner surface and acts as a barrier. The basic components of the coating are $\mathrm{Si}, \mathrm{Cr}, \mathrm{Al}, \mathrm{Ti}$, and alkali and alkaline-earth. In a pilot plant set-up for ethane cracking at $65 \%$ conversion, the coating showed no pressure drop and temperature drop. The uncoated reactor showed a pressure drop of $27 \mathrm{psi}$ and temperature difference of $26{ }^{\circ} \mathrm{C}$ higher than the start of the operation.

Another furnace coil coating technology called catalyzed assisted manufacture of olefins (CAMOL) by BASF aims to have a coke-free environment in cracking furnaces. ${ }^{21-23}$ This technology proposed to increase the run-length of the reactor and has been undergoing commercial trials since 2006 . These coatings have the ability to be used in high temperature furnaces above $1130{ }^{\circ} \mathrm{C}$, and they can potentially reduce the amount of steam required for dilution to keep coke formation to an optimum. The coatings act as a barrier between the metal sites from the reactor and the hydrocarbon gases and usually exist as an oxide layer $<10 \mu \mathrm{m}$ in thickness. The coating also has a catalytic layer that can gasify the coke formed on the surface of the coating. Around $1-2$ furnace run-lengths have been achieved with this technology for lighter feedstocks and around 100 days for higher feedstocks. The coating was reported to have no impact on the product distribution and a positive impact on the yield of products, by mitigating the formation of filamentous and amorphous coke. Two types of coatings have been developed, including one for low-level catalytic gasification for lighter feeds and another for high-level catalytic gasification coating for heavier feeds. 
The Alcroplex ${ }^{\circledR}$ diffusion coating from Alon Surface Technologies Inc., which is a surface modified HP material (heat resistant alloy made of iron-nickel-chromium), has been reported to reduce the coke formation rate up to $90 \%$ in the cracking of ethane. ${ }^{24}$ It is a technology that uses a CVD mechanism for creating a stable coating on the surface of the reactor. Commercially, it has performed well by reducing the carburization of the steel and also the surface-induced catalytic coking.

NOVA Chemicals developed a technology called ANK 400 over the past 10 years. ${ }^{25,26}$ They claim to have increased run lengths in the crackers around 10 fold with the help of an inert, nanocrystalline spinel coating that reduces both catalytic and radical coke. They also have various pretreatments that could be carried out on stainless steel reactors that can help passivate the reactor surface and reduce coke formation. ${ }^{27}$

Schietekat et al. recently developed a coating called YieldUp based on a perovskite catalyst system for reducing coke formation during steam cracking. ${ }^{25}$ These coatings reduced the coke formed on Incoloy $800 \mathrm{HT}$ drastically by aiding the reaction of coke with steam. A reduction of $76 \%$ in the coke deposition on Incoloy was reported. Performance of the coating in an industrial reactor was checked by a simulation of the reactor. It was estimated that a $525 \%$ increase in the run length could be achieved by application of the coating.

In other work, an $\mathrm{H}_{2} \mathrm{PtCl}_{6}$ additive lowered the rate of coke formation during steam cracking of ethane or propane, both on a quartz and a stainless steel reactor. ${ }^{4}$ Quartz is inert in nature due to the absence of metallic sites on its surface. The coke formed on quartz surfaces is mainly gas phase coke. Stainless steel has presence of metallic sites which can catalyze coke formation. Both pyrolytic and catalytic coke species are formed on stainless steel surfaces. The addition of $\mathrm{H}_{2} \mathrm{PtCl}_{6}$ was able to reduce both pyrolytic and catalytic coke. 
The coatings of materials on cracking furnaces develop cracks after prolonged use at higher operating temperatures. These cracks might then serve as the sites for catalytic coke formation. Thus, efforts are underway to increase the stability of the coatings used to passivate the surface, thus further increasing run lengths.

\subsection{Cerium-based oxides: Promising anti-coking coating materials for steam crackers}

Ceria-based materials have received a lot of interest because of their demonstrated catalytic activity in several reactions, such as $\mathrm{CO}$ oxidation and soot oxidation, which can be attributed to the redox property of cerium. ${ }^{28-31}$ Ceria-based materials have been widely used in the Three Way Catalysts (TWC) for the emission control of gasoline cars since the mid-1980s. ${ }^{32-}$ 34

\subsubsection{Ceria-based materials for soot oxidation with dioxygen}

Ceria-based materials have been extensively studied for soot abatement of diesel engines. Early studies used cerium salts as fuel additives in diesel engines. Cerium oxides were formed in the combustion process and entered the soot particles, which significantly lowered the ignition temperature of the soot and increased the oxidation rates by 20 fold. ${ }^{35,36}$ However, the exhaust of cerium nanoparticles poses potential environmental, health and ecological effects, which need to be taken into consideration, disfavoring use of these species as fuel additives. ${ }^{37}$

Bueno-López et al. studied the $\mathrm{CeO}_{2}$ catalyzed soot oxidation reaction with labelled oxygen in an advanced TAP reactor. ${ }^{38}$ They found that the oxygen from $\mathrm{CeO}_{2}$ reacted with soot, and the direct reaction of the gas-phase oxygen with soot did not occur under the conditions used. They defined such oxygen as "active oxygen", which was induced from the chemisorption of 
gas-phase dioxygen on $\mathrm{CeO}_{2}$. Such "active oxygen" may be oxygen superoxide ions $\left(\mathrm{O}_{2}{ }^{-}\right)$, which were detected by $\mathrm{ESR}^{39}$ and FTIR experiments. ${ }^{40,41}$

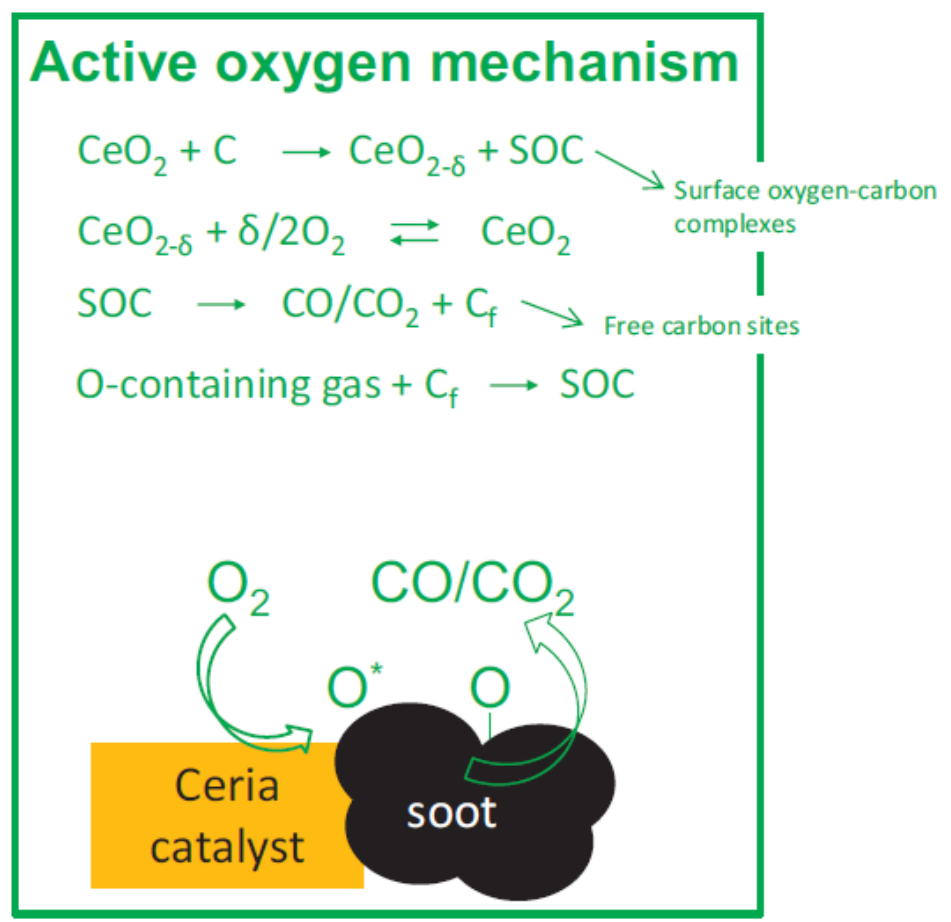

Figure 1.5 Scheme of active oxygen mechanism for $\mathrm{CeO}_{2}$ catalyzed carbon oxidation, ${ }^{28}$ Copyright Elsevier.

However, these measurements were not performed under in-situ soot oxidation reactions. DFT calculations have also confirmed the formation of superoxide and peroxide ions on ceriabased catalysts. ${ }^{42,43}$ Machida et al. concluded that active oxygen could be formed by either the lattice oxygen at the $\mathrm{CeO}_{2}$ /soot interface or gas-phase oxygen adsorbed at the boundary of soot + reduced $\mathrm{CeO}_{2}+$ the gas phase, with the former being much more important. ${ }^{39}$ The active oxygen was not only localized at the $\mathrm{CeO}_{2} /$ soot interface, but also transferred to the soot surface by spillover through surface diffusion. ${ }^{44}$ However, the distance of spillover for active oxygen 
species was still not clear. The active oxygen species then reacted with soot to form surface oxygen species, followed by their decomposition to form $\mathrm{CO}$ and $\mathrm{CO}_{2}$. Figure 1.5 shows a scheme of the proposed active oxygen mechanism for $\mathrm{CeO}_{2}$ catalyzed carbon oxidation.

Although ceria is active for the soot oxidation reaction, it suffers from sintering under high temperatures and thus a loss of activity. Therefore, modification of ceria with other metal ions has been explored to improve its thermal stability, enhance the reducibility of $\mathrm{Ce}^{4+} / \mathrm{Ce}^{3+}$ and improve the bulk oxygen mobility. These elements include $\mathrm{La},{ }^{45-47} \mathrm{Zr},{ }^{48-51} \mathrm{Hf},{ }^{50} \mathrm{Co},{ }^{52} \mathrm{Mn},{ }^{53}$ $\mathrm{Sm},{ }^{54} \mathrm{~Tb},{ }^{54} \mathrm{Nd},{ }^{55} \mathrm{Fe},{ }^{56} \mathrm{Gd},{ }^{57}$ and Lu. Among those parameters, surface reducibility is thought to be the most important. Mixed oxides can be prepared by various methods: coprecipitation, ${ }^{51}$ solgel, ${ }^{58-60}$ thermal decomposition of mixed salts, ${ }^{48}$ solid combustion, ${ }^{61}$ formation of inverse micromulsion, ${ }^{61}$ and with poly(methyl methacrylate) (PMMA) colloidal crystal templates. ${ }^{62}$ The carbon oxidation reaction mechanism of carbon oxidation is thought to remain the same after the doping of rare-earth metals, while the reaction mechanism may change after modifications with alkali metals, transition metals and noble metals. These mechanisms are discussed in a recent review by Liu et al. ${ }^{63}$

It is well established that the doping of cerium oxide with $\mathrm{Zr}^{4+}$ leads to the formation of solid solutions, which increases the thermal stability, reducibility and enhances the oxygen storage capacity of the oxide. ${ }^{64}$ Aneggi et al. investigated the roles of lattice/surface oxygen in cerium-zirconium oxide catalysts for soot oxidation. They found that there was an inverse correlation of total available surface oxygen and $\mathrm{T}_{50}$. Furthermore, the oxygen storage capacity was only important in the absence of gaseous oxygen. ${ }^{51}$ Hurtado et al. found that the cerium zirconium mixed oxides prepared from $\left(\mathrm{NH}_{4}\right)_{2} \mathrm{Ce}\left(\mathrm{NO}_{3}\right)_{6}$ showed higher activity than those made from $\mathrm{Ce}\left(\mathrm{NO}_{3}\right)_{6} \cdot 6 \mathrm{H}_{2} \mathrm{O} .{ }^{65}$ The cubic structure of the cerium zirconium mixed oxides gradually 
turned into a tetragonal structure with an increased amount of zirconium. The ceria-rich mixed oxides showed higher catalytic activity than the corresponding zirconium-rich mixed oxides. The optimal molar fraction of $\mathrm{Ce}$ in the mixed oxides was between 0.7 and $0.8 .^{51,66,65}$ The morphology of cerium zirconium mixed oxides was found to affect the soot oxidation activity. ${ }^{67}$ Hierarchically porous cerium zirconium mixed oxides were synthesized with a biotemplate method: pine sawdust was impregnated with a solution of cerium and zirconium nitrates and the dried sample was calcined at $600{ }^{\circ} \mathrm{C}$ to give a mixed oxide with predictable porosity. The resulting mixed oxides showed higher soot oxidation activity than the corresponding ones made from a co-precipitation method, which was attributed to higher amount of mobile lattice oxygen, as characterized by the lower temperature peak in $\mathrm{H}_{2}-\mathrm{TPR}$ and the higher oxygen storage capacity.

\subsubsection{Effect of cerium addition during steam reforming reactions: Inhibition of coke formation}

To the best of my knowledge, there is no study about the application of cerium-based materials for steam gasification of coke. However, the presence of cerium in the catalysts has been shown to inhibit coke formation during the steam reforming of hydrocarbons ${ }^{68-71}$. Zhuang et al. investigated the effect of cerium oxide in $\mathrm{MgAlO}_{3}$ supported Ni catalyst for methane steam reforming ${ }^{68}$. Cerium oxide not only decreased the rate of coke deposition, but also increased the catalytic activity of steam reforming. Natesakhawat et al. reported the beneficial effects of cerium promoter in a Ni/Al2O3 catalyst for propane steam reforming by both inhibiting coke formation and improving catalytic activity ${ }^{69}$. Wang et al. compared the steam reforming rates of methane, ethane, n-butane, n-hexane on a Pd/ceria catalyst and a $\mathrm{Pd} /$ alumina catalyst ${ }^{71}$. The $\mathrm{Pd} /$ ceria catalyst had much higher reaction rates than the Pd/alumina catalyst, as well as higher 
resistance to coke formation. The improved resistance to coke deposition has been attributed to the high oxygen mobility over $\mathrm{CeO}_{2}$, which facilitates the gasification of coke. ${ }^{72,73}$ Thus, the ceria-based materials may also present high activity for steam gasification of coke, which can reduce coke formation in steam crackers.

\subsection{Objectives of this work}

The overall goal of this work is to explore the utilization of ceria-based materials for anticoking coating materials for steam crackers. In particular, this dissertation aims to develop a quantitative method to obtain the reproducible kinetics of reactions involving coke and compare the reaction rates of coke gasification with different ceria-based materials to obtain the best catalyst composition. The specific objectives of this dissertation are outlined below:

1. Synthesize coke at elevated temperature to mimic coke formation during steam cracking and characterize the physical properties of the obtained coke.

2. Synthesize cerium-zirconium mixed oxides of varying chemical compositions and investigate the effect of composition on structure, oxygen storage capacity and reducibility, as well as the catalytic behavior during gasification of coke.

3. Develop a quantitative method to study reactions involving coke, which makes the comparison of coke gasification catalysts more accurate.

4. Explore the effect of alkaline earth metals addition to cerium-zirconium mixed oxides on the catalytic behavior of coke gasification with dioxygen and steam.

The prepared coke and catalysts were extensively characterized by a variety of techniques, including X-ray diffraction (XRD), Raman spectroscopy, elemental analysis, surface area analysis, X-ray photoelectron spectroscopy (XPS), scanning electron microscopy (SEM), 
transmission electron microscopy (TEM) and temperature-programmed reduction (TPR). The coke gasification with dioxygen was carried out in a thermogravimetric analyzer (SDT Q600, TA instruments). The coke gasification with steam was carried out in a customized thermogravimetric analyzer (STA449F3 Jupiter, NETSCH). Coke gasification with dioxygen and steam were evaluated both with temperature-programmed oxidation and isothermal reactions. The tight contact samples of coke and catalyst mixture were prepared by extensive grinding of the mixture. The $\mathrm{CO}$ oxidation was conducted in a fix-bed stainless steel reactor to confirm the method we developed for study of coke gasification.

\section{Reference for Chapter 1}

(1) Ropital, F.; Broutin, P.; Reyniers, M. F.; Froment, G. F. Anticoking Coatings for High Temperature Petrochemical Reactors. Oil Gas Sci. Technol. 1999, 54 (3), 375-385.

(2) Mittal, K. G. Cracking Paraffinic Hydrocarbons to Make Alpha Olefins-a Review. J. Chem. Technol. Biotechnol. 2007, 36 (7), 291-299.

(3) Cai, H.; Krzywicki, A.; Oballa, M. C. Coke Formation in Steam Crackers for Ethylene Production. Chem. Eng. Process. 2002, 41 (3), 199-214.

(4) Grace Chan, K. Y.; Inal, F.; Senkan, S. Suppression of Coke Formation in the Steam Cracking of Alkanes: Ethane and Propane. Ind. Eng. Chem. Res. 1998, 37 (3), 901-907.

(5) Shah, Y.; Stuart, E.; Sheth, K. Coke Formation during Thermal Cracking. Ind. Eng. Chem. 
Process Des. Dev. 1976, 15 (4), 518-523.

(6) Niaei, A.; Salari, D.; Towfighi, J.; Chamandeh, A.; Nabavi R. Aluminized Steel and Zinc Coating for Reduction of Coke Formation in Thermal Cracking of Naphtha. Internatonal J. Chem. React. Eng. 2008, 6, 1-11.

(7) Sundaram, K. M.; Van Damme, P. S.; Froment, G. F. Coke Deposition in the Thermal Cracking of Ethane. AIChE J. 1981, 27 (6), 946-951.

(8) Towfighi J., Sadrameli M., N. A. Coke Formation Mechanism. J. Chem. Eng. Japan 2002, $35(10), 923-937$.

(9) Zimmermann G., Kopinke F-D, Reyniers G. C., F. G. F. Relative Rates of Coke Formation from Hydrocarbons in Steam Cracking of Naphtha. 2. Paraffins, Naphthenes, Mono-, Di-, and Cycloolefins, and Acetylenes. Ind. Eng. Chem. Res. 1993, No. 32, 56-61.

(10) Kopinke, F. D.; Zimmermann, G.; Nowak, S. On the Mechanism of Coke Formation in Steam Cracking-Conclusions from Results Obtained by Tracer Experiments. Carbon 1988, $26(2), 117-124$.

(11) Towfighi, J.; Sadrameli, M.; Niaei, A. Coke Formation Mechanisms and Coke Inhibiting Methods in Pyrolysis Furnaces. J. Chem. Eng. Japan 2002, 35 (10), 923-937.

(12) Albright, L. F.; Marekt, J. C. Mechanistic Model for Formation of Coke in Pyrolysis Units Producing Ethylene. Ind. Eng. Chem. Res. 1988, 27, 755-759.

(13) Lahaye, J.; Badie, P.; Ducret, J. Mechanism of Carbon Formation during Steam Cracking of Hydrocarbons. Carbon 1977, 15 (2), 87-93.

(14) Niaei, A.; Salari, D.; Daneshvar, N.; Chamandeh, A.; Nabavi, R. Effect of Tube Materials 
and Special Coating on Coke Deposition in the Steam Cracking of Hydrocarbons. World Acad. Sci. Eng. Technol. 2007, 5, 15-17.

(15) Zhou, J.; Xu, H.; Liu, J.; Qi, X.; Zhang, L.; Jiang, Z. Study of Anti-Coking Property of $\mathrm{SiO} 2 / \mathrm{S}$ Composite Coatings Deposited by Atmospheric Pressure Chemical Vapor Deposition. Mater. Lett. 2007, 61 (29), 5087-5090.

(16) Zhou, J.; Xu, H.; Luan, X.; Ling, X. Influence of the SiO2/S Coating and Sulfur/phosphorus-Containing Coking Inhibitor on Coke Formation during Thermal Cracking of Light Naphtha. Fuel Process. Technol. 2012, 104, 198-203.

(17) Zhou, J.; Xu, H.; Ma, Q.; Zhang, L.; Dai, Y.; Peng, B. Mechanical and Thermal Properties of $\mathrm{SiO}_{2} / \mathrm{S}$ Composite Coating Prepared by APCVD. Mater. Sci. Eng. A 2008, 491 (1-2), $147-153$.

(18) Horsley, G. W.; Cairns, J. A. The Inhibition of Carbon Deposition on Stainless Steel by Prior Selective Oxidation. Appl. Surf. Sci. 1984, 18, 273-286.

(19) Redmond, T.; Bergeron, M. P. Tests Demonstrate Anticoking Capability of New Coating. Oil and Gas Journal. 1999, p 97.

(20) Choi, A.; Yang, I.; Kang, S. SK Corporation. Theories and Applications of Chem. Eng. 2002.

(21) BASF. CAMOL Catalytic Coatings for Steam Cracker Furnace Tubes; BASF Qtech (Canada), Inc.; Mississauga, Ontario, Canada, 2012.

(22) Petrone, S.; Deuis, R. L.; Kong, F.; Unwin, P. Catalyzed-Assisted Manufacture of Olefins (CAMOL): Year-(4) Update on Commercial Furnace Installations. Presented in AIChE 
Spring National Meeting; San Antonio, TX, March 21-25, 2010.

(23) Petrone, S.; Deuis, R. L.; Kong, F.; Sherwood, Y. C. Catalytic Surfaces and Coatings for the Manufacture of Petrochemicals, 2015.

(24) Zychlinski, W.; Wynns, K. A.; Ganser, B. Characterization of Material Samples for Coking Behavior of HP40 Material Both Coated and Uncoated Using Naphtha and Ethane Feedstock. Mater. Corros. 2002, 53 (1), 30-36.

(25) Schietekat, C. M.; Sarris, S. A.; Reyniers, P. A.; Kool, L. B.; Peng, W.; Lucas, P.; Van Geem, K. M.; Marin, G. B. Catalytic Coating for Reduced Coke Formation in Steam Cracking Reactors. Ind. Eng. Chem. Res. 2015, 54 (39), 9525-9535.

(26) McKimpson, M. G.; Albright, L. F. Future Coils for Ethylene Furnaces: Reduced or No Coking and Increaed Coil Longevity. ACS Div. Fuel Chem. Prepr. 2004, 49 (2), 776-777.

(27) Cai, H.; Oballa, M. C. Passivation of Steel Surface to Reduce Coke Formation, 2011.

(28) Bueno-López, A. Diesel Soot Combustion Ceria Catalysts. Appl. Catal. B Environ. 2014, $146,1-11$.

(29) Hernández-Giménez, A. M.; Castelló, D. L.; Bueno-López, A. Diesel Soot Combustion Catalysts: Review of Active Phases. Chem. Pap. 2013, 68 (9), 1154-1168.

(30) Aneggi, E.; Boaro, M.; De Leitenburg, C.; Dolcetti, G.; Trovarelli, A. Insights into the Redox Properties of Ceria-Based Oxides and Their Implications in Catalysis. J. Alloys Compd. 2006, 408-412, 1096-1102.

(31) Trovarelli, A. Catalytic Properties of Ceria and $\mathrm{CeO}_{2}$-Containing Materials. Catal. Rev. Sci. Eng. 1996, 38 (4), 439-520. 
(32) Trovarelli, A.; de Leitenburg, C.; Boaro, M.; Dolcetti, G. The Utilization of Ceria in Industrial Catalysis. Catal. Today 1999, 50 (2), 353-367.

(33) Kašpar, J.; Fornasiero, P.; Graziani, M. Use of $\mathrm{CeO}_{2}-$ Based Oxides in the Three-Way Catalysis. Catal. Today 1999, 50, 285-298.

(34) Gorte, R. J. Ceria in Catalysis: From Automotive Applications to the Water-Gas Shift Reaction. AIChE J. 2010, 56 (5), 1126-1135.

(35) Jung, H.; Kittelson, D. B.; Zachariah, M. R. The Influence of a Cerium Additive on Ultrafine Diesel Particle Emissions and Kinetics of Oxidation. Combust. Flame 2005, 142, $276-288$.

(36) Stratakis, G. A.; Stamatelos, A. M. Thermogravimetric Analysis of Soot Emitted by a Modern Diesel Engine Run on Catalyst-Doped Fuel. Combust. Flame 2003, 132, 157-169.

Cassee, F. R.; van Balen, E. C.; Singh, C.; Green, D.; Muijser, H.; Weinstein, J.; Dreher, K. Exposure, Health and Ecological Effects Review of Engineered Nanoscale Cerium and Cerium Oxide Associated with Its Use as a Fuel Additive. Crit. Rev. Toxicol. 2011, 41 (3), $213-229$.

(38) Bueno-López, A.; Krishna, K.; Makkee, M.; Moulijn, J. Active Oxygen from $\mathrm{CeO}_{2}$ and Its Role in Catalysed Soot Oxidation. Catal. Letters 2005, 99 (3-4), 203-205.

(39) Machida, M.; Murata, Y.; Kishikawa, K.; Zhang, D.; Ikeue, K. On the Reasons for High Activity of $\mathrm{CeO}_{2}$ Catalyst for Soot Oxidation. Chem. Mater. 2008, 20, 4489-4494.

(40) Gross, M. S.; Sánchez, B. S.; Querini, C. A. Diesel Particulate Matter Combustion with $\mathrm{CeO}_{2}$ as Catalyst. Part II: Kinetic and Reaction Mechanism. Chem. Eng. J. 2011, 168 (1), 
413-419.

(41) Gross, M. S.; Ulla, M. A.; Querini, C. A. Diesel Particulate Matter Combustion with $\mathrm{CeO} 2$ as Catalyst. Part I: System Characterization and Reaction Mechanism. J. Mol. Catal. A Chem. 2012, 352, 86-94.

(42) Preda, G.; Pacchioni, G. Formation of Oxygen Active Species in Ag-Modified $\mathrm{CeO}_{2}$ Catalyst for Soot Oxidation: A DFT Study. Catal. Today 2011, 177 (1), 31-38.

(43) Keating, P. R. L.; Scanlon, D. O.; Watson, G. W. The Nature of Oxygen States on the Surfaces of $\mathrm{CeO}_{2}$ and La-Doped $\mathrm{CeO}_{2}$. Chem. Phys. Lett. 2014, 608, 239-243.

(44) Krishna, K.; Bueno-López, A.; Makkee, M.; Moulijn, J. A. Potential Rare-Earth Modified $\mathrm{CeO}_{2}$ Catalysts for Soot Oxidation Part III. Effect of Dopant Loading and Calcination Temperature on Catalytic Activity with $\mathrm{O}_{2}$ and $\mathrm{NO}_{+} \mathrm{O}_{2}$. Appl. Catal. B Environ. 2007, 75 (3-4), 210-220.

(45) Krishna, K.; Bueno-López, A.; Makkee, M.; Moulijn, J. A. Potential Rare Earth Modified $\mathrm{CeO}_{2}$ Catalysts for Soot Oxidation I. Characterization and Catalytic Activity with $\mathrm{O}_{2}$. Appl. Catal. B Environ. 2007, 75 (3-4), 189-200.

(46) Bueno-López, A.; Krishna, K.; van der Linden, B.; Mul, G.; Moulijn, J. A.; Makkee, M. On the Mechanism of Model Diesel Soot- $\mathrm{O}_{2}$ Reaction Catalysed by Pt-Containing $\mathrm{La}^{3+}-$ Doped $\mathrm{CeO}_{2}$ : A TAP Study with Isotopic $\mathrm{O}_{2}$. Catal. Today 2007, 121 (3-4), 237-245.

(47) Bueno-López, A.; Krishna, K.; Makkee, M.; Moulijn, J. A. Enhanced Soot Oxidation by Lattice Oxygen via $\mathrm{La}^{3+}$-Doped $\mathrm{CeO}_{2}$. J. Catal. 2005, 230 (1), 237-248.

(48) Atribak, I.; Bueno-López, A.; García-García, A. Thermally Stable Ceria-zirconia 
Catalysts for Soot Oxidation by $\mathrm{O}_{2}$. Catal. Commun. 2008, 9 (2), 250-255.

(49) Liu, J.; Zhao, Z.; Liang, P.; Xu, C.; Duan, A.; Jiang, G.; Lin, W.; Wachs, I. E. Study on the Reaction Mechanism for Soot Oxidation over $\mathrm{TiO}_{2}$ or $\mathrm{ZrO}_{2}$-Supported Vanadium Oxide Catalysts by Means of In-Situ UV-Raman. Catal. Letters 2008, 120 (2), 148-153.

(50) Reddy, B. M.; Bharali, P.; Thrimurthulu, G.; Saikia, P.; Katta, L.; Park, S.-E. Catalytic Efficiency of Ceria-zirconia and Ceria-hafnia Nanocomposite Oxides for Soot Oxidation. Catal. Letters 2008, 123 (3-4), 327-333.

(51) Aneggi, E.; de Leitenburg, C.; Trovarelli, A. On the Role of Lattice/surface Oxygen in Ceria-zirconia Catalysts for Diesel Soot Combustion. Catal. Today 2012, 181 (1), 108115.

(52) Dhakad, M.; Mitshuhashi, T.; Rayalu, S.; Doggali, P.; Bakardjiva, S.; Subrt, J.; Fino, D.; Haneda, H.; Labhsetwar, N. $\mathrm{Co}_{3} \mathrm{O}_{4}-\mathrm{CeO}_{2}$ Mixed Oxide-Based Catalytic Materials for Diesel Soot Oxidation. Catal. Today 2008, 132 (1-4), 188-193.

(53) Shan, W.; Ma, N.; Yang, J.; Dong, X.; Liu, C.; Wei, L. Catalytic Oxidation of Soot Particulates over $\mathrm{MnOx}-\mathrm{CeO}_{2}$ Oxides Prepared by Complexation-Combustion Method. $J$. Nat. Gas Chem. 2010, 19 (1), 86-90.

(54) Aneggi, E.; de Leitenburg, C.; Dolcetti, G.; Trovarelli, A. Promotional Effect of Rare Earths and Transition Metals in the Combustion of Diesel Soot over $\mathrm{CeO}_{2}$ and $\mathrm{CeO}_{2}-\mathrm{ZrO}_{2}$. Catal. Today 2006, 114 (1), 40-47.

Dulgheru, P.; Sullivan, J. A. Rare Earth (La, Nd, Pr) Doped Ceria Zirconia Solid Solutions for Soot Combustion. Top. Catal. 2013, 56, 504-510. 
(56) Gu, Z.; Sang, X.; Wang, H.; Li, K. Structure and Catalytic Property of $\mathrm{CeO}_{2}-\mathrm{ZrO}_{2}-\mathrm{Fe}_{2} \mathrm{O}_{3}$ Mixed Oxide Catalysts for Diesel Soot Combustion: Effect of Preparation Method. J. Rare Earths 2014, 32 (9), 817-823.

Durgasri, D. N.; Vinodkumar, T.; Lin, F.; Alxneit, I.; Reddy, B. M. Gadolinium Doped Cerium Oxide for Soot Oxidation: Influence of Interfacial Metal-support Interactions. Appl. Surf. Sci. 2014, 314, 592-598.

(58) Wu, X.; Liu, S.; Weng, D.; Lin, F. Textural-structural Properties and Soot Oxidation Activity of MnOx-CeO 2 Mixed Oxides. Catal. Commun. 2011, 12 (5), 345-348.

(59) Wu, X.; Liang, Q.; Weng, D.; Lu, Z. The Catalytic Activity of CuO-CeO 2 Mixed Oxides for Diesel Soot Oxidation with a NO/O 2 Mixture. Catal. Commun. 2007, 8 (12), 21102114.

(60) Liang, Q.; Wu, X.; Weng, D.; Xu, H. Oxygen Activation on Cu/Mn-Ce Mixed Oxides and the Role in Diesel Soot Oxidation. Catal. Today 2008, 139 (1-2), 113-118.

(61) Atribak, I.; Bueno-Lopez, A.; Garcia-Garcia, A. Further Insights into the Key Features of Ceria-Zirconia Mixed Oxides Governing the Catalysed Soot Combustion Under $\mathrm{NO}_{\mathrm{X}} / \mathrm{O}_{2}$. Top. Catal. 2009, 52 (13-20), 2088-2091.

(62) Wei, Y.; Liu, J.; Zhao, Z.; Duan, A.; Jiang, G.; Xu, C.; Gao, J.; He, H.; Wang, X. ThreeDimensionally Ordered Macroporous $\mathrm{Ce}_{0.8} \mathrm{Zr}_{0.2} \mathrm{O}_{2}-\mathrm{Supported}$ Gold Nanoparticles: Synthesis with Controllable Size and Super-Catalytic Performance for Soot Oxidation. Energy Environ. Sci. 2011, 4, 2959.

(63) Liu, S.; Wu, X.; Weng, D.; Ran, R. Ceria-Based Catalysts for Soot Oxidation: A Review. 
J. Rare Earths 2015, 33 (6), 567-590.

(64) Djuričić, B.; Pickering, S. Nanostructured Cerium Oxide: Preparation and Properties of Weakly-Agglomerated Powders. J. Eur. Ceram. Soc. 1999, 19 (11), 1925-1934.

(65) Guillén-Hurtado, N.; Bueno-López, A.; García-García, A. Catalytic Performances of Ceria and Ceria-Zirconia Materials for the Combustion of Diesel Soot under $\mathrm{NOx} / \mathrm{O}_{2}$ and $\mathrm{O}_{2}$. Importance of the Cerium Precursor Salt. Appl. Catal. A Gen. 2012, 437-438 (2), 166-172.

(66) Zhang, G.; Zhao, Z.; Liu, J.; Jiang, G.; Duan, A.; Zheng, J.; Chen, S.; Zhou, R. Three Dimensionally Ordered Macroporous $\mathrm{Ce}_{1-\mathrm{x}} \mathrm{Zr}_{\mathrm{x}} \mathrm{O}_{2}$ Solid Solutions for Diesel Soot Combustion. Chem. Commun. 2010, 46 (3), 457-459.

(67) Zaletova, N. V; Turakulova, A. O.; Lunin, V. V. Hierarchical Porous Ce-Zr Materials for Oxidation of Diesel Soot Particulate. Catal. Letters 2011, 141, 489-490.

(68) Zhuang, Q.; Qin, Y.; Chang, L. Promoting Effect of Cerium Oxide in Supported Nickel Catalyst for Hydrocarbon Steam-Reforming. Appl. Catal. 1991, 70 (1), 1-8.

(69) Natesakhawat, S.; Watson, R. B.; Wang, X.; Ozkan, U. S. Deactivation Characteristics of Lanthanide-Promoted Sol-Gel Ni/ $\mathrm{Al}_{2} \mathrm{O}_{3}$ Catalysts in Propane Steam Reforming. J. Catal. 2005, 234 (2), 496-508.

(70) Navarro, R. M.; Pena, M. A.; Fierro, J. L. G. Hydrogen Production Reactions from Carbon Feedstocks : Fossil Fuels and Biomass. Chem. Rev. 2007, 107, 3952-3991.

(71) Wang, X.; Gorte, R. J. A Study of Steam Reforming of Hydrocarbon Fuels on Pd/Ceria. Appl. Catal. A Gen. 2002, 224 (1-2), 209-218.

(72) Ramírez-Cabrera, E.; Atkinson, A.; Chadwick, D. Catalytic Steam Reforming of Methane 


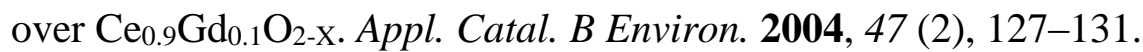

(73) Fornasiero, P.; Balducci, G.; Di Monte, R.; Kašpar, J.; Sergo, V.; Gubitosa, G.; Ferrero, A.; Graziani, M. Modification of the Redox Behaviour of $\mathrm{CeO}_{2}$ Induced by Structural Doping with $\mathrm{ZrO}_{2}$. J. Catal. 1996, 164 (373), 173-183. 


\title{
Chapter 2. Catalytic Oxidation of Solid Carbon and Carbon
}

\section{Monoxide over Cerium-Zirconium Mixed Oxides}

\begin{abstract}
:
A series of cerium-zirconium mixed oxides was prepared by coprecipitation and evaluated in the catalytic oxidation of solid coke under tight contact conditions with 10 vol.\% $\mathrm{O}_{2}$ in He at $673 \mathrm{~K}$ using a thermogravimetric analyzer. The measured first order rate constant for coke oxidation was proportional to the catalyst loading when the mass ratio of catalyst to coke was low, which enabled the calculation of a surface area specific reaction rate. The validity of the normalization method was confirmed by performing $\mathrm{CO}$ oxidation over the ceriumzirconium mixed oxides in a fixed bed reactor at $573 \mathrm{~K}$ with 2 vol. $\%$ of $\mathrm{CO}$ and 2 vol. $\%$ of $\mathrm{O}_{2}$ in He at ambient total pressure. Although there was no correlation between the coke oxidation rate and the oxygen storage capacity or the reducibility of the catalysts, there was an excellent correlation to the $\mathrm{CO}$ oxidation rate. Kinetic studies of both coke and $\mathrm{CO}$ oxidation suggested an important role of surface lattice oxygen from the catalyst in the two reactions.
\end{abstract}




\subsection{Introduction}

Carbon formation reactions are common in chemical processes involving hydrocarbons, such as coke buildup on catalysts in hydrocarbon cracking reactors, ${ }^{1,2}$ deposition of solid carbon on the walls of steam cracking reactors, ${ }^{3,4}$ and production of soot in diesel engines. ${ }^{5,6}$ While carbon rejection via coke may be desirable in some processes for upgrading petroleum residue (e.g. FCC), ${ }^{7}$ it often leads to catalyst deactivation, poor heat transfer through reactor walls and even damage to the reactor. ${ }^{2,8}$ Emission of soot particle from diesel engines also poses a threat to the environment and human health because of the small particle sizes and residual volatile organic compounds. ${ }^{9}$ Thus, mitigation of solid carbon by catalytic oxidation reactions can be an important remediation step in these processes, either in-situ or after its formation. Ceria-based materials are recognized as promising catalysts for carbon oxidation because of their excellent redox behavior and oxygen storage capacity. ${ }^{10}$ Indeed, ceria compounds have been an important component of the automotive three-way catalyst for decades. ${ }^{11}$ Ceria-based catalysts have also demonstrated activity in soot oxidation, especially after doping with other elements, such as $\mathrm{La}^{12-14}$ and $\mathrm{Zr} .^{15-18}$

Although there is an abundance of literature on the study of catalysts for carbon oxidation, three important problems remain unsolved. First, there is not a well-defined method to quantitatively assess the catalyst performance since the reaction involves the reactivity of a solidsolid interface together with a gas. Most studies utilize temperature-programmed oxidation (TPO) reactions, from which specific temperatures of carbon oxidation in the presence of catalysts are reported and compared. The most common characteristic temperatures used to compare catalyst performance are $\mathrm{T}_{50}$ (temperature at which $50 \%$ of the carbon is oxidized) and $\mathrm{T}_{\max }$ (peak temperature of the TPO curve). Although some researchers evaluate catalyst activity by 
calculating carbon oxidation rates under isothermal conditions, ${ }^{19,20}$ these rates are normalized to the total surface area of catalyst in the sample, which may not be strictly proportional to observed rate. In fact, the catalyst/carbon mass ratio is an important parameter for reporting carbon oxidation activity. Neeft et al. found that the carbon oxidation temperature in the presence of a $\mathrm{V}_{2} \mathrm{O}_{5}$ catalyst decreased with increasing catalyst/carbon mass ratio, but remained constant at a mass ratio greater than $4 .{ }^{21}$ A similar relationship was observed with a $\mathrm{K} / \mathrm{CeO}_{2}$ catalyst, with a constant carbon oxidation temperature being observed at catalyst/carbon mass ratio greater than 5. ${ }^{22}$ These reports clearly indicate how rates of oxidation do not always scale linearly with total catalyst surface area and may lead to improper comparison of catalyst performance. Therefore, a method that gives reproducible specific reaction rates is desired. Second, the doping of cerium oxide with other metal ions often leads to changes in physical and chemical properties of the solid, such as specific surface area, surface reducibility of cerium, oxygen storage capacity and oxygen mobility throughout the bulk of the solid. ${ }^{23}$ There is still no consensus regarding which property changes are responsible for the variation in carbon oxidation activity of ceria catalysts after doping. Third, detailed kinetic studies of carbon oxidation catalyzed by ceria-based oxides are still lacking.

In this work, a series of cerium-zirconium mixed oxides was prepared and used for solid carbon oxidation. A methodology was developed to obtain reproducible rates of carbon oxidation. The physical and chemical properties of different mixed oxides were characterized with various techniques and compared with carbon oxidation activity to determine which properties were the most important for oxidation catalysis. A classic catalytic oxidation reaction, $\mathrm{CO}$ oxidation, was also performed to validate the results from the carbon oxidation studies.

\subsection{Experimental methods}




\subsubsection{Catalyst preparation}

A series of cerium-zirconium mixed oxides $(\mathrm{Ce} / \mathrm{Zr}$ atomic ratio $=4,1,0.25)$, cerium oxide and zirconium oxide were prepared using a controlled precipitation method. First, an aqueous solution of $\mathrm{Ce}\left(\mathrm{NO}_{3}\right)_{3} \cdot 6 \mathrm{H}_{2} \mathrm{O}$ (99.99\%, Sigma Aldrich) and $\mathrm{ZrONO}_{3}$ (99.99\%, Sigma Aldrich) was prepared with a total metal ion concentration of $0.2 \mathrm{M}$. The metal precursor solution was added dropwise to $100 \mathrm{~cm}^{3}$ of distilled deionized water (DDI) at $298 \mathrm{~K}$ while a solution of $15 \mathrm{wt} . \%$ aqueous ammonia was added continuously during precipitation to maintain a $\mathrm{pH}$ of 10. The resulting suspension was stirred for $20 \mathrm{~h}$ at $298 \mathrm{~K}$. The precipitate was recovered by vacuum filtration, washed 3 times with DDI water, dried in air at $400 \mathrm{~K}$ overnight. The samples were then heated to $1073 \mathrm{~K}$ in air at a rate of $5 \mathrm{~K} \mathrm{~min}^{-1}$ and held at $1073 \mathrm{~K}$ for $6 \mathrm{~h}$. To obtain a cerium oxide sample with higher surface area (closer to that of the Ce-Zr mixed oxides), the calcination temperature for cerium oxide was decreased to $873 \mathrm{~K}$.

\subsubsection{Coke formation from thermal reaction of ethylene}

Solid carbon, otherwise known as coke, was formed by passing a mixture of ethylene and He through a quartz tube placed in a high temperature furnace (GSL 1100X, MTI Corporation). The quartz tube was heated to $1150 \mathrm{~K}$ at a rate of $10 \mathrm{~K} \mathrm{~min}^{-1}$ in $20 \mathrm{~cm}^{3} \mathrm{~min}^{-1} \mathrm{He}$. Upon reaching $1150 \mathrm{~K}$, a mixture of $20 \mathrm{~cm}^{3} \mathrm{~min}^{-1}$ ethylene and $20 \mathrm{~cm}^{3} \mathrm{~min}^{-1} \mathrm{He}$ was fed to the quartz tube for 4 hours, followed by cooling to the room temperature in $20 \mathrm{~cm}^{3} \mathrm{~min}^{-1}$ flowing He. Three types of coke were formed: solid coke, soft coke and liquid coke. Liquid coke was removed by rinsing the quartz tube with toluene and solid coke was collected by scraping the tube. Soft coke could not be isolated. The collected solid coke was dried in air at $400 \mathrm{~K}$ to remove the remaining volatile organic compounds, followed by milling with zirconium beads in a plastic bottle on a jar mill (US Stoneware) for 64 hours. The recovered solid coke was used as a model carbon in this study. 


\subsubsection{Characterization of catalyst and coke}

Powder X-ray diffraction (XRD) patterns of the catalysts and coke were obtained on a PANalytical X'Pert Pro MPD Diffractometer with $\mathrm{Cu}$ K $\alpha$ radiation. Each sample was scanned at a rate of $0.2^{\circ} \mathrm{s}^{-1}$, over a range of $2 \theta$ from $10^{\circ}$ to $90^{\circ}$. For coke, the mean size of crystal in the cdirection, Lc, and mean size of crystal in the a-direction (layer diameter), La, were calculated using the Scherrer equation.

$$
\mathrm{L}=\frac{K \cdot \lambda}{B_{2 \theta} \cos \theta}
$$

where $\lambda$ is the wavelength of $\mathrm{X}$-rays used $(0.15418 \mathrm{~nm}), B_{2 \theta}$ is the full width at the half height and $\mathrm{K}$ is a constant, which was 0.91 and 1.84 for calculation of $\mathrm{Lc}$ and La, respectively. ${ }^{24}$

Specific surface area of the catalysts and coke was obtained by $\mathrm{N}_{2}$ adsorption measured at $77 \mathrm{~K}$ using the BET method on a Micromeritics ASAP 2020 automated analyzer.

Elemental analyses of the catalysts and coke were performed at Galbraith Laboratories (Knoxville, TN). The contents of cerium and zirconium in the oxide catalysts were determined by inductively coupled plasma atomic emission spectroscopy while the contents of carbon and hydrogen in the coke were determined by combustion analysis.

Raman spectra of the oxide catalysts and coke were recorded with a Renishaw InVia Raman Microscope with an Ar laser (514 nm) and a $3000 \mathrm{~g} \mathrm{~mm}^{-1}$ grating. The Raman scope was calibrated using a silicon wafer.

Scanning electron microscopy was performed on an FEI Quanta 650 FEG-SEM with a working distance of $10 \mathrm{~mm}$ under the secondary electron imaging mode. The sample was prepared by adhering the catalyst powders to a copper conductive tape on a sample stage. 
The high-resolution transmission electron microscopy (HR-TEM) was performed on an FEI Titan 80-300 operating at $300 \mathrm{kV}$ that is equipped with a Gatan 794 Multi-scan Camera (EFTEM). To prepare a sample, $\sim 1 \mathrm{mg}$ of catalyst was suspended in $10 \mathrm{~cm}^{3}$ of ethanol by agitating the mixture for 30 min in a sonication bath. A copper grid with a holey carbon film was dipped into the solution to capture the particles and the ethanol was thoroughly evaporated before microscopy.

The X-ray photoelectron spectroscopy (XPS) was carried out at the Nanomaterials Core Characterization Facility of the Virginia Commonwealth University (Richmond, VA), utilizing a Thermo Scientific ESCALAB 250 spectrometer equipped with a focused monochromatic Al Ka $\mathrm{X}$-ray radiation source $(1486.6 \mathrm{eV})$ and a hemispherical analyzer with a 6-element multichannel detector. The incident X-ray beam was $45^{\circ}$ off normal to the sample while the X-ray photoelectron detector was normal to the sample. A large area magnetic lens with a $500 \mu \mathrm{m}$ spot size in constant analyzer energy mode was utilized with a pass energy of $20 \mathrm{eV}$ for region scans. Charge compensation was employed during data collection with an internal electron flood gun (2 $\mathrm{eV}$ ) and a low energy external Ar ion flood gun. The Ce $3 \mathrm{~d}$ core level spectra were deconvoluted into 10 peaks using a combination of Lorentzian and Gaussian peaks. The percent of $\mathrm{Ce}^{3+}\left(\mathrm{V}_{0}, \mathrm{~V}^{\prime}\right.$, $\mathrm{U}_{0}$ and $\left.\mathrm{U}^{\prime}\right)$ and $\mathrm{Ce}^{4+}\left(\mathrm{V}, \mathrm{V}, \mathrm{V}\right.$ "', $\mathrm{U}, \mathrm{U}^{\prime \prime}$ and $\left.\mathrm{U}^{\prime \prime}\right)$ was calculated from the peak assignments proposed by Burroughs et al. ${ }^{25}$

The measurement of oxygen storage capacity (OSC) and $\mathrm{H}_{2}$-temperature programmed reduction $\left(\mathrm{H}_{2}\right.$-TPR) were performed on a Micromeritics Autochem II 2920 equipped with a thermal conductivity detector (TCD) using $0.20 \mathrm{~g}$ of sample. For OSC measurement, the catalyst was heated to $673 \mathrm{~K}$ in a $10 \mathrm{vol} . \% \mathrm{O}_{2} / \mathrm{He}$ mixture at a rate of $5 \mathrm{~K} \mathrm{~min}^{-1}$ and held at $673 \mathrm{~K}$ for 30 min, followed by a He purge at $673 \mathrm{~K}$ for $30 \mathrm{~min}$. The gas was then switched to $5 \mathrm{vol} . \% \mathrm{H}_{2} / \mathrm{Ar}$ 
and reduced for $6 \mathrm{~h}$ at $673 \mathrm{~K}$, followed by a He purge at $673 \mathrm{~K}$ for $30 \mathrm{~min}$. The catalyst was then pulsed with $10 \mathrm{vol} . \% \mathrm{O}_{2} / \mathrm{He}$ at $673 \mathrm{~K}$ until saturation was reached. For $\mathrm{H}_{2}$-TPR, the catalyst was heated to $673 \mathrm{~K}$ in a $10 \mathrm{vol} . \% \mathrm{O}_{2} / \mathrm{He}$ at a rate of $5 \mathrm{~K} \mathrm{~min}^{-1}$ and held at $673 \mathrm{~K}$ for $30 \mathrm{~min}$, followed by a He purge at $673 \mathrm{~K}$ for 30 min prior to cooling to room temperature in He. The catalyst was then heated to $1273 \mathrm{~K}$ in $5 \mathrm{vol} \% \mathrm{H}_{2} / \mathrm{Ar}$ using a rate of $5 \mathrm{~K} \mathrm{~min}^{-1}$.

\subsubsection{Coke oxidation by $\mathrm{O}_{2}$}

The coke oxidation rate was measured in an $\mathrm{O}_{2} / \mathrm{He}$ mixture in both temperatureprogrammed oxidation (TPO) experiments and isothermal reactions in a thermogravimetric analyzer (SDT Q600, TA instruments). Approximately $5 \mathrm{mg}$ of sample (coke mixed with catalyst) was placed in a small, flat $\mathrm{Al}_{2} \mathrm{O}_{3}$ sample cup. For TPO experiments, the sample was heated at a ramp rate of $1 \mathrm{~K} \mathrm{~min}^{-1}$ up to $1273 \mathrm{~K}$. For isothermal reactions, samples were heated to the target isothermal temperature at a rate of $20 \mathrm{~K} \mathrm{~min}^{-1}$, then held at the temperature for a specified time. The samples were prepared in tight contact conditions by grinding the catalyst with the coke using a mortar and pestle for an extensive time (about $70 \mathrm{~min}$ ).

\subsubsection{CO oxidation by $\mathrm{O}_{2}$}

The CO oxidation rate was evaluated in a fixed-bed stainless steel reactor (BTRS Jr., Autoclave Engineers) in the temperature range from $473 \mathrm{~K}$ to $573 \mathrm{~K}$ at ambient total pressure. Typical feed conditions were $\mathrm{CO}(2$ vol. $\%), \mathrm{O}_{2}(2$ vol. $\%)$, and $\mathrm{He}$ as diluent. The $\mathrm{CO}$ was purified by passing it through a silica trap immersed in a dry ice-acetone mixture (195 K) to remove any trace iron carbonyls before introduction to the reactor. The product and reactant gases were analyzed by a Hewlett-Packard 5890 series II gas chromatograph equipped with a 
TCD and a 6-ft long Alltech-8700 packed column. All of the activity results were obtained at the steady state. Reactant gas flow rates were adjusted to attain $\sim 5 \% \mathrm{CO}$ conversion.

\subsection{Results}

\subsubsection{Characterization of $\mathrm{CeO}_{2}, \mathrm{ZrO}_{2}$ and $\mathrm{Ce}-\mathrm{Zr}$ mixed oxides}

Table 2.1 Physical properties of $\mathrm{CeO}_{2}, \mathrm{ZrO}_{2}$ and $\mathrm{Ce}-\mathrm{Zr}$ mixed oxides

\begin{tabular}{llllll}
\hline $\begin{array}{l}\text { Composition } \\
\text { of oxides }\end{array}$ & $\begin{array}{l}\text { BET } \\
\text { surface area } \\
\left(\mathrm{m}^{2} \mathrm{~g}^{-1}\right)\end{array}$ & $\begin{array}{l}\text { Internal } \\
\text { surface } \\
\left(\mathrm{m}^{2} \mathrm{~g}^{-1}\right)^{\mathrm{a}}\end{array}$ & $\begin{array}{l}\text { External } \\
\text { surface area } \\
\left(\mathrm{m}^{2} \mathrm{~g}^{-1}\right)\end{array}$ & $\begin{array}{l}\text { Pore volume } \\
\left(\mathrm{cm}^{3} \mathrm{~g}^{-1}\right)^{\mathrm{b}}\end{array}$ & $\begin{array}{l}\text { Average pore } \\
\text { diameter } \\
(\AA)^{\mathrm{c}}\end{array}$ \\
\hline $\mathrm{CeO}_{2}$ & 62 & 2.4 & 60 & 0.08 & 49 \\
$\mathrm{Ce}_{0.8} \mathrm{Zr}_{0.2} \mathrm{O}_{2}$ & 25 & 1.6 & 23 & 0.07 & 102 \\
$\mathrm{Ce}_{0.5} \mathrm{Zr}_{0.5} \mathrm{O}_{2}$ & 13 & 1.1 & 12 & 0.04 & 107 \\
$\mathrm{Ce}_{0.2} \mathrm{Zr}_{0.8} \mathrm{O}_{2}$ & 15 & 1.1 & 14 & 0.08 & 197 \\
$\mathrm{ZrO}_{2}$ & 7.6 & 1.1 & 6.5 & 0.06 & 324 \\
\hline
\end{tabular}

${ }^{\mathrm{a}}$ Calculated from t-plot

${ }^{\mathrm{b}} \mathrm{BJH}$ cumulative pore volume

${ }^{\mathrm{c}}$ Calculated by BJH adsorption method

The results from $\mathrm{N}_{2}$ physisorption are summarized in Table 2.1. The internal surface area, calculated from the t-plot method, provides an estimate of the surface area inside of micropores. Because micropore surface area is very small compared with the BET surface area, the samples are considered to be non-porous. The external surface area obtained by subtracting the internal surface area from the BET surface area includes the surface area inside mesopores and the area on the external surface of particles. Since it may be possible for coke to enter the mesopores between $2 \mathrm{~nm}$ and $50 \mathrm{~nm}$ in width, the surface area of mesopores was estimated. The pore volume of the oxides was calculated by the BJH adsorption method and revealed very low values $\left(<0.1 \mathrm{~cm}^{3} \mathrm{~g}^{-1}\right)$, indicating the oxides are essentially non-porous. To further assess any possible contribution of mesopores to surface area of the oxides, the average particle diameter of $\mathrm{Ce}_{0.8} \mathrm{Zr}_{0.2} \mathrm{O}_{2}$ was calculated from the BET surface area assuming the oxide particles are spherical 
and the value was compared with the surface-weighted particle diameter measured by TEM (Figure 2.1). The particle diameter calculated from BET surface area $(36 \mathrm{~nm})$ was larger than that estimated from TEM $(19 \mathrm{~nm})$, which indicates $\mathrm{Ce}_{0.8} \mathrm{Zr}_{0.2} \mathrm{O}_{2}$ is virtually non-porous. Thus, the average pore diameter measured by $\mathrm{N}_{2}$ physisorption is not associated with intracrystalline mesopores, but apparently results from the voids between primary particles present in aggregates.

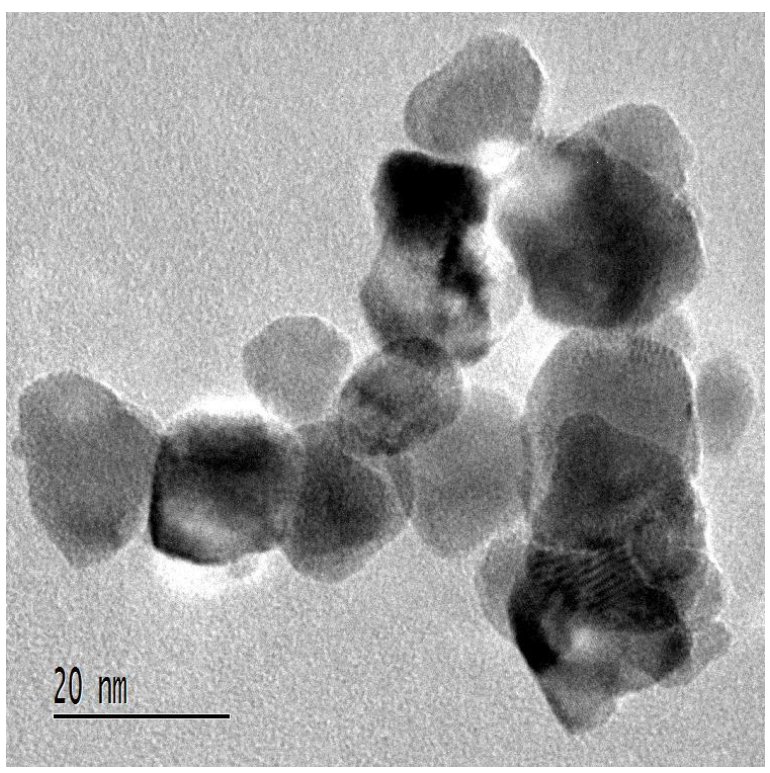

Figure 2.1 TEM image of $\mathrm{Ce}_{0.8} \mathrm{Zr}_{0.2} \mathrm{O}_{2}$. 


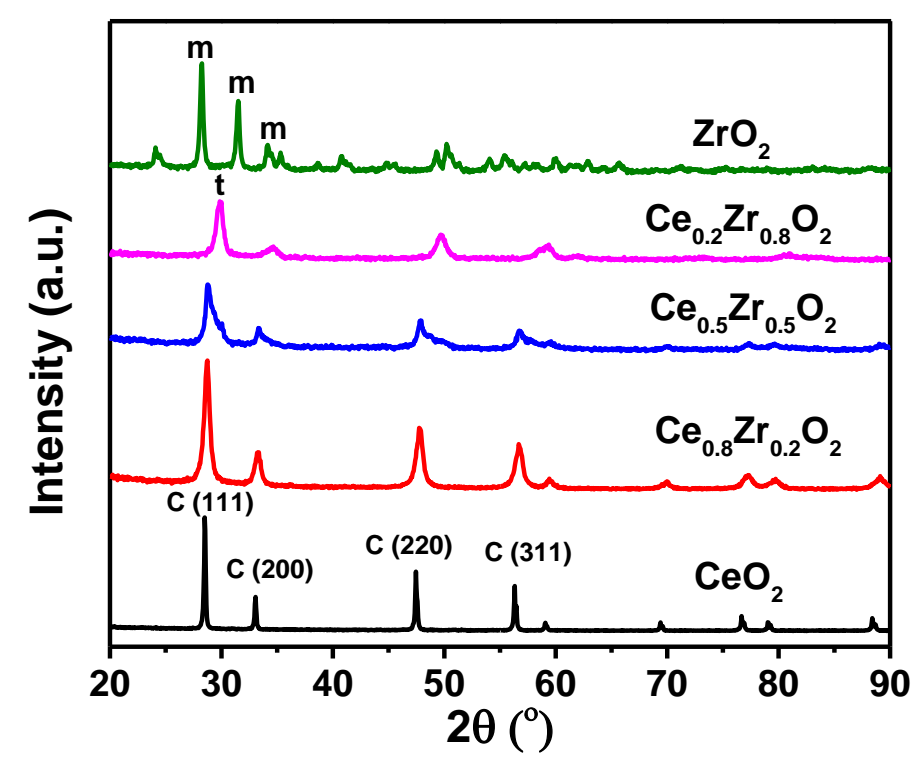

Figure 2.2 X-ray diffraction patterns of $\mathrm{CeO}_{2}$ and $\mathrm{ZrO}_{2}$, and $\mathrm{Ce}-\mathrm{Zr}$ mixed oxides. C: cubic, $\mathrm{m}$ : monoclinic, t: tetragonal.

Figure 2.2 shows the $\mathrm{X}$-ray diffraction patterns of $\mathrm{Ce}-\mathrm{Zr}$ mixed oxides compared to the pure oxides. Cerium oxide exhibited the main reflections typical of a fluorite-structure material with a face-centered cubic unit cell. ${ }^{26}$ The incorporation of $\mathrm{Zr}$ into the cubic structure of $\mathrm{CeO}_{2}$ resulted in broader peaks, indicating smaller crystal size of the mixed oxides. No evidence of phase segregation was observed for $\mathrm{Ce}_{0.8} \mathrm{Zr}_{0.2} \mathrm{O}_{2}$, suggesting the formation of a solid solution. The $\mathrm{Ce}_{0.2} \mathrm{Zr}_{0.8} \mathrm{O}_{2}$ sample presented the pattern of tetragonal zirconia whereas the $\mathrm{ZrO}_{2}$ sample revealed the pattern of monoclinic zirconia. ${ }^{27,28} \mathrm{The} \mathrm{Ce}_{0.5} \mathrm{Zr}_{0.5} \mathrm{O}_{2}$ sample showed the patterns of both cubic and tetragonal phases, with the features associated with the cubic structure being much more intense. The change of crystal structure from cubic to tetragonal with increasing amount of zirconium in Ce- $\mathrm{Zr}$ mixed oxides is consistent with prior reports. ${ }^{27}$ 

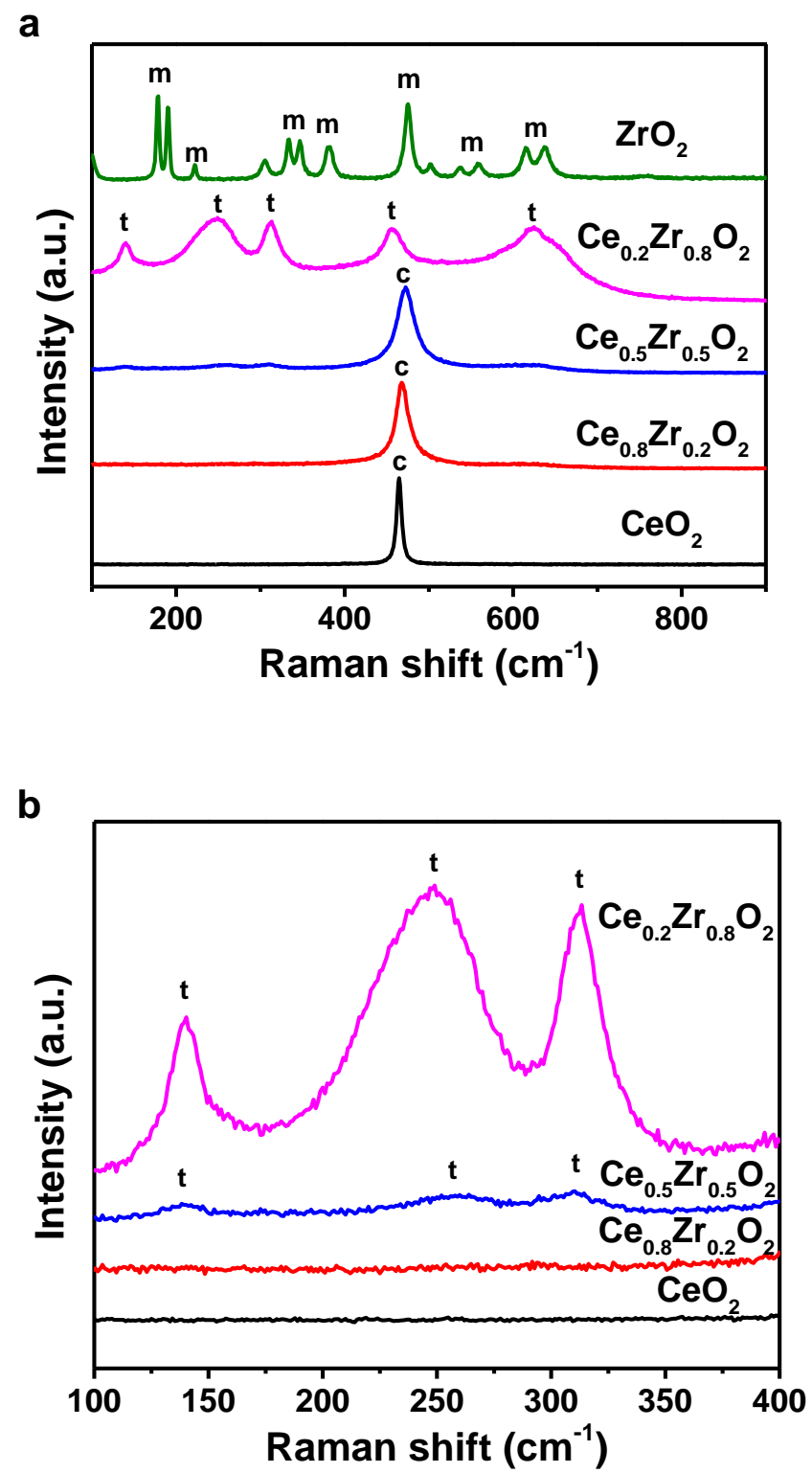

Figure 2.3 Raman spectra of $\mathrm{CeO}_{2}, \mathrm{ZrO}_{2}$ and $\mathrm{Ce}-\mathrm{Zr}$ mixed oxides. $\mathrm{C}$ : cubic, t: tetragonal, m: monoclinic.

Raman spectroscopy was used to determine the coordination symmetry of cations in the oxides. The Raman spectra of Ce-Zr mixed oxides as well as pure $\mathrm{Ce}$ and $\mathrm{Zr}$ oxides are shown in Figure 2.3. The pure $\mathrm{CeO}_{2}$ presented a band positioned at $464 \mathrm{~cm}^{-1}$, which is the $\mathrm{F}_{2 \mathrm{~g}}$ mode of the cubic fluorite structure. ${ }^{29}$ The $\mathrm{ZrO}_{2}$ is monoclinic, which presents the main bands at 179,190 , 
$334,347,382,475,615$ and $637 \mathrm{~cm}^{-1} \cdot{ }^{30}$ The addition of $\mathrm{Zr}$ to $\mathrm{CeO}_{2}$ shifted the Raman features of $\mathrm{CeO}_{2}$ towards higher wavenumbers while maintaining its fluorite structure, which resulted from a lattice contraction by substitution of $\mathrm{Ce}^{4+}$ by the smaller cation $\mathrm{Zr}^{4+} \cdot{ }^{31}$ The Raman band associated with $\mathrm{Ce}_{0.8} \mathrm{Zr}_{0.2} \mathrm{O}_{2}$ and $\mathrm{Ce}_{0.5} \mathrm{Zr}_{0.5} \mathrm{O}_{2}$ was $467 \mathrm{~cm}^{-1}$ and $472 \mathrm{~cm}^{-1}$, respectively. The $\mathrm{Zr}$ rich mixed oxide $\mathrm{Ce}_{0.2} \mathrm{Zr}_{0.8} \mathrm{O}_{2}$ presented bands at $139,248,312,457$ and $625 \mathrm{~cm}^{-1}$, which are characteristic of the tetragonal structure. ${ }^{32}$ The equimolar mixed oxide, $\mathrm{Ce}_{0.5} \mathrm{Zr}_{0.5} \mathrm{O}_{2}$, also presented very weak bands corresponding to the tetragonal structure, which is evidenced in Figure 3b. However, their intensities were much lower than the feature from the cubic structure, indicating the cubic phase is the main one in $\mathrm{Ce}_{0.5} \mathrm{Zr}_{0.5} \mathrm{O}_{2}$. All of the Raman results are consistent with the observed XRD patterns.

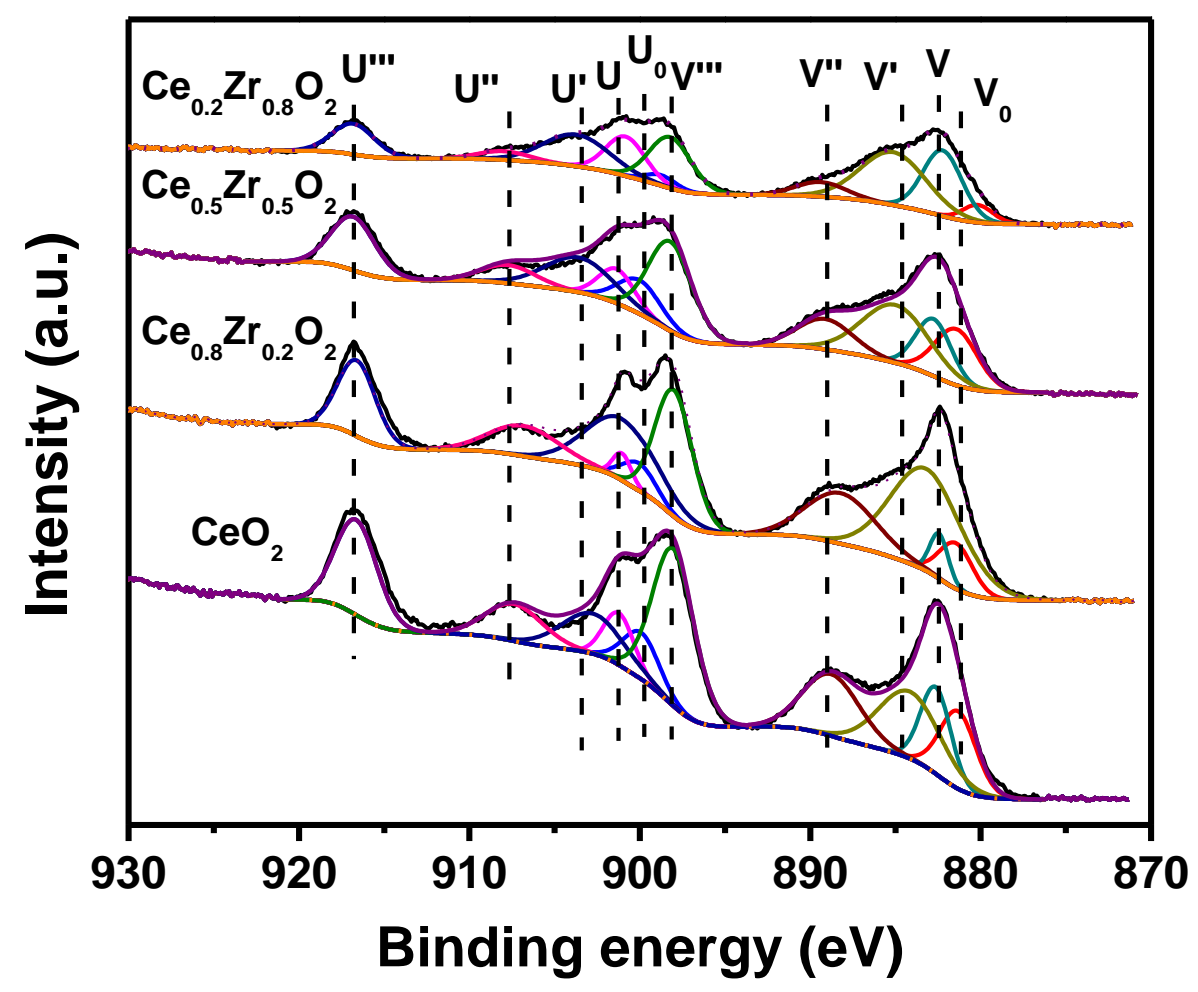

Figure 2.4 X-ray photoelectron spectra of $\mathrm{Ce} 3 \mathrm{~d}$ core electrons of $\mathrm{CeO}_{2}$ and $\mathrm{Ce}-\mathrm{Zr}$ mixed oxides. 
Table 2.2 Surface compositions of $\mathrm{CeO}_{2}, \mathrm{CeO}_{2}$ and $\mathrm{Ce}-\mathrm{Zr}$ mixed oxides derived from XPS.

\begin{tabular}{llllll}
\hline Catalysts & $\begin{array}{l}\text { Bulk } \\
\text { atomic ratio }\end{array}$ & $\begin{array}{l}\mathrm{Ce} / \mathrm{Zr} \\
\text { Surface } \\
\text { atomic ratio }\end{array}$ & $\begin{array}{l}\mathrm{Ce} / \mathrm{Zr} \\
\begin{array}{l}\text { Surface } \mathrm{O} /(\mathrm{Ce}+\mathrm{Zr}) \\
\text { atomic ratio }\end{array}\end{array}$ & $\begin{array}{l}\mathrm{Ce}^{4+} / \\
\left(\mathrm{Ce}^{4+}+\mathrm{Ce}^{3+}\right)\end{array}$ \\
\hline $\mathrm{CeO}_{2}$ & N.A. & N.A. & 3.31 & 0.65 \\
$\mathrm{Ce}_{0.8} \mathrm{Zr}_{0.2} \mathrm{O}_{2}$ & 4.95 & 5.05 & 2.37 & 0.51 \\
$\mathrm{Ce}_{0.5 \mathrm{Zr}} \mathrm{Zn}_{2} \mathrm{O}_{2}$ & 1.23 & 1.07 & 2.42 & 0.55 \\
$\mathrm{Ce}_{0.2} \mathrm{Zr}_{0.8} \mathrm{O}_{2}$ & 0.30 & 0.36 & 2.16 & 0.58 \\
$\mathrm{ZrO}_{2}$ & N.A. & N.A. & 2.30 & N.A. \\
\hline
\end{tabular}

${ }^{\mathrm{a}}$ Measured by ICP-AES

While both XRD and Raman spectroscopy provided information about bulk properties of the oxides, XPS was used to obtain information about the surface composition and cerium oxidation state in the oxides. The $\mathrm{Ce} 3 \mathrm{~d}$ spectra of $\mathrm{CeO}_{2}$ and $\mathrm{Ce}-\mathrm{Zr}$ mixed oxides are shown in Figure 2.4 and the fitting results are summarized in Table 2.2. The surface $\mathrm{Ce} / \mathrm{Zr}$ ratios were close to the bulk $\mathrm{Ce} / \mathrm{Zr}$ ratios determined by elemental analysis, suggesting no surface segregation of either cerium or zirconium had occurred. The $\mathrm{O} /(\mathrm{Ce}+\mathrm{Zr})$ ratios were slightly above the stoichiometric value 2 , which can be attributed to adsorbed water as well as the presence of $\mathrm{CO}$ and $\mathrm{CO}_{2} \cdot{ }^{33}$ For $\mathrm{CeO}_{2}, 65 \%$ of the surface cerium was present as $\mathrm{Ce}^{4+}$. After the addition of $\mathrm{Zr}$, the percent of $\mathrm{Ce}^{4+}$ was between $51 \%$ and $58 \%$, which may suggest more surface oxygen vacancies were present in the mixed oxides relative to $\mathrm{CeO}_{2}$. However, it is known that photoreduction process of cerium during XPS analysis is possible, which can result in the reduction of 30-40\% of surface cerium in $\mathrm{CeO}_{2} \cdot{ }^{34,35}$ Therefore, we cannot definitely conclude from XPS whether the addition of $\mathrm{Zr}$ promotes the formation of oxygen vacancies. 


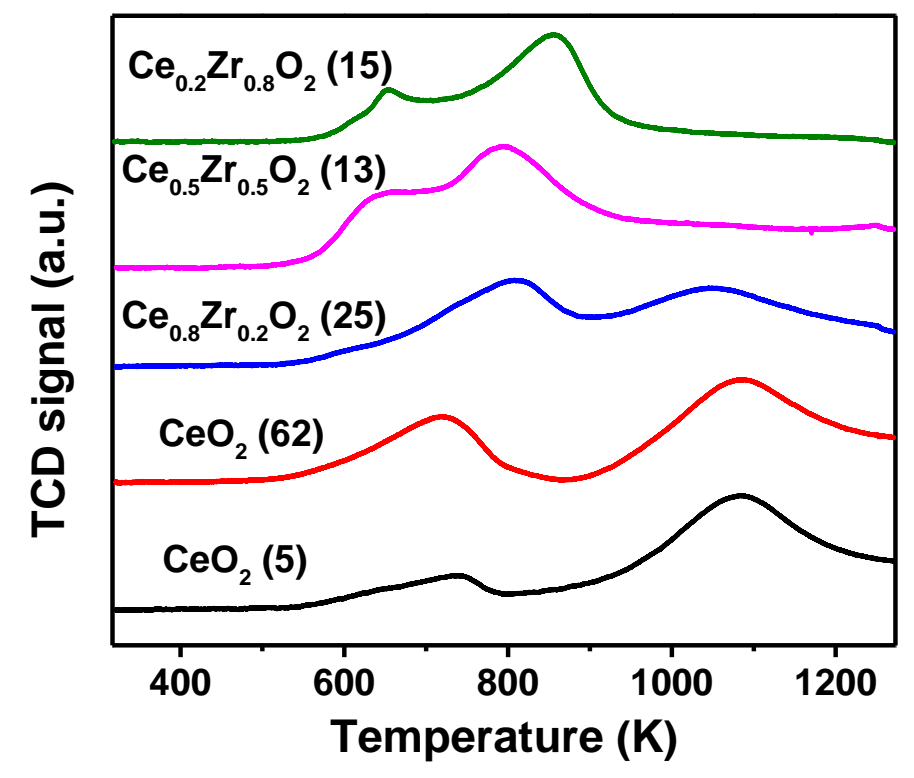

Figure 2.5 $\mathrm{H}_{2}$-TPR of $\mathrm{CeO}_{2}$ and $\mathrm{Ce}-\mathrm{Zr}$ mixed oxide. Surface area of the oxide sample, provided in parentheses, is in $\mathrm{m}^{2} \mathrm{~g}^{-1}$.

The redox property of the samples was characterized by $\mathrm{H}_{2}$-TPR and the results are shown in Figure 2.5. Pure ceria showed two reduction peaks at about $720 \mathrm{~K}$ and $1080 \mathrm{~K}$. The low temperature peak is assigned to the reduction of surface cerium while the high temperature peak is attributed to the reduction of bulk cerium. ${ }^{36}$ The low temperature peak of ceria with a surface area of $62 \mathrm{~m}^{2} \mathrm{~g}^{-1}$ was much larger than that of ceria with a surface area of $5 \mathrm{~m}^{2} \mathrm{~g}^{-1}$, which is consistent with the peak assignments. The addition of $\mathrm{Zr}$ to $\mathrm{CeO}_{2}$ modified its redox property. For $\mathrm{Ce}_{0.8} \mathrm{Zr}_{0.2} \mathrm{O}_{2}$, the surface reduction peak shifted to a higher temperature while the bulk reduction peak shifted to a lower temperature, leading to the overlap of the two peaks. Further addition of $\mathrm{Zr}$ resulted in significant decrease in both surface and bulk reduction temperatures, with the lowest reduction temperatures observed on $\mathrm{Ce}_{0.5} \mathrm{Zr}_{0.5} \mathrm{O}_{2}$, which had surface and bulk reduction temperatures of about $650 \mathrm{~K}$ and $790 \mathrm{~K}$, respectively. 
Table 2.3 Oxygen storage capacity of $\mathrm{CeO}_{2}$ and $\mathrm{Ce}-\mathrm{Zr}$ mixed oxides.

\begin{tabular}{|c|c|c|c|c|c|c|}
\hline Oxides & $\begin{array}{l}\text { Surface } \\
\text { area } \\
\left(\mathrm{m}^{2} \mathrm{~g}^{-1}\right)\end{array}$ & $\begin{array}{l}\text { OSC } \\
(\mu \mathrm{mol} O \\
\left.\mathrm{g}^{-1}\right)\end{array}$ & 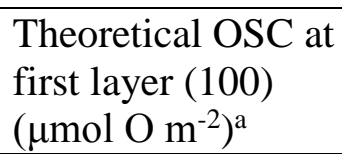 & $\begin{array}{l}\text { Number of } \\
\text { reduced } \\
\text { layers }\end{array}$ & $\begin{array}{l}\text { Depth of } \\
\text { reduction } \\
(\mathrm{nm})\end{array}$ & $\begin{array}{l}\text { Particle } \\
\text { radius } \\
(\mathrm{nm})^{\mathrm{b}}\end{array}$ \\
\hline $\mathrm{CeO}_{2}$ & 5 & 113 & 5.70 & 4.0 & 1.1 & 84 \\
\hline $\mathrm{CeO}_{2}$ & 62 & 304 & 5.70 & 0.9 & 0.27 & 7 \\
\hline $\mathrm{Ce}_{0.8} \mathrm{Zr}_{0.2} \mathrm{O}_{2}$ & 25 & 321 & 4.70 & 2.7 & 0.85 & 17 \\
\hline $\mathrm{Ce}_{0.5} \mathrm{Zr}_{0.5} \mathrm{O}_{2}$ & 13 & 750 & 2.91 & 20 & 6.2 & 36 \\
\hline $\mathrm{Ce}_{0.2} \mathrm{Zr}_{0.8} \mathrm{O}_{2}$ & 15 & 527 & 0.98 & 36 & 13 & 36 \\
\hline
\end{tabular}

${ }^{a}$ Assume that $\mathrm{Zr}$ atoms do not participate in the storage process and the surface exposed is $(100)^{37}$

${ }^{\mathrm{b}}$ Calculated from the BET surface area, assuming spherical, non-porous particles

The oxygen storage capacity (OSC) of the oxides was measured by $\mathrm{O}_{2}$ pulse chemisorption at $673 \mathrm{~K}$ after reduction in $\mathrm{H}_{2}$ at $673 \mathrm{~K}$ for $6 \mathrm{~h}$, and the results are listed in Table 2.3. All of the Ce- $\mathrm{Zr}$ mixed oxides revealed larger OSC than the pure $\mathrm{CeO}_{2}$, with the highest OSC observed on $\mathrm{Ce}_{0.5} \mathrm{Zr}_{0.5} \mathrm{O}_{2}$, which had OSC of $750 \mu \mathrm{mol} \mathrm{O} \mathrm{g}$. To explore whether or not the bulk oxygen is involved in the oxygen storage process, the number of layers reduced and the depth of reduction were calculated based on the method proposed by Madier et al. ${ }^{37}$ For the high surface area ceria, only the surface layer participated in the OSC measurement. The number of reduced layers increased to 2.7 for $\mathrm{Ce}_{0.8} \mathrm{Zr}_{0.2} \mathrm{O}_{2}$. This number further increased to 20 and 36 for $\mathrm{Ce}_{0.5} \mathrm{Zr}_{0.5} \mathrm{O}_{2}$ and $\mathrm{Ce}_{0.2} \mathrm{Zr}_{0.8} \mathrm{O}_{2}$, respectively. Considering the fact that a deeper layer consists of fewer oxygen atoms than the outer layer, the actual numbers of layers reduced for $\mathrm{Ce}_{0.5} \mathrm{Zr}_{0.5} \mathrm{O}_{2}$ and $\mathrm{Ce}_{0.2} \mathrm{Zr}_{0.8} \mathrm{O}_{2}$ are larger than the values reported in Table 2.3. Although the number of layers that could be reduced on low surface area ceria was 4.0, that degree of reduction was still much smaller than that associated with $\mathrm{Ce}_{0.5} \mathrm{Zr}_{0.5} \mathrm{O}_{2}$ and $\mathrm{Ce}_{0.2} \mathrm{Zr}_{0.8} \mathrm{O}_{2}$, indicating the high OSC in $\mathrm{Ce}_{0.5} \mathrm{Zr}_{0.5} \mathrm{O}_{2}$ and $\mathrm{Ce}_{0.2} \mathrm{Zr}_{0.8} \mathrm{O}_{2}$ is attributed to the introduction of $\mathrm{Zr}$, not to a difference in surface area. These results support the conclusion that the introduction of $\mathrm{Zr}$ into $\mathrm{CeO}_{2}$ improves oxygen 
mobility. In fact, Balducci et al. found that the activation energy for bulk oxygen migration decreased with increasing $\mathrm{Zr}$ content in $\mathrm{Ce}-\mathrm{Zr}$ mixed oxides using atomistic simulation methods. ${ }^{38}$ Two factors contribute to the OSC of Ce-Zr mixed oxides: the amount of cerium and the oxygen mobility in the oxides. The compromise of these two factors resulted in the highest OSC exhibited by $\mathrm{Ce}_{0.5} \mathrm{Zr}_{0.5} \mathrm{O}_{2}$.

\subsubsection{Characterization of coke}

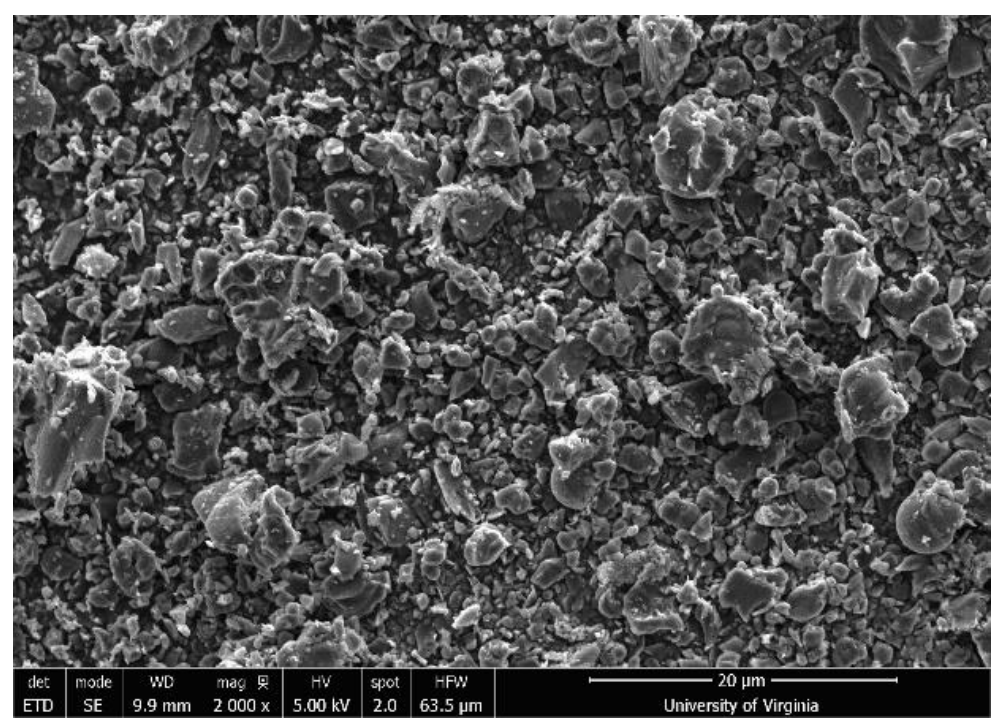

Figure 2.6 SEM image of synthetic coke after 64 hours milling.

The composition of coke collected and prepared after milling was characterized by the combustion method. The coke had 98 wt.\% carbon and less than 0.5 wt.\% hydrogen. The $\mathrm{N}_{2-}$ physisorption of coke provided a BET surface area of $14 \mathrm{~m}^{2} \mathrm{~g}^{-1}$, a micropore surface area of $2 \mathrm{~m}^{2}$ $\mathrm{g}^{-1}$ and a pore volume of $0.03 \mathrm{~cm}^{3} \mathrm{~g}^{-1}$, suggesting that it is nonporous. The morphology of the coke was characterized by SEM, as shown in Figure 2.6, which revealed a wide size distribution of particles, with the majority being smaller than $1 \mu \mathrm{m}$ and some as large as $10 \mu \mathrm{m}$. 
The X-ray diffraction pattern of the coke is shown in Figure 2.7. The peaks at $24.9^{\circ}$ and $43.1^{\mathrm{o}}$ are attributed to the (002) and (100) features of graphitic carbon, respectively. ${ }^{24}$ Both of the peaks are broad, indicating the small sizes of graphitic carbon domains. The peak parameters of the (002) feature were used to obtain the d-spacing between graphitic carbon layers and the crystalline size Lc (perpendicular to the graphitic carbon layer), which are 0.36 and $1.7 \mathrm{~nm}$, respectively. The crystallite size $\mathrm{La}$ (parallel to the graphitic carbon layer) is $2.2 \mathrm{~nm}$ calculated from the peak parameters of the (100) feature.

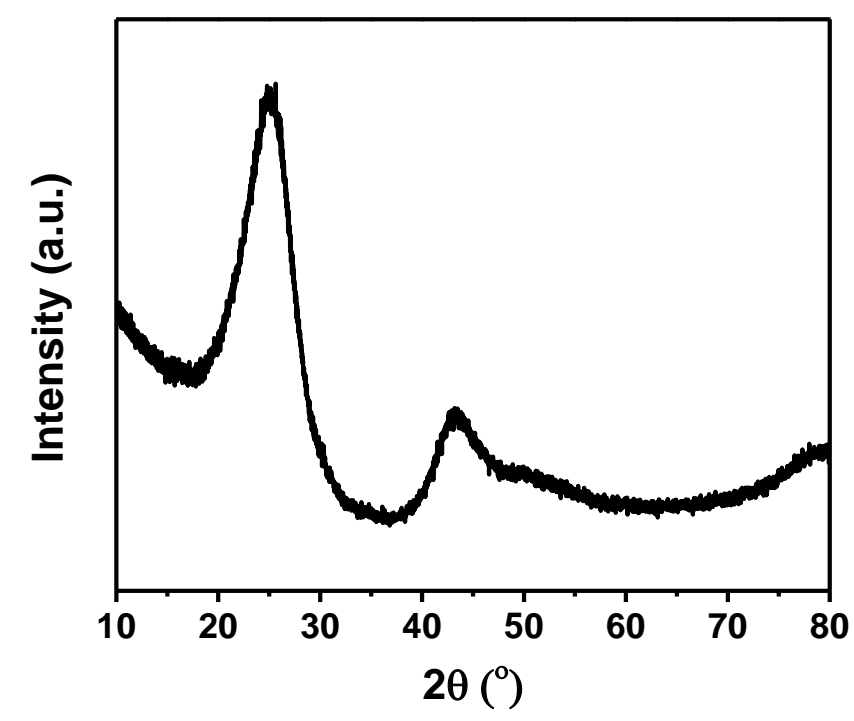

Figure 2.7 X-ray diffraction pattern of synthetic coke.

Figure 2.8 shows a typical HRTEM image of synthetic coke. Small graphitic carbon domains with crystalline sizes Lc and La of several nanometers can be clearly observed. The interlayer spacing determined from microscopy is $0.37 \mathrm{~nm}$, which is consistent with the result obtained from XRD $(0.36 \mathrm{~nm})$ and is slightly larger than the spacing in graphene $(0.34 \mathrm{~nm}){ }^{39}$ 


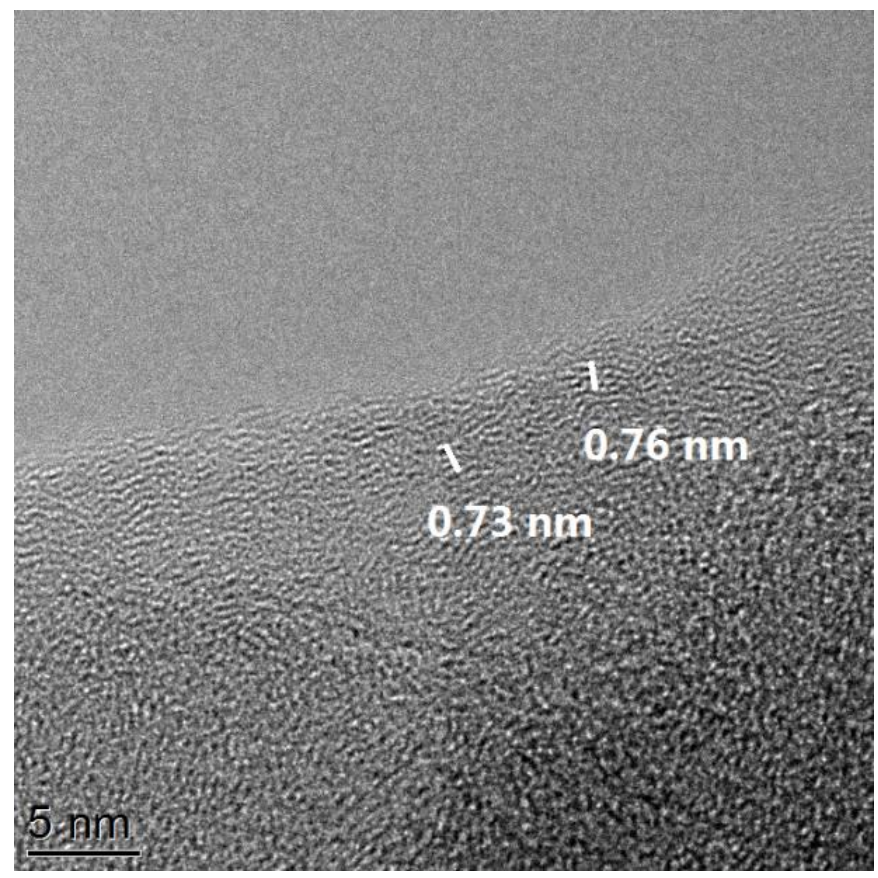

Figure 2.8 HRTEM image of synthetic coke.

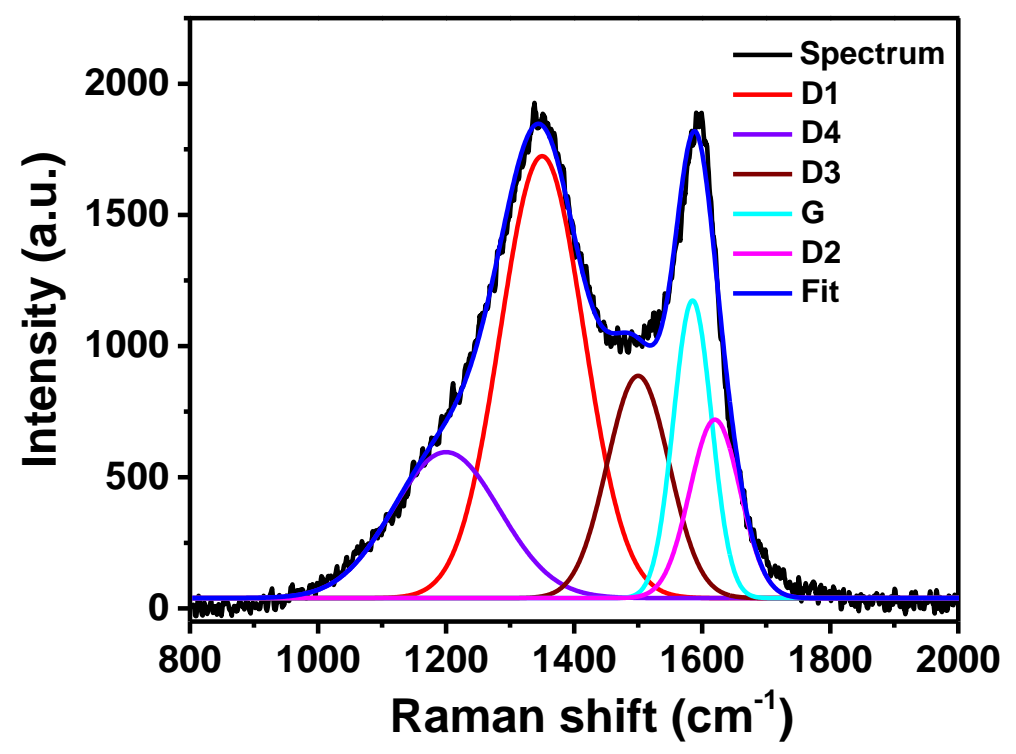

Figure 2.9 Raman spectrum of synthetic coke evaluated with an excitation $\lambda_{0}=514 \mathrm{~nm}$. Colors associated with various components can be found in the on-line version of the article. 
Figure 2.9 presents the Raman spectrum of coke using an excitation source with $\lambda_{0}=514$ $\mathrm{nm}$. The spectrum revealed two broad peaks with maxima at $1349 \mathrm{~cm}^{-1}$ and $1598 \mathrm{~cm}^{-1}$, which result from the overlapping contributions from five different types of carbon structures. The five features are known as the $\mathrm{G}$ band $\left(1580 \mathrm{~cm}^{-1}\right.$, ideal graphitic lattice), the D1 band $\left(1350 \mathrm{~cm}^{-1}\right.$, disordered graphitic lattice), the D2 band $\left(1620 \mathrm{~cm}^{-1}\right.$, disordered graphitic lattice), the D3 band $\left(1500 \mathrm{~cm}^{-1}\right.$, amorphous carbon) and the D4 band $\left(1200 \mathrm{~cm}^{-1}\right.$, disordered graphitic lattice) ${ }^{40}$ Sadezky et al. reported that curve fitting of an experimental spectrum with four Lorentzianshaped bands (G, D1, D2, D4) and one Gaussian-shaped band (D3) was best suited for the decomposition of first-order spectra of carbonaceous materials. ${ }^{40}$ Therefore, the same fitting method was applied here to deconvolute the contributions of different carbon structures in our synthetic coke. The results of the fitting procedure are summarized in Table 2.4 and indicate synthetic coke is composed primarily of disordered graphitic and amorphous carbon, which is generally consistent with the Raman characterization of coke formed by thermal reaction of propylene and ethylene. ${ }^{41}$

Table 2.4 Deconvolution of Raman features associated with synthetic coke.

\begin{tabular}{llllll}
\hline & $\mathrm{G}(\%)$ & $\mathrm{D} 1(\%)$ & $\mathrm{D} 2(\%)$ & $\mathrm{D} 3(\%)$ & $\mathrm{D} 4(\%)$ \\
Synthetic Coke & 11 & 32 & 4 & 33 & 20 \\
\hline
\end{tabular}

The combined results from XRD, HRTEM and Raman spectroscopy are consistent with the synthetic coke produced by ethylene decomposition in this work being a mixture of graphitic carbon and amorphous carbon, with the size of graphitic carbon domains being several nanometers. 


\subsubsection{Kinetics of coke oxidation in the presence of $\mathrm{CeO}_{2}$ and $\mathrm{Ce}-\mathrm{Zr}$ mixed oxides}

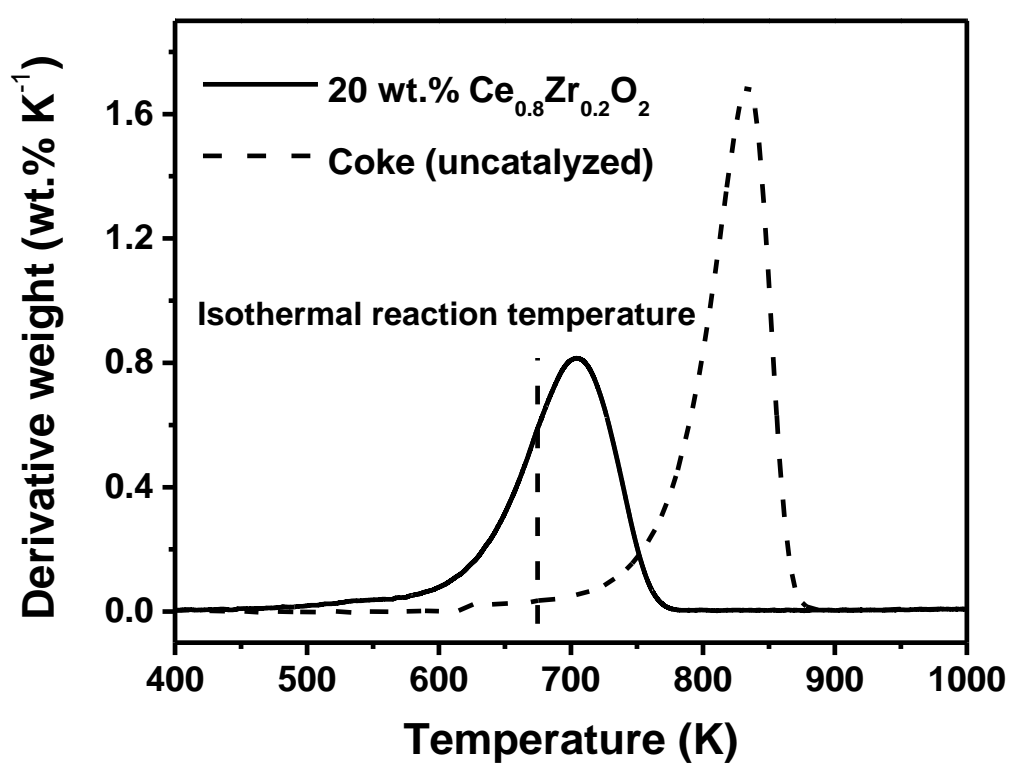

Figure 2.10 Temperature-programmed oxidation of synthetic coke with and without 20 wt.\% $\mathrm{Ce}_{0.8} \mathrm{Zr}_{0.2} \mathrm{O}_{2}$. Reaction conditions: $1 \mathrm{~K} \mathrm{m^{-1 }}, 100 \mathrm{~cm}^{3} \mathrm{~min}^{-1} 10 \mathrm{vol} \% \mathrm{O}_{2} / \mathrm{He}$, tight contact sample.

Temperature-programmed oxidation in the presence and absence of catalyst was performed to determine a reasonable isothermal reaction temperature at which uncatalyzed coke oxidation was insignificant. Typical results from TPO are presented in Figure 2.10. The addition of 20 wt.\% $\mathrm{Ce}_{0.8} \mathrm{Zr}_{0.2} \mathrm{O}_{2}$ to the coke sample decreased the peak oxidation temperature to $705 \mathrm{~K}$ from $834 \mathrm{~K}$ for the uncatalyzed combustion reaction. We chose to use $673 \mathrm{~K}$ as the isothermal reaction temperature to ensure the contribution from the uncatalyzed reaction was negligible. 
The dashed curve in Figure 2.11 shows the weight loss profile during the isothermal oxidation of coke with $20 \mathrm{wt} . \% \mathrm{Ce}_{0.8} \mathrm{Zr}_{0.2} \mathrm{O}_{2}$ at $673 \mathrm{~K}$. The profile clearly represents a first order decay that reacted nearly all of the coke after about $400 \mathrm{~min}$. For the reaction at $673 \mathrm{~K}$ in the absence of catalyst, only $4 \mathrm{wt} \%$ of the coke was oxidized, confirming that $673 \mathrm{~K}$ is an appropriate isothermal reaction temperature to study the catalyzed reaction rate. A first order rate equation was used to fit the weight loss profile and the model is shown in as the solid curve in Figure 2.11. The first order fit matched with the experimental loss curve very well over the entire profile.

$$
\frac{m}{m_{o}}=e^{-k t}
$$

where $\mathrm{m}$ is the weight of coke at time $\mathrm{t}, \mathrm{m}_{0}$ is the initial weight of coke in the sample, $\mathrm{t}$ is the isothermal reaction time and $\mathrm{k}$ is the first order rate constant. 


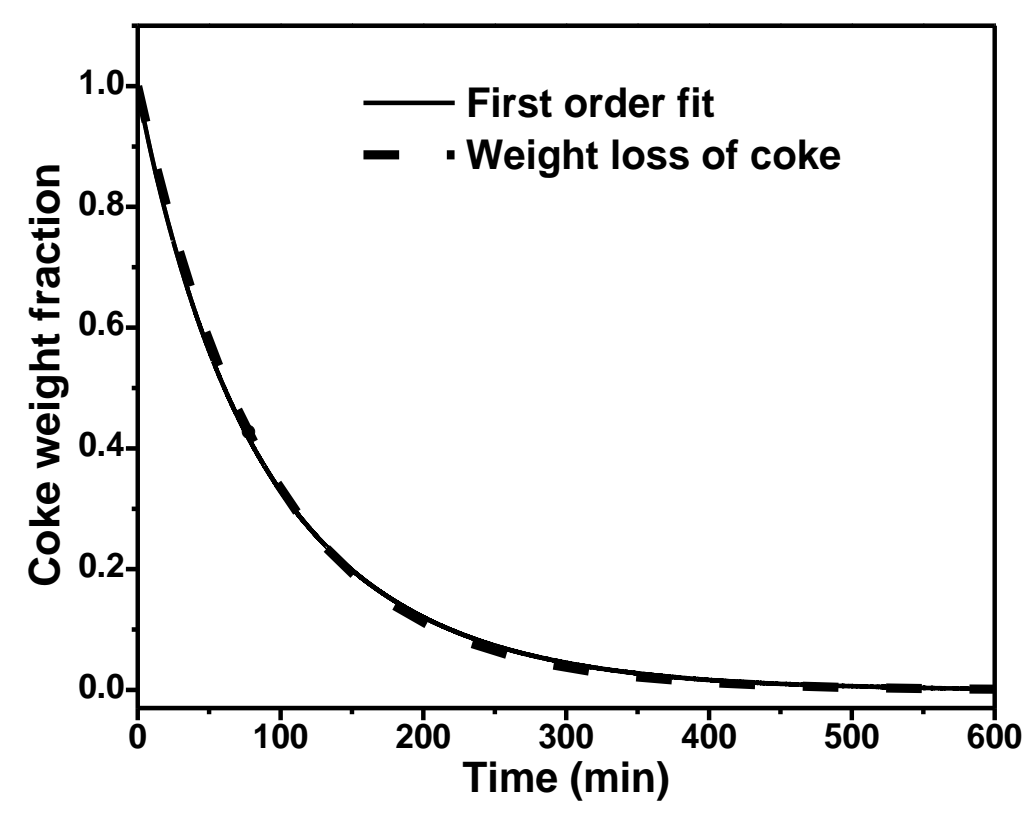

Figure 2.11 Weight loss profile of coke during coke oxidation catalyzed by $\mathrm{Ce}_{0.8} \mathrm{Zr}_{0.2} \mathrm{O}_{2}$ at 673 K. Reaction conditions: 20 wt. $\% \mathrm{Ce}_{0.8} \mathrm{Zr}_{0.2} \mathrm{O}_{2}, 100 \mathrm{~cm}^{3} \mathrm{~min}^{-1} 10 \mathrm{vol} . \% \mathrm{O}_{2} / \mathrm{He}$, tight contact sample.

The first order model described well the coke oxidation weight loss profiles in the presence of $\mathrm{CeO}_{2}$ and other $\mathrm{Ce}-\mathrm{Zr}$ mixed oxides used in this study. Therefore, the first order rate constant of coke oxidation was used to evaluate the effectiveness of the various catalysts.

For catalyzed coke oxidation, the contact conditions between catalyst and coke can significantly affect the observed rate constant. The effect of grinding time was then investigated to determine the appropriate contact conditions to obtain reproducible results, as shown in Figure 2.12. Grinding the mixture of catalyst and coke with a mortar and pestle for $20 \mathrm{~min}$ increased the observed rate constant by an order of magnitude compared to a loose contact sample in which the coke and catalyst were ground for $1 \mathrm{~h}$ separately and gently mixed by spatula. Further grinding of the coke-catalyst mixture increased the rate constant until it reached a constant value, 
indicating that the sample had achieved an optimal contact condition, which is defined here as a tight contact sample. All of the coke-catalyst samples in this study were ground for an extensive time (about $70 \mathrm{~min}$ ) to ensure tight contact conditions were achieved.

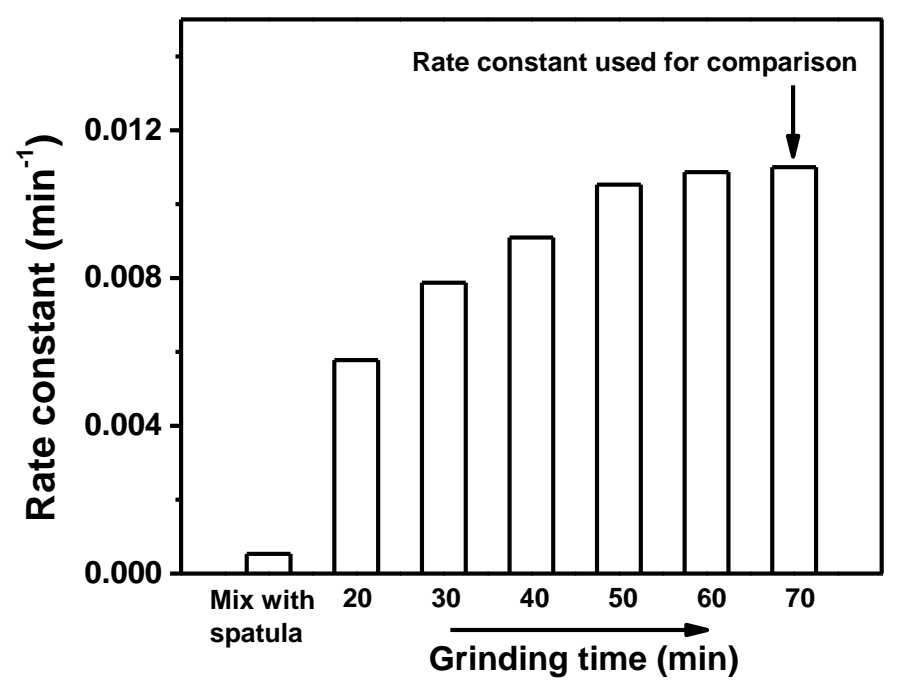

Figure 2.12 Effect of grinding time on the rate constant of coke oxidation catalyzed by $\mathrm{Ce}_{0.8} \mathrm{Zr}_{0.2} \mathrm{O}_{2}$. Reaction conditions: $20 \mathrm{wt} . \% \mathrm{Ce}_{0.8} \mathrm{Zr}_{0.2} \mathrm{O}_{2}, 100 \mathrm{~cm}^{3} \mathrm{~min}^{-1} 10$ vol.\% $\mathrm{O}_{2} / \mathrm{He}$.

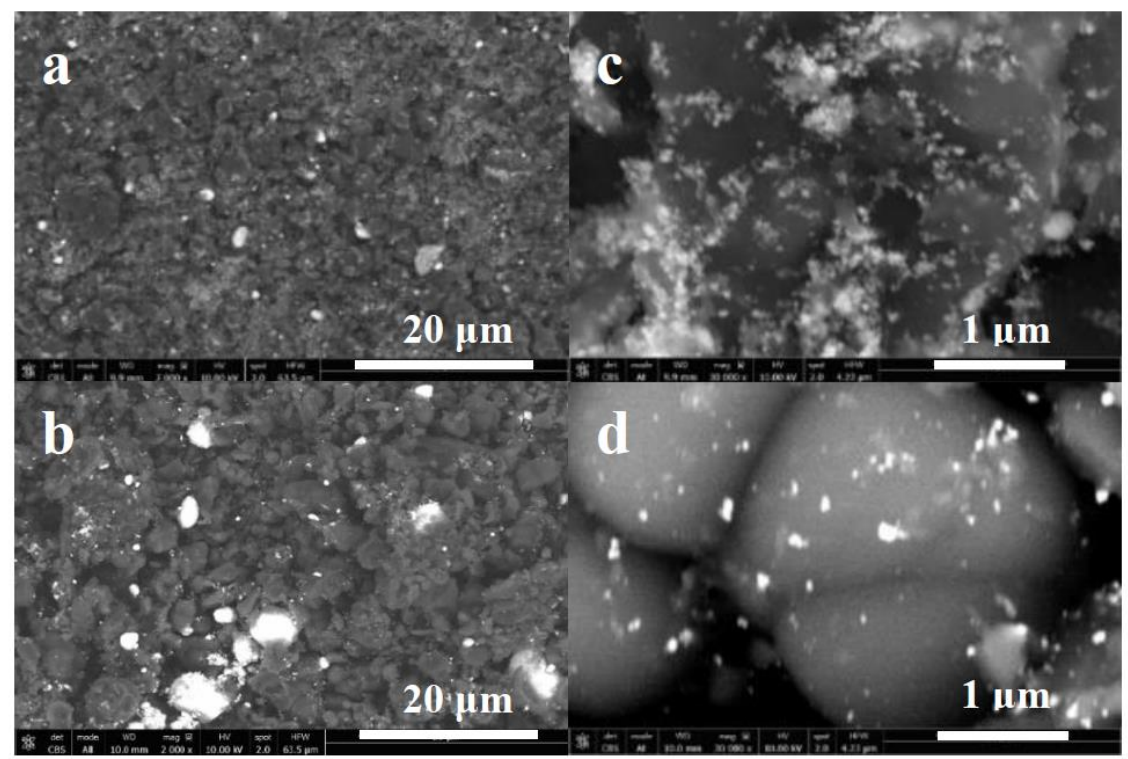

Figure 2.13 SEM images of a mixture of $20 \mathrm{wt} . \% \mathrm{Ce}_{0.8} \mathrm{Zr}_{0.2} \mathrm{O}_{2}$ and $80 \mathrm{wt} . \%$ synthetic coke at tight contact ( $\mathrm{a}$ and $\mathrm{c}$ ) and loose contact ( $\mathrm{b}$ and $\mathrm{d}$ ) conditions. 
The morphology of tight and loose contact conditions was studied by SEM, with representative micrographs presented in Figure 2.13. The dark spots in the images were coke particles whereas the bright ones were catalyst particles. There were larger catalyst particles (presumably aggregates of primary particles) in the loose contact sample (Figure 2.13b) than in the tight contact sample (Figure 2.13a). At higher magnification, small catalyst particles were observed to be well-distributed on the coke particles in the tight contact sample (Figure 2.13c) relative to the loose contact sample (Figure 2.13d). Evidently, grinding the coke with the catalyst helps disperse the catalyst and enhance the contact area between the catalyst and the coke.

Although the first order rate constant is one quantifiable measure of oxidation rate, a catalytic reaction must be operated under conditions at which the rate is proportional to the number of active sites to properly compare performance among various catalysts. Therefore, coke-catalyst samples with different amounts of catalyst were prepared and evaluated in the oxidation reaction. Figure 2.14 shows the relationship between rate constant and catalyst loading, in which the catalyst loading is presented by the total surface area of catalyst per gram of coke in the sample. For all of the four catalysts tested, the same trend was observed: at low catalyst loadings, the oxidation rate constant was proportional to the total surface area of catalyst whereas at high catalyst loadings, the rate constant was independent of the total surface area of the catalyst. There is a saturation amount of catalyst for coke oxidation, beyond which the excess catalyst present in the sample does not participate in the reaction. To obtain the maximum active surface area of catalyst in the mixture, the rate constants at low catalyst loadings were fitted with a line through the origin and the rate constants beyond saturation were fitted with a line at the average value of rate constants. The intersection of these two lines corresponds to coke-catalyst mixture with the maximum active catalyst surface area. The coke oxidation rates determined 
from the slopes of the lines in Figure 2.14 at low catalyst loadings can be used to compare the various catalysts. The coke oxidation rate was actually an initial rate because the values on the $\mathrm{x}$ axis (total catalyst surface area per gram of coke) were calculated from the initial weight percent of coke. It should be noted that even at low catalyst loadings, the conversion of coke during a run will eventually produce condition at which the catalyst area greatly exceeds the remaining coke area in the mixture. Thus, the first order loss of coke as depicted in Figure 2.11 results from an evolving contact condition throughout the reaction.
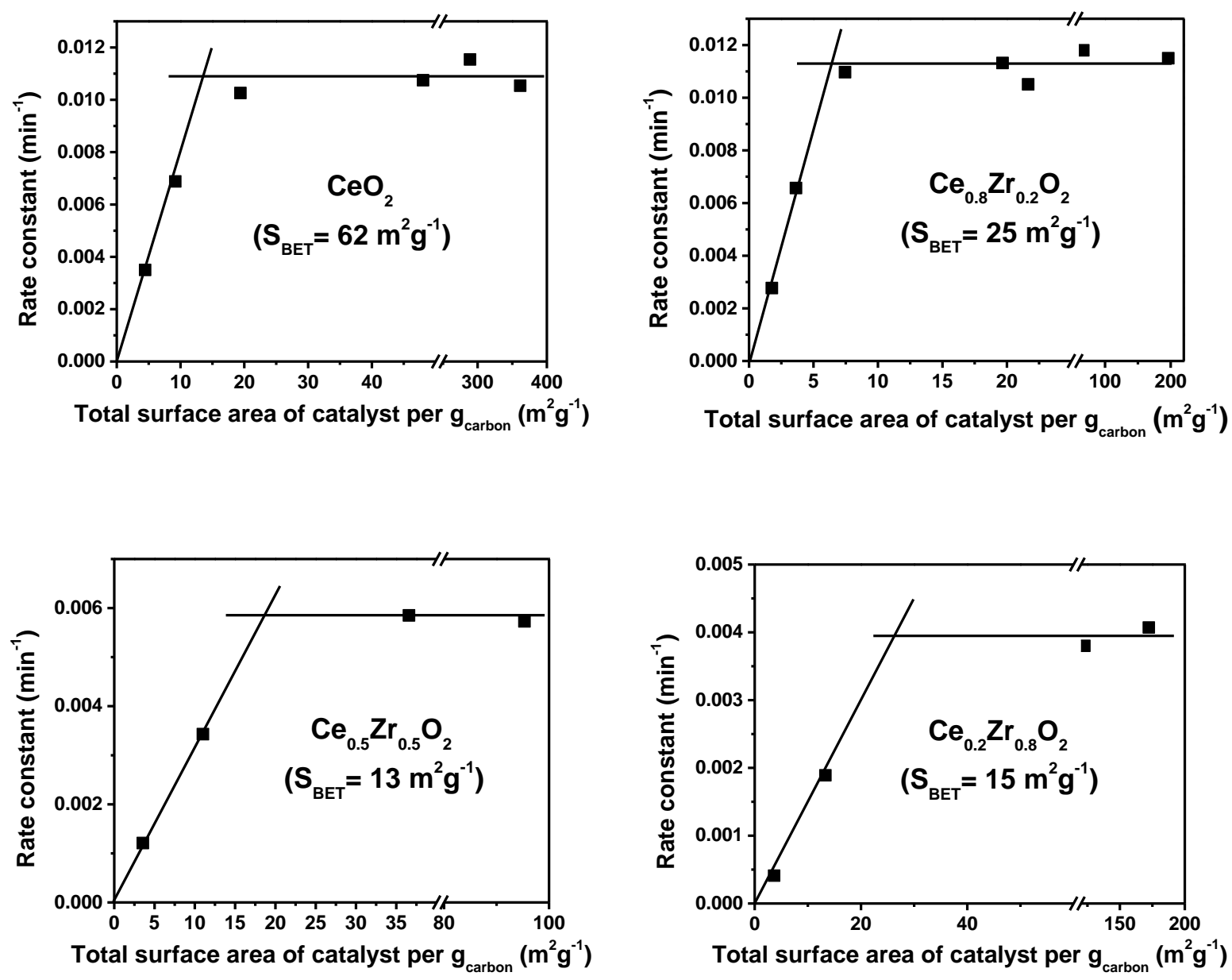

Figure 2.14 Relationship between measured first order rate constant and normalized catalyst loading for $\mathrm{CeO} 2$ and Ce-Zr mixed oxides. Reaction conditions: 673 K, 100 cm3 min-1 10 vol.\% $\mathrm{O} 2 / \mathrm{He}$, tight contact samples. 
The maximum active catalyst surface area and coke oxidation rate at $673 \mathrm{~K}$ for the four oxides are presented in Table 2.5. For Ce- $\mathrm{Zr}$ mixed oxides, the maximum active surface area increased and the coke oxidation rate decreased with increasing zirconium content. The coke oxidation rate with $\mathrm{CeO}_{2}$ was between those with $\mathrm{Ce}_{0.8} \mathrm{Zr}_{0.2} \mathrm{O}_{2}$ and $\mathrm{Ce}_{0.5} \mathrm{Zr}_{0.5} \mathrm{O}_{2}$.

Table 2.5 Active catalyst surface area and coke oxidation rates at $673 \mathrm{~K}$ for $\mathrm{CeO}_{2}$ and $\mathrm{Ce}-\mathrm{Zr}$ mixed oxides.

\begin{tabular}{lllll}
\hline & $\mathrm{CeO}_{2}$ & $\mathrm{Ce}_{0.8} \mathrm{Zr}_{0.2} \mathrm{O}_{2}$ & $\mathrm{Ce}_{0.5} \mathrm{Zr}_{0.5} \mathrm{O}_{2}$ & $\mathrm{Ce}_{0.2} \mathrm{Zr}_{0.8} \mathrm{O}_{2}$ \\
\hline $\begin{array}{l}\text { Average rate constant at high } \\
\text { catalyst loading (min }\end{array}$ & 0.011 & 0.011 & 0.0059 & 0.0040 \\
$\begin{array}{l}\text { Ratio of maximum active catalyst } \\
\text { surface area to coke mass } \\
\left(\mathrm{m}^{2} \text { cat } \mathrm{g}^{-1} \text { carbon }\right)\end{array}$ & 14 & 7 & 19 & 28 \\
$\begin{array}{l}\text { Ratio of maximum active catalyst } \\
\text { surface area to coke surface area } \\
\left(\mathrm{m}^{2} \text { cat } \mathrm{m}^{-2} \text { carbon }\right)\end{array}$ & 1.2 & 0.58 & 1.6 & 2.3 \\
$\begin{array}{l}\text { Coke oxidation rate } \\
\left(10^{-4} \mathrm{~g}_{\text {carbon }} \mathrm{m}^{-2} \text { cat } \text { min }^{-1}\right)\end{array}$ & 7.9 & 17 & 3.0 & 1.4 \\
\hline
\end{tabular}

Table 2.6 Order of reaction with respect to dioxygen during coke oxidation with $\mathrm{Ce}_{0.8} \mathrm{Zr}_{0.2} \mathrm{O}_{2 .}{ }^{\mathrm{a}}$

\begin{tabular}{llllll}
\hline Catalyst loading (wt. $\%$ ) & 0 & 10 & 20 & 50 & 70 \\
\hline Order with respect to $\mathrm{O}_{2}$ & 1.0 & 0.38 & 0.36 & 0.30 & 0.26 \\
\hline
\end{tabular}

${ }^{\mathrm{a}}$ Reaction conditions: $2.1-21$ vol.\% $\mathrm{O}_{2} / \mathrm{He}, 673 \mathrm{~K}$

The reaction order with respect to dioxygen during coke oxidation was measured by varying the gas phase percentage of dioxygen between 2.1 vol. $\%$ and 21 vol. $\%$ at $673 \mathrm{~K}$. First order rate constants were used to calculate the apparent reaction order and the results are summarized in Table 2.6. The uncatalyzed coke oxidation reaction was first order in $\mathrm{O}_{2}$, which is consistent the reported order for diesel soot oxidation. ${ }^{42,43}$ The presence of $\mathrm{Ce}_{0.8} \mathrm{Zr}_{0.2} \mathrm{O}_{2}$ decreased the order of reaction in dioxygen to about 0.30 , which also varied with the amount of catalyst in the samples (See Table 2.6). The $\mathrm{O}_{2}$ reaction order in the presence of other $\mathrm{Ce}-\mathrm{Zr}$ mixed oxides 
as well as $\mathrm{CeO}_{2}$ was determined using 70-90 wt.\% catalyst and the results are listed in Table 2.7. The four oxide catalysts exhibited similar reaction order in dioxygen of about 0.3 . Issa et al. observed a reaction order in $\mathrm{O}_{2}$ of 0.2 for carbon black oxidation catalyzed by $\mathrm{CeO}_{2}$ at $701 \mathrm{~K}^{44}$ Fino et al. proposed that an order in dioxygen lower than 0.50 during catalyzed carbon oxidation indicates that the active oxygen species are oxygen atoms generated by dissociative adsorption of dioxygen on the catalyst surface. ${ }^{45}$

Table 2.7 Order of reaction with respect to $\mathrm{O}_{2}$ during coke oxidation over Ce-based catalysts. ${ }^{\mathrm{a}}$

\begin{tabular}{ll}
\hline Catalyst & Order in $\mathrm{O}_{2}$ \\
\hline $\mathrm{CeO}_{2}$ & 0.28 \\
$\mathrm{Ce}_{0.8} \mathrm{Zr}_{0.2} \mathrm{O}_{2}$ & 0.26 \\
$\mathrm{Ce}_{0.5} \mathrm{Zr}_{0.5} \mathrm{O}_{2}$ & 0.30 \\
$\mathrm{Ce}_{0.2} \mathrm{Zr}_{0.8} \mathrm{O}_{2}$ & 0.25 \\
\hline
\end{tabular}

${ }^{a}$ Reaction conditions: $80-90$ wt. \% catalyst loading, $673 \mathrm{~K}$, tight contact samples.

Table 2.8 Apparent activation energy of coke oxidation in the presence of Ce-based catalysts. ${ }^{\text {a }}$

\begin{tabular}{ll}
\hline Catalyst & Apparent activation energy $\left(\mathrm{kJ} \mathrm{mol}^{-1}\right)$ \\
\hline None & 150 \\
$\mathrm{CeO}_{2}$ & 117 \\
$\mathrm{Ce}_{0.8} \mathrm{Zr}_{0.2} \mathrm{O}_{2}$ & 129 \\
$\mathrm{Ce}_{0.5} \mathrm{Zr}_{0.5} \mathrm{O}_{2}$ & 123 \\
$\mathrm{Ce}_{0.2 \mathrm{Zr} .8} \mathrm{O}_{2}$ & 123 \\
\hline${ }^{\mathrm{a}}$ Reaction temperature varied from $653-693 \mathrm{~K}$ while $\mathrm{O}_{2}$ concentration was maintained at 10 \\
vol.\%.
\end{tabular}

Coke oxidation over $\mathrm{Ce}-\mathrm{Zr}$ mixed oxides with $10 \mathrm{vol} . \% \mathrm{O}_{2}$ was performed at different reaction temperatures so that an apparent activation energy could be derived from the measured first order rate constants. The apparent activation energies of the catalytic oxidation reactions, which are summarized in Table 2.8 , were $20-30 \mathrm{~kJ} \mathrm{~mol}^{-1}$ lower than that of the uncatalyzed reaction.

\subsection{4 $\mathrm{CO}$ oxidation over $\mathrm{CeO}_{2}$ and $\mathrm{Ce}-\mathrm{Zr}$ mixed oxides}


To maintain differential conversion and minimize the uncatalyzed $\mathrm{CO}$ oxidation reactions, the $\mathrm{CO}$ oxidation experiments were conducted at $573 \mathrm{~K}$ and the reaction rates were calculated at $5 \% \mathrm{CO}$ conversion. As revealed in Table 2.9, the incorporation of $20 \mathrm{~mol} . \% \mathrm{Zr}$ into $\mathrm{CeO}_{2}$ doubled the rate of $\mathrm{CO}$ oxidation. However, the reaction rates decreased significantly with additional $\mathrm{Zr}$ in the catalyst.

Table 2.9 Rate of $\mathrm{CO}$ oxidation at $5 \% \mathrm{CO}$ conversion over $\mathrm{CeO}_{2}$ and $\mathrm{Ce}-\mathrm{Zr}$ mixed oxides. ${ }^{\mathrm{a}}$

\begin{tabular}{|c|c|c|c|c|}
\hline & $\mathrm{CeO}_{2}$ & $\mathrm{Ce}_{0.8} \mathrm{Zr}_{0.2} \mathrm{O}_{2}$ & $\mathrm{Ce}_{0.5} \mathrm{Zr}_{0.5} \mathrm{O}_{2}$ & $\mathrm{Ce}_{0.2} \mathrm{Zr}_{0.8} \mathrm{O}_{2}$ \\
\hline $\begin{array}{l}\text { CO oxidation rate } \\
\left(10^{-7} \text { mol }_{\mathrm{CO}} \mathrm{m}_{\text {cat }}^{-2} \min ^{-1}\right)\end{array}$ & 29 & 68 & 13 & 3.8 \\
\hline
\end{tabular}

${ }^{\text {a }}$ Reaction conditions: $573 \mathrm{~K}$, total pressure 1 atm, 2 vol.\% $\mathrm{CO}$ and 2 vol.\% $\mathrm{O}_{2}$ in $\mathrm{He}$ 

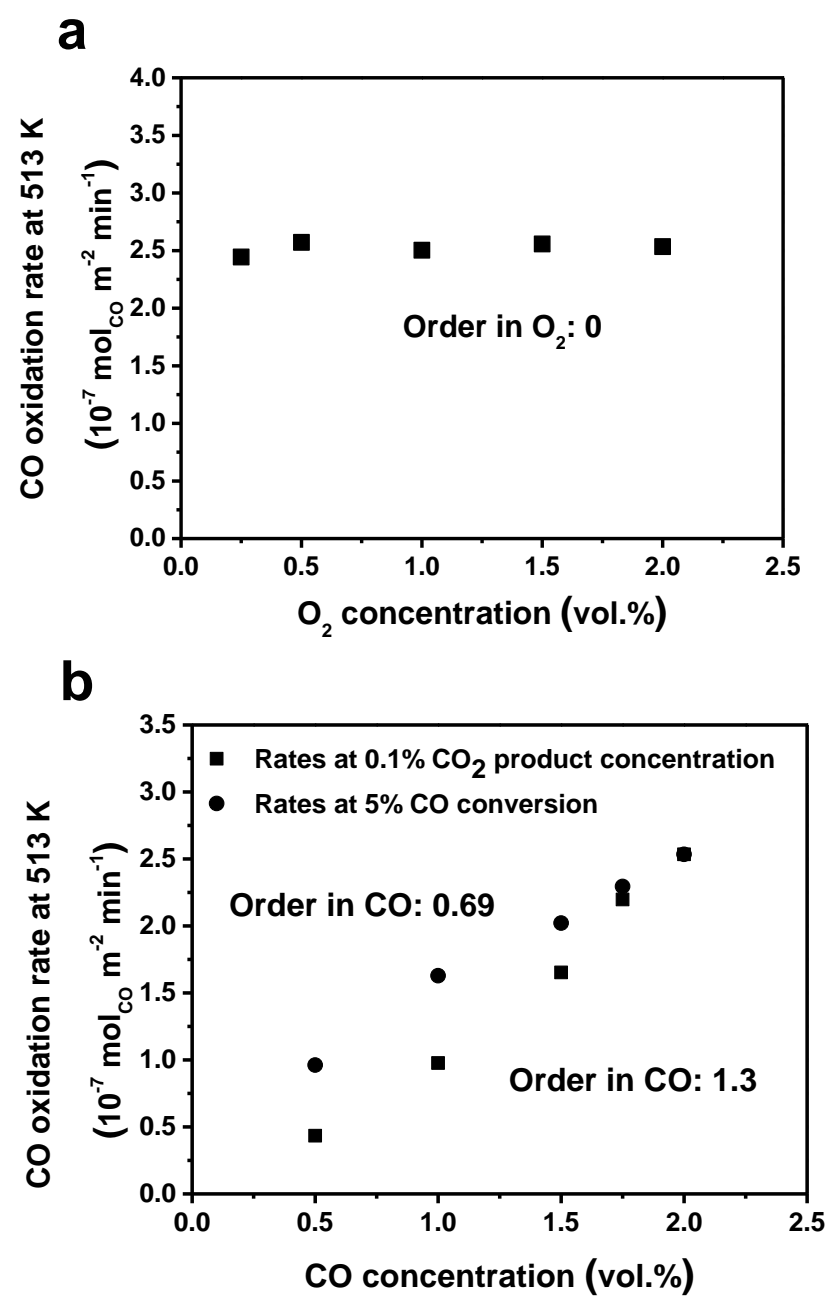

Figure 2.15 Influence of (a) $\mathrm{O}_{2}$ and (b) $\mathrm{CO}$ concentration on $\mathrm{CO}$ oxidation rate over $\mathrm{CeO}_{2}$ at 513 $\mathrm{K}$. While varying the concentration of one gas, the other gas was kept at 2 vol. $\%$. 


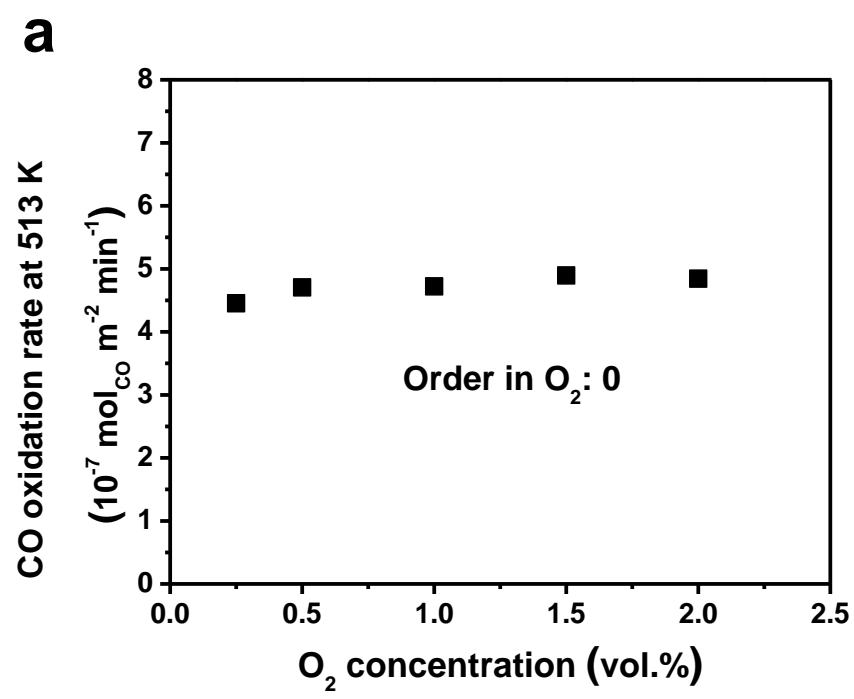

b

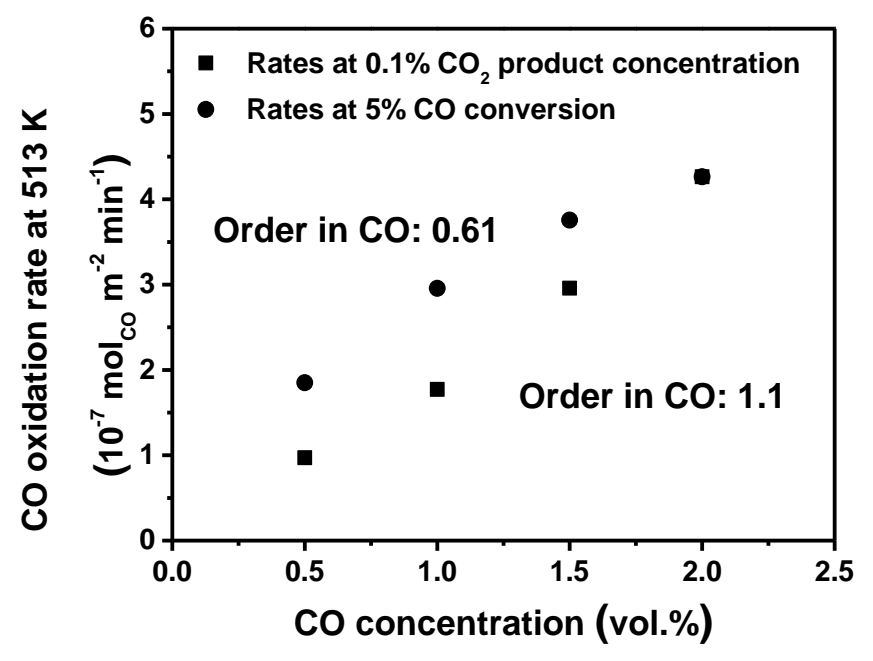

Figure 2.16 Influence of (a) $\mathrm{O}_{2}$ and (b) $\mathrm{CO}$ concentration on $\mathrm{CO}$ oxidation rate over $\mathrm{Ce}_{0.8} \mathrm{Zr}_{0.2} \mathrm{O}_{2}$ at $513 \mathrm{~K}$. While varying the concentration of one gas, the other gas was kept at 2 vol.\%.

The influences of $\mathrm{CO}$ and $\mathrm{O}_{2}$ concentration on $\mathrm{CO}$ oxidation rates over $\mathrm{CeO}_{2}$ were studied at $513 \mathrm{~K}$ and the results are presented in Figure 2.15. The rates of $\mathrm{CO}$ oxidation were unaffected by change in the $\mathrm{O}_{2}$ concentration, indicating zero order behavior. The influence of $\mathrm{CO}$ concentration was more complex and depended on how the experiments were performed. The reaction rates obtained at $5 \%$ conversion of $\mathrm{CO}$ at different $\mathrm{CO}$ concentrations gave an order 
of 0.69 for CO, which is similar with those reported in the literature. ${ }^{46,47}$ Since the presence of product $\mathrm{CO}_{2}$ can inhibit $\mathrm{CO}$ oxidation, ${ }^{46}$ a more appropriate method to determine the order in $\mathrm{CO}$ is to use rates obtained at the same level of $\mathrm{CO}_{2}$ concentration in the catalyst bed. Results obtained at constant $\mathrm{CO}_{2}$ level gave an order in $\mathrm{CO}$ of 1.3.

To investigate the effect of $\mathrm{Zr}$ addition to $\mathrm{CeO}_{2}$ on the reaction orders in $\mathrm{CO}$ and $\mathrm{O}_{2}$, the response of $\mathrm{CO}$ oxidation rates over $\mathrm{Ce}_{0.8} \mathrm{Zr}_{0.2} \mathrm{O}_{2}$ to changing the concentrations of $\mathrm{CO}$ and $\mathrm{O}_{2}$ are presented in Figure 2.16. The reaction orders are similar with those found over $\mathrm{CeO}_{2}$, with the order in $\mathrm{O}_{2}$ being 0 and the order in $\mathrm{CO}$ (at constant $\mathrm{CO}_{2}$ level) being 1.1. Evidently, the reaction mechanism over the two catalysts is unaffected by the addition of zirconium.

Table 2.10 Apparent activation energy of CO oxidation over Ce-based catalysts. ${ }^{\mathrm{a}}$

\begin{tabular}{ll}
\hline Catalysts & Apparent activation energy $\left(\mathrm{kJ} \mathrm{mol}^{-1}\right)$ \\
\hline $\mathrm{CeO}_{2}$ & 114 \\
$\mathrm{Ce}_{0.8} \mathrm{Zr}_{0.2} \mathrm{O}_{2}$ & 117 \\
$\mathrm{Ce}_{0.5} \mathrm{Zr}_{0.5} \mathrm{O}_{2}$ & 113 \\
$\mathrm{Ce}_{0.2} \mathrm{Zr}_{0.8} \mathrm{O}_{2}$ & 98 \\
\hline
\end{tabular}

${ }^{\text {a }}$ Reaction conditions: temperature range of $543-573 \mathrm{~K}$, total pressure $1 \mathrm{~atm}, 2$ vol.\% CO and 2 vol. $\% \mathrm{O}_{2}$ in $\mathrm{He}$.

Oxidation of $\mathrm{CO}$ over $\mathrm{CeO}_{2}$ and $\mathrm{Ce}-\mathrm{Zr}$ mixed oxides was performed at different reaction temperatures to determine an apparent activation energy. As presented in Table 2.10, the apparent activation energy for $\mathrm{CO}$ oxidation over $\mathrm{CeO}_{2}$ is $114 \mathrm{~kJ} \mathrm{~mol}^{-1}$, which is similar to values reported for $\mathrm{CO}$ oxidation over $\mathrm{CeO}_{2}$ under similar conditions. ${ }^{47,48}$ Cerium zirconium mixed oxides exhibited similar apparent activation energies to $\mathrm{CeO}_{2}$, suggesting that the reaction mechanism is not altered after the addition of zirconium, which is consistent with the observed orders of reaction. 


\subsection{Discussion}

In this study, a methodology to evaluate the performance of catalyst for coke oxidation was developed to obtain reproducible reaction kinetics. Samples with different catalyst/coke mass ratios need to be prepared at the same tight contact conditions, followed by the isothermal oxidation reaction to obtain a first order rate constant. Finally, the amount of active catalyst in the mixture and therefore a normalized coke oxidation rate can be calculated. Although the weight loss of coke during catalyzed coke oxidation in this study showed a simple first order decay, this may not be observed with other types of carbon samples. ${ }^{49}$ Therefore, if a first order rate constant cannot be evaluated, the reaction rate at a specified level of conversion could also be related to the amount of catalyst in the reaction. A constant reaction rate per catalyst mass (area) can be determined regardless of the oxidation kinetics. The importance of proper normalization is revealed in Table 5. For example, the average rate constant at high catalyst loading for $\mathrm{CeO}_{2}$ and $\mathrm{Ce}_{0.8} \mathrm{Zr}_{0.2} \mathrm{O}_{2}$ was $0.011 \mathrm{~min}^{-1}$, which might suggest the catalysts exhibit identical catalytic activity. However, once proper normalization of the rates is performed, the rate with $\mathrm{Ce}_{0.8} \mathrm{Zr}_{0.2} \mathrm{O}_{2}\left(17 \times 10^{-4} \mathrm{~g}_{\text {carbon }} \mathrm{m}^{-2}\right.$ cat $\left.\mathrm{min}^{-1}\right)$ was more than twice that with $\mathrm{CeO}_{2}\left(7.9 \times 10^{-4}\right.$ $\mathrm{g}_{\text {carbon }} \mathrm{m}^{-2}$ cat $\left.\mathrm{min}^{-1}\right)$. To validate this conclusion, we can examine the rate of $\mathrm{CO}$ oxidation over the exact same catalysts, as summarized in Table 9. Again the $\mathrm{CO}$ oxidation rate over $\mathrm{Ce}_{0.8} \mathrm{Zr}_{0.2} \mathrm{O}_{2}\left(68 \times 10^{-7} \mathrm{~mol}_{\text {co }} \mathrm{m}_{\text {cat }}^{-2} \mathrm{~min}^{-1}\right)$ was more than twice that over $\mathrm{CeO}_{2}\left(29 \times 10^{-7} \mathrm{~mol}_{\text {co }} \mathrm{m}^{-}\right.$ ${ }^{2}$ cat $\left.\min ^{-1}\right)$. In fact, the results in Figure 17 reveal that coke oxidation rates are completely correlated to the $\mathrm{CO}$ oxidation rates over the entire series of catalysts. 


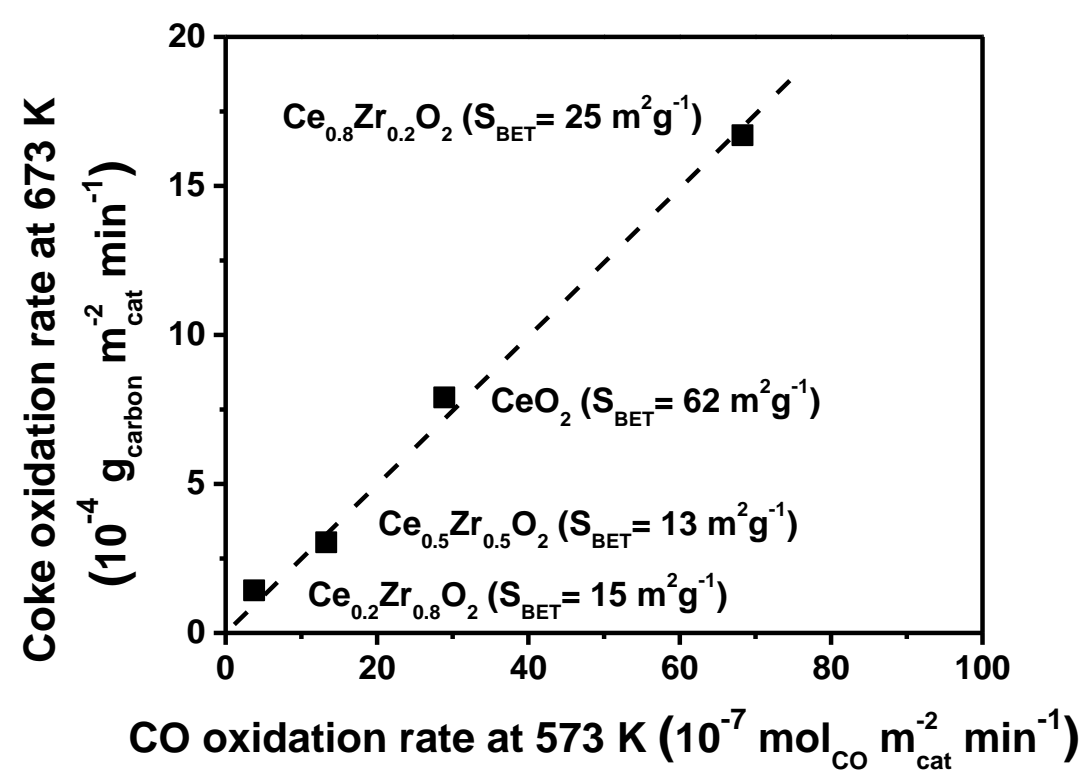

Figure 2.17 Correlation of coke oxidation rates at $673 \mathrm{~K}$ and $\mathrm{CO}$ oxidation rates at $573 \mathrm{~K}$ over Ce-based materials.

We searched for a correlation between coke oxidation (or CO oxidation) rate and either oxygen storage capacity or reducibility of the catalyst, but found none. The highest coke oxidation rate was observed with $\mathrm{Ce}_{0.8} \mathrm{Zr}_{0.2} \mathrm{O}_{2}$ whereas the highest OSC and the lowest reduction temperatures were observed with $\mathrm{Ce}_{0.5} \mathrm{Zr}_{0.5} \mathrm{O}_{2}$.

The correlation between coke oxidation and $\mathrm{CO}$ oxidation over the catalyst is likely the result of proper normalization of the rates and similar mechanisms of reaction. Indeed, the first order dependence on reactant (coke or $\mathrm{CO}$ ), the low order dependence on $\mathrm{O}_{2}$, and the similar apparent activation energy are consistent with similar mechanism.

It is generally accepted that the mechanism of $\mathrm{CO}$ oxidation over ceria-based oxides involves a redox Mars-van Krevelen path, $, 36,37,40$ as illustrated in Figure 2.18. During the reaction, surface lattice oxygen reacts with the adsorbed $\mathrm{CO}$ to form $\mathrm{CO}_{2}$, followed by the 
desorption of $\mathrm{CO}_{2}$ and the reoxidation of the surface by gas-phase $\mathrm{O}_{2}$. If a simple rate expression (Equation 1) associated with the Mars-van Krevelen mechanism is considered, ${ }^{52}$ it can be further simplified to the expression in equation 2 when the surface reoxidation step is much faster than the surface reduction step. In this way, first order behavior in $\mathrm{CO}$ and zero order behavior in $\mathrm{O}_{2}$ can be easily explained and are consistent with our experimental results.

$$
\begin{gathered}
\frac{1}{r}=\frac{1}{k_{1} P_{C O}^{n}}+\frac{2}{k_{2} P_{O_{2}}^{m}} \\
r=k_{1} P_{C O}
\end{gathered}
$$

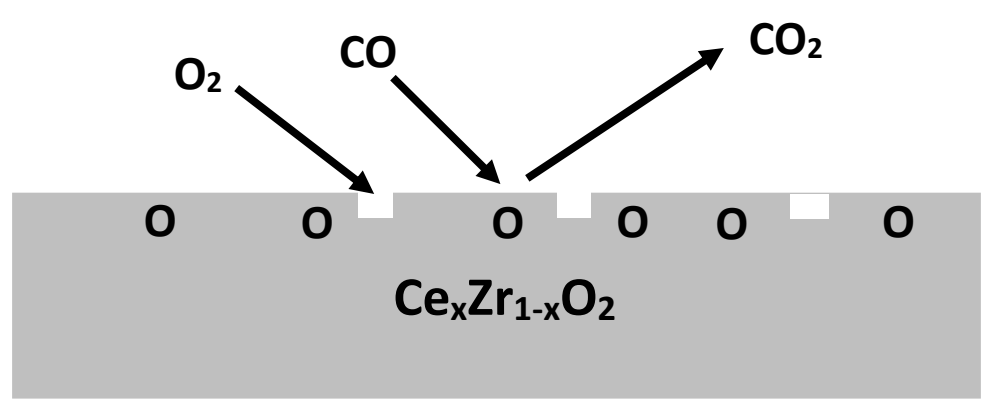

Figure 2.18 Scheme of the CO oxidation mechanism over Ce-based catalysts.

For coke oxidation in the presence of ceria-based oxides, two reaction mechanisms have been proposed previously, a redox Mars-van Krevelen path and a spill-over of active oxygen path, ${ }^{53}$ as illustrated in Figure 2.19. The redox path involves the reaction of surface lattice oxygen with solid coke at their interface, followed by the reoxidation of the catalyst surface. This path has been demonstrated by studies with environmental transmission electron microscopy ${ }^{54}$ and ${ }^{18} \mathrm{O}$ isotopic labelling experiments. ${ }^{53,55}$ The second reaction path involves the formation of active oxygen species, such as superoxide and peroxide ions, followed by the spill-over of these species to the coke surface and their subsequent reaction with coke. ${ }^{12,53}$ Such active oxygen 
species have been detected in ESR measurements ${ }^{53}$ and FT-IR experiments, ${ }^{56}$ however, these experiments were not performed at reaction conditions and the distance of active oxygen spillover is unknown but is believed to be only several nanometers. ${ }^{54}$ Therefore, in both paths, the active catalytic sites are at or very close to the interface between the catalyst and the coke. In our study, the ratio of maximum active catalyst surface area to the initial surface area of coke was close to unity for all of the four catalysts (Table 2.5), and combined with the fact that both the catalyst and the coke were nonporous, suggest coke oxidation mainly occurs at or near the interface of the catalyst and the coke. We therefore imaged a catalyst/coke mixture by SEM after partial conversion of coke (Figure 2.20). Most of the pits on the coke surface from oxidation are in the vicinity of catalyst particles.

Path 1

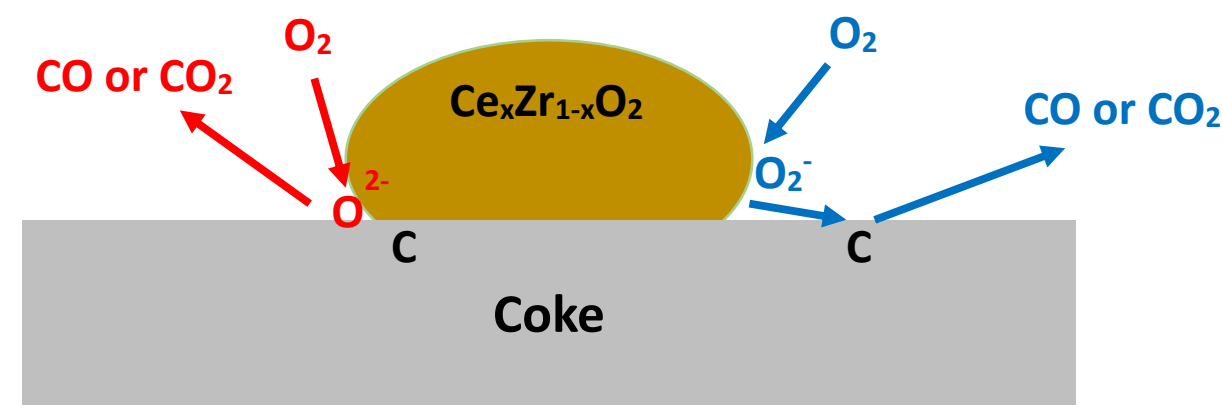

Figure 2.19 Scheme of the mechanism of coke oxidation over Ce-based materials: 1 . redox path, 2. spill-over of active oxygen path. Colors associated with various components can be found in the on-line version of the article. 


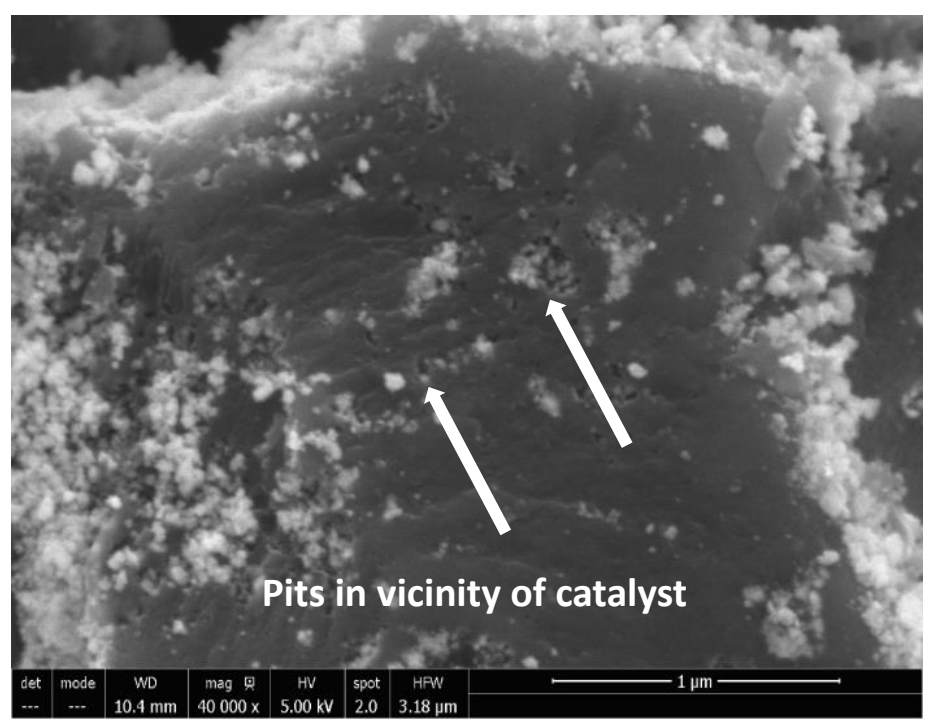

Figure 2.20 SEM image of coke- $\mathrm{Ce}_{0.8} \mathrm{Zr}_{0.2} \mathrm{O}_{2}$ mixture at $50 \%$ coke conversion.

The correlation between coke and $\mathrm{CO}$ oxidation rates over the Ce-based materials confirms that the methodology to quantify coke oxidation rates is reasonable. Both of the reactions involve the participation of surface lattice oxygen of the catalyst without significant involvement of oxygen from the bulk of the catalyst. Therefore, it is reasonable that the oxidation rates are not correlated with bulk OSC or reducibility of the oxides. During the OSC and $\mathrm{H}_{2}$-TPR experiments, a large amount of bulk oxygen is involved, as evidenced by the large number of layers reduced for the Zr-rich mixed oxides (Table 2.3). The correlation between coke and $\mathrm{CO}$ oxidation rates also suggests that $\mathrm{CO}$ oxidation might be used as a rapid probe to screen new catalysts for coke oxidation.

The best catalyst composition of the $\mathrm{Ce}-\mathrm{Zr}$ mixed oxides for coke oxidation was $\mathrm{Ce}_{0.8} \mathrm{Zr}_{0.2} \mathrm{O}_{2}$. Coke oxidation with other similar mixed oxides was also studied by Aneggi et al. ${ }^{57}$ The values in Table 2.11 are reaction rates derived from the results of Aneggi et al. The reaction rates are an order of magnitude higher than those in our study, which may be caused by a higher reaction temperature $(723 \mathrm{~K})$ and a different type of coke (Printex-U) used in their study. Aneggi 
et al. report that $\mathrm{Ce}_{0.44} \mathrm{Zr}_{0.56} \mathrm{O}_{2}$ was the most active catalyst composition, which is slightly different from the result in the current study. As pointed out earlier, the area of catalyst cannot exceed the area of coke in the mixture, or rates cannot be properly normalized. The high ratio of catalyst area to coke area for $\mathrm{CeO}_{2}$ and $\mathrm{Ce}_{0.75} \mathrm{Zr}_{0.25} \mathrm{O}_{2}$ (Table 2.11) indicates there might be a significant over supply of catalyst in those cases, which will affect the ranking of catalyst activities.

Table 2.11 Coke oxidation rates and its reaction conditions for cerium zirconium mixed oxides in literature. ${ }^{57}$

\begin{tabular}{|c|c|c|c|c|}
\hline & $\mathrm{CeO}_{2}$ & $\mathrm{Ce}_{0.75} \mathrm{Zr}_{0.25} \mathrm{O}_{2}$ & $\mathrm{Ce}_{0.44} \mathrm{Zr}_{0.56} \mathrm{O}_{2}$ & $\mathrm{Ce}_{0.28} \mathrm{Zr}_{0.72} \mathrm{O}_{2}$ \\
\hline $\begin{array}{l}\text { Catalyst surface area } \\
\left(\mathrm{m}^{2} \mathrm{~g}^{-1}\right)\end{array}$ & 54 & 27 & 11 & 10 \\
\hline $\begin{array}{l}\text { Initial ratio of total surface area } \\
\text { of catalyst over coke } \\
\left(\mathrm{m}^{2} \text { cat } \mathrm{m}^{-2} \text { carbon }\right)\end{array}$ & 11 & 5.5 & 2.2 & 2.0 \\
\hline $\begin{array}{l}\text { Coke oxidation rate } \\
\left(10^{-4} \mathrm{~g}_{\text {carbon }} \mathrm{m}_{\text {cat }}^{-2} \min ^{-1}\right)\end{array}$ & 29 & 44 & 49 & 36 \\
\hline
\end{tabular}

\subsection{Conclusions}

Coke oxidation over ceria-based oxides was studied under isothermal tight contact conditions to obtain normalized reaction rates on a catalyst surface area basis. A methodology involving the evaluation of maximum active catalyst surface area has been developed. The weight loss of coke in catalyzed coke oxidation was first order in coke, which enabled the straightforward calculation of a first order rate constant. When reaction rates were determined in a regime that was strictly proportional to catalyst loading, then $\mathrm{Ce}_{0.8} \mathrm{Zr}_{0.2} \mathrm{O}_{2}$ was found to be the most active oxidation catalyst. Coke oxidation rates were very well correlated with $\mathrm{CO}$ oxidation rates, but not with oxygen storage capacity or reducibility of the catalyst, indicating that $\mathrm{CO}$ oxidation might be a useful probe for the discovery of new coke oxidation catalysts. Detailed 
kinetic studies of coke and $\mathrm{CO}$ oxidation revealed similar reaction orders and apparent activation energy, and suggested the participation of surface lattice oxygen of the catalyst in the two reactions. For coke oxidation, the ratio of catalyst area to coke area in the mixture should be close to unity to maximize rate and catalyst utilization.

\section{References for Chapter 2}

(1) Cumming, K.A., Wojciechowski, B. W. Chain Mechanism of Catalytic Cracking Hydrogen Transfer, Coke Formation, and Catalyst Decay and Their Role in the Chain Mechanism of Catalytic Cracking. Catal. Rev. Sci. Eng. 1996, 38 (1), 101-157.

(2) Forzatti, P.; Lietti, L. Catalyst Deactivation. Catal. Today 1999, 52, 165-181.

(3) Cai, H.; Krzywicki, A.; Oballa, M. C. Coke Formation in Steam Crackers for Ethylene Production. Chem. Eng. Process. 2002, 41 (3), 199-214.

(4) Abghari, S. Z. Investigation of Coke Formation in Steam Cracking of Atmospheric Gasoil. Pet. Sci. Technol. 2013, 2 (2), 82-91.

(5) Stanmore, B. R.; Brilhac, J. F.; Gilot, P. The Oxidation of Soot: A Review of Experiments, Mechanisms and Models. Carbon N. Y. 2001, 39, 2247-2268.

(6) Prasad, R.; Bella, V. R. A Review on Diesel Soot Emission, Its Effect and Control. Bull. Chem. React. Eng. Catal. 2010, 5 (2), 69-86.

(7) Sawarkar, A. N.; Pandit, A. B.; Samant, S. D.; Joshi, J. B. Petroleum Residue Upgrading via Delayed Coking: A Review. Can. J. Chem. Eng. 2007, 85, 1-24.

(8) Neeft, J. P. A.; Makkee, M.; Moulijn, J. A. Diesel Particulate Emission Control. Fuel 
Process. Technol. 1996, 47, 1-69.

(9) Bueno-López, A. Diesel Soot Combustion Ceria Catalysts. Appl. Catal. B Environ. 2014, $146,1-11$.

(10) Kašpar, J.; Fornasiero, P.; Graziani, M. Use of $\mathrm{CeO}_{2}$-Based Oxides in the Three-Way Catalysis. Catal. Today 1999, 50, 285-298.

(11) Krishna, K.; Bueno-López, A.; Makkee, M.; Moulijn, J. A. Potential Rare Earth Modified $\mathrm{CeO}_{2}$ Catalysts for Soot Oxidation I. Characterization and Catalytic Activity with $\mathrm{O}_{2}$. Appl. Catal. B Environ. 2007, 75, 189-200.

(12) Bueno-López, A.; Krishna, K.; van der Linden, B.; Mul, G.; Moulijn, J. A.; Makkee, M. On the Mechanism of Model Diesel Soot- $\mathrm{O}_{2}$ Reaction Catalysed by Pt-Containing $\mathrm{La}^{3+}-$ Doped $\mathrm{CeO}_{2}$ : A TAP Study with Isotopic $\mathrm{O}_{2}$. Catal. Today 2007, 121 (3-4), 237-245.

(13) Bueno-López, A.; Krishna, K.; Makkee, M.; Moulijn, J. A. Enhanced Soot Oxidation by Lattice Oxygen via $\mathrm{La}^{3+}$-Doped $\mathrm{CeO}_{2}$. J. Catal. 2005, 230 (1), 237-248.

(14) Aneggi, E.; de Leitenburg, C.; Trovarelli, A. On the Role of Lattice/surface Oxygen in Ceria-zirconia Catalysts for Diesel Soot Combustion. Catal. Today 2012, 181 (1), 108115.

(15) Reddy, B. M.; Bharali, P.; Thrimurthulu, G.; Saikia, P.; Katta, L.; Park, S.-E. Catalytic Efficiency of Ceria-zirconia and Ceria-hafnia Nanocomposite Oxides for Soot Oxidation. Catal. Letters 2008, 123 (3-4), 327-333.

(16) Atribak, I.; Bueno-López, A.; García-García, A. Thermally Stable Ceria-Zirconia Catalysts for Soot Oxidation by $\mathrm{O}_{2}$. Catal. Commun. 2008, 9, 250-255. 
(17) Liu, J.; Zhao, Z.; Liang, P.; Xu, C.; Duan, A.; Jiang, G.; Lin, W.; Wachs, I. E. Study on the Reaction Mechanism for Soot Oxidation over $\mathrm{TiO}_{2}$ or $\mathrm{ZrO}_{2}$-Supported Vanadium Oxide Catalysts by Means of in-Situ UV-Raman. Catal. Letters 2007, 120 (1-2), 148-153.

(18) Aneggi, E.; Wiater, D.; de Leitenburg, C.; Llorca, J.; Trovarelli, A. Shape-Dependent Activity of Ceria in Soot Combustion. ACS Catal. 2014, 4 (1), 172-181.

(19) Jelles, S. J.; van Setten, B. A. A. L.; Makkee, M.; Moulijn, J. A. Molten Salts as Promising Catalysts for Oxidation of Diesel Soot: Importance of Experimental Conditions in Testing Procedures. Appl. Catal. B Environ. 1999, 21 (1), 35-49.

(20) Neeft, J. P. A. Catalytic Oxidation of Soot-Potential for Reduction of Diesel Particulate Emissions, 1995.

(21) Peralta, M. A.; Gross, M. S.; Sánchez, B. S.; Querini, C. A. Catalytic Combustion of Diesel Soot: Experimental Design for Laboratory Testing. Chem. Eng. J. 2009, 152, 234241.

(22) Liu, S.; Wu, X.; Weng, D.; Ran, R. Ceria-Based Catalysts for Soot Oxidation: A Review. J. Rare Earths 2015, 33 (6), 567-590.

(23) Sharma, A.; Kyotani, T.; Tomita, A. Comparison of Structural Parameters of PF Carbon from XRD and HRTEM Techniques. Carbon N. Y. 2000, 38 (14), 1977-1984.

(24) Burroughs, B. P.; Hamnett, A.; Orchard, A. F.; Thornton, G. Satellite Structure in the XRay Photoelectron Spectra of Some Binary and Mixed Oxides of Lanthanum and Cerium. J. C. S. Dalt. 1976, 17, 1686-1698.

(25) Terribile, D.; Trovarelli, A.; Llorca, J.; Leitenburg, C. De; Dolcetti, G. The Preparation of 
High Surface Area $\mathrm{CeO}_{2} \pm \mathrm{ZrO}_{2}$ Mixed Oxides by a Surfactant-Assisted Approach. Catal. Today $\mathbf{1 9 9 8 , ~ 4 3 , ~ 7 9 - 8 8 . ~}$

(26) Atribak, I.; Bueno-López, A.; García-García, A. Thermally Stable Ceria-zirconia Catalysts for Soot Oxidation by $\mathrm{O}_{2}$. Catal. Commun. 2008, 9 (2), 250-255.

(27) Wang, S.; Yin, K.; Zhang, Y.; Liu, H. Glycerol Hydrogenolysis to Propylene Glycol and Ethylene Glycol on Zirconia Supported Noble Metal Catalysts. ACS Catal. 2013, 3 (9), 2112-2121.

(28) Trovarelli, A.; Zamar, F.; Llorca, J.; Leitenburg, C. de; Dolcetti, G.; Kiss, J. T. Nanophase Fluorite-Structured $\mathrm{CeO}_{2}-\mathrm{ZrO}_{2}$ Catalysts Prepared by High-Energy Mechanical Milling. $J$. Catal. 1997, 169 (2), 490-502.

(29) Keramidas, V. G.; White, W. B. Raman Scattering Study of the Crystallization and Phase Transformations of $\mathrm{ZrO}_{2}$. J. Am. Ceram. Soc. 1974, 57 (1), 22-24.

(30) Oliveira, C. F.; Garcia, F. A. C.; Araújo, D. R.; Macedo, J. L.; Dias, S. C. L.; Dias, J. A. Effects of Preparation and Structure of Cerium-Zirconium Mixed Oxides on Diesel Soot Catalytic Combustion. Appl. Catal. A Gen. 2012, 413-414, 292-300.

(31) Kim, D.-J.; Jung, H.-J.; Yang, I.-S. Raman Spectroscopy of Tetragonal Zirconia Solid Solutions. J. Am. Ceram. Soc. 1993, 76, 2106-2108.

(32) Galtayries, A.; Sporken, R.; Riga, J.; Blanchard, G.; Caudano, R. XPS Comparative Study of Ceria/zirconia Mixed Oxides: Powders and Thin Film Characterisation. J. Electron Spectros. Relat. Phenomena 1998, 88-91, 951-956.

(33) Park, P. W.; Ledford, J. S. Effect of Crystallinity on the Photoreduction of Cerium Oxide: 
A Study of $\mathrm{CeO}_{2}$ and $\mathrm{Ce} / \mathrm{Al}_{2} \mathrm{O}_{3}$ Catalysts. Langmuir 1996, 12 (7), 1794-1799.

(34) Hughes, A. E.; Gorman, J. D.; Patterson, P. J. K.; Carter, R. Unusual Peak Shifts in the Core Levels of $\mathrm{CeO}_{2}$ Films Deposited on Si(100). Surf. Interface Anal. 1996, 24 (9), 634640.

(35) Fally, F.; Perrichon, V.; Vidal, H.; Kaspar, J.; Blanco, G.; Pintado, J. M.; Bernal, S.; Colon, G.; Daturi, M.; Lavalley, J. C. Modification of the Oxygen Storage Capacity of $\mathrm{CeO}_{2}-\mathrm{ZrO}_{2}$ Mixed Oxides after Redox Cycling Aging. Catal. Today 2000, 59 (3), 373386.

(36) Madier, Y.; Descorme, C.; Le Govic, A. M.; Duprez, D. Oxygen Mobility in $\mathrm{CeO}_{2}$ and $\mathrm{Ce}_{\mathrm{x}} \mathrm{Zr}_{(1-\mathrm{x})} \mathrm{O}_{2}$ Compounds: Study by $\mathrm{CO}$ Transient Oxidation and ${ }^{18} \mathrm{O} /{ }^{16} \mathrm{O}$ Isotopic Exchange. J. Phys. Chem. B 1999, 103 (50), 10999-11006.

(37) Balducci, G.; Islam, M. S.; Kaspar, J.; Fornasiero, P.; Graziani, M. Bulk Reduction Oxygen Migration in the Ceria-Based Oxides. Chem. Mater. 2000, 12 (3), 677-681.

(38) Castro Neto, A. H.; Guinea, F.; Peres, N. M. R.; Novoselov, K. S.; Geim, A. K. The Electronic Properties of Graphene. Rev. Mod. Phys. 2009, 81 (March), 109-162.

(39) Sadezky, A.; Muckenhuber, H.; Grothe, H.; Niessner, R.; Pöschl, U. Raman Microspectroscopy of Soot and Related Carbonaceous Materials: Spectral Analysis and Structural Information. Carbon 2005, 43 (8), 1731-1742.

(40) Mahamulkar, S.; Yin, K.; Davis, R. J.; Shibata, H.; Malek, A.; Jones, C. W.; Agrawal, P. K. In Situ Generation of Radical Coke and the Role of Coke-Catalyst Contact on Coke Oxidation. Ind. Eng. Chem. Res. 2016, 55 (18), 5271-5278. 
(41) Darcy, P.; Da Costa, P.; Mellottée, H.; Trichard, J.-M.; Djéga-Mariadassou, G. Kinetics of Catalyzed and Non-Catalyzed Oxidation of Soot from a Diesel Engine. Catal. Today 2007, $119(1-4), 252-256$.

(42) Neeft, J. P. A.; Nijhuis, T. X.; Smakman, E.; Makkee, M.; Moulijn, J. A. Kinetics of the Oxidation of Diesel Soot. Fuel 1997, 76, 1129-1136.

(43) Issa, M.; Mahzoul, H.; Brillard, A.; Brilhac, J.-F. Catalytic Carbon Oxidation in the Presence of Cerium Oxide: Experimental Study and Modeling of the Effect of Oxygen Concentration. Chem. Eng. Technol. 2009, 32 (12), 1859-1865.

(44) Fino, D.; Fino, P.; Saracco, G.; Specchia, V. Studies on Kinetics and Reactions Mechanism of $\mathrm{La}_{2-\mathrm{x}} \mathrm{K}_{\mathrm{x}} \mathrm{Cu}_{1-\mathrm{y}} \mathrm{V}_{\mathrm{y}} \mathrm{O}_{4}$ Layered Perovskites for the Combined Removal of Diesel Particulate and $\mathrm{NO}_{x}$. Appl. Catal. B Environ. 2003, 43 (3), 243-259.

(45) Wilkes, M. F.; Hayden, P.; Bhattacharya, A. K. Catalytic Studies on Ceria Lanthana Solid Solutions II. Oxidation of Carbon Monoxide. J. Catal. 2003, 219, 295-304.

(46) Breysse, M.; Guenin, M.; Claudel, B.; Veron, J. Catalysis of Carbon Monoxide Oxidation by Cerium Dioxide I. Correlations between Catalytic Activity and Electrical Conductivity. J. Catal. 1972, 27, 275-280.

(47) Sun, Y.; Liu, Q.; Gao, S.; Cheng, H.; Lei, F.; Sun, Z.; Jiang, Y.; Su, H.; Wei, S.; Xie, Y. Pits Confined in Ultrathin cerium(IV) Oxide for Studying Catalytic Centers in Carbon Monoxide Oxidation. Nat. Commun. 2013, 4, 2899.

(48) Liu, S.; Wu, X.; Liu, W.; Chen, W.; Ran, R.; Li, M.; Weng, D. Soot Oxidation over $\mathrm{CeO}_{2}$ and $\mathrm{Ag} / \mathrm{CeO}_{2}$ : Factors Determining the Catalyst Activity and Stability during Reaction. J. Catal. 2016, 337, 188-198. 
(49) Aneggi, E.; Boaro, M.; De Leitenburg, C.; Dolcetti, G.; Trovarelli, A. Insights into the Redox Properties of Ceria-Based Oxides and Their Implications in Catalysis. J. Alloys Compd. 2006, 408-412, 1096-1102.

(50) Aneggi, E.; Llotca, J.; Boaro, M.; Ttovarelli, A. Surface-Structure Sensitivity of CO Oxidation over Polycrystalline Ceria Powders. J. Catal. 2005, 234 (1), 88-95.

(51) Mars, P.; van Krevelen, D. W. Oxidations Carried out by Means of Vanadium Oxide Catalysts. Chem. Eng. Sci. 1954, 3, 41-59.

(52) Machida, M.; Murata, Y.; Kishikawa, K.; Zhang, D.; Ikeue, K. On the Reasons for High Activity of $\mathrm{Ce}_{\mathrm{O} 2}$ Catalyst for Soot Oxidation. Chem. Mater. 2008, No. 20, 4489-4494.

(53) Simonsen, S. B.; Dahl, S.; Johnson, E.; Helveg, S. Ceria-Catalyzed Soot Oxidation Studied by Environmental Transmission Electron Microscopy. J. Catal. 2008, 255 (1), 15.

(54) Krishna, K.; Makkee, M.; Moulijn, J. A. Enhanced Soot Oxidation by Lattice Oxygen via $\mathrm{La}^{3+}$-Doped $\mathrm{CeO}_{2}$. J. Catal. 2005, 230, 237-248.

(55) Descorme, C.; Madier, Y.; Duprez, D. Infrared Study of Oxygen Adsorption and Activation on Cerium-zirconium Mixed Oxides. J. Catal. 2000, 196, 167-173.

(56) Aneggi, E.; de Leitenburg, C.; Llorca, J.; Trovarelli, A. Higher Activity of Diesel Soot Oxidation over Polycrystalline Ceria and Ceria-zirconia Solid Solutions from More Reactive Surface Planes. Catal. Today 2012, 197 (1), 119-126. 


\title{
Chapter 3. Catalytic Gasification of Coke with Dioxygen and Steam over Alkaline-earth-metal-doped Cerium-Zirconium Mixed Oxides
}

\author{
Abstract: \\ A series of cerium zirconium mixed oxides doped with alkaline earth metals was \\ prepared by calcining a mixture of $\mathrm{Ce}_{0.8} \mathrm{Zr}_{0.2} \mathrm{O}_{2}$ and the nitrate salt of alkaline earth metals at \\ $1173 \mathrm{~K}$. The results of X-ray diffraction, Raman spectroscopy and analytical electron \\ microscopy indicated the alkaline earth compounds were dispersed on the surface of $\mathrm{Ce}_{0.8} \mathrm{Zr}_{0.2} \mathrm{O}_{2}$. \\ The doped mixed oxides were evaluated in the catalytic gasification of solid coke under tight \\ contact conditions with 10 vol\% $\mathrm{O}_{2}$ in $\mathrm{He}$ at $693 \mathrm{~K}$ and with 100 vol.\% $\mathrm{H}_{2} \mathrm{O}$ at $993 \mathrm{~K}$ using \\ thermogravimetric analysis. For coke gasification with $\mathrm{O}_{2}$, the weight loss was first order in coke \\ and the measured first order rate constant was proportional to the total surface area of catalyst at \\ low catalyst loadings. For coke gasification with $\mathrm{H}_{2} \mathrm{O}$, the weight loss was nearly zero order in \\ coke and the measured reaction rate was independent of the total surface area of catalyst at low \\ catalyst loadings. The addition of alkaline earth metals inhibited coke gasification with dioxygen \\ but promoted coke gasification with steam.
}




\subsection{Introduction}

Ethylene is one of the most important building blocks for the chemical industry. Steam cracking has been widely used for the industrial production of olefins, which involves heating hydrocarbons to high temperatures $(1023 \mathrm{~K}-1123 \mathrm{~K})$ in the presence of diluting steam. ${ }^{1-3}$ The reactions of hydrocarbons in the steam crackers are free radical in nature because of the high temperature and the primary desired reaction for steam cracking of ethane involves its dehydrogenation to ethylene:

$$
\mathrm{H}_{3} \mathrm{C}-\mathrm{CH}_{3} \rightarrow \mathrm{H}_{2} \mathrm{C}=\mathrm{CH}_{2}+\mathrm{H}_{2}
$$

The product stream which contains a complex mixture of hydrocarbons is immediately cooled in a transfer line heat exchanger (TLE) to avoid the undesired side reactions and is separated by distillation and absorption processes to obtain the valuable olefinic products. ${ }^{4}$ One of the major by-products of the steam cracking process is the formation of carbonaceous deposits (coke) on the walls of the reactor. There are three coke formation mechanisms during steam cracking: catalytic coke formation, radical coke formation, and droplet condensation. ${ }^{2,5}$ Coke formation in steam crackers can cause a number of problems such as increase of pressure drop in the reactor, decrease of heat transfer at the reactor walls, increase of tube metal temperature and carburization of tube materials, ${ }^{2,6,7}$ which eventually leads to the shutdown of the furnace for coke removal every 1-3 months depending on the type of feed and reactor tubes. ${ }^{7}$ Coke formed in the reactor is combusted by passing a mixture of steam and air at high temperatures through the reactor. After multiple coking-decoking cycles, the cracker tubes also need to be replaced. These undesirable shutdowns motivate efforts directed towards increasing the continuous run of steam crackers. 
Researchers have studied different methods to reduce the coke formation in steam crackers, with a focus on the development of coatings on the internal walls of the cracker tubes. One type of coating contains materials that are inert to coke formation at steam cracking conditions, such as aluminum, ${ }^{8}{ }^{89} \mathrm{TiC}$ and $\mathrm{SiC}^{3}$ This type of coating act as a barrier between the gas phase and the active metallic sites on the reactor wall, thus preventing catalytic coke formation. Another type of coating contains materials that not only inhibit metal-catalyzed coke formation, but additionally catalyze coke gasification. A novel furnace coil coating technology called catalyzed assisted manufacture of olefins (CAMOL) was developed by BASF. ${ }^{10,11}$ The CAMOL coating is inert to filamentous coke formation and facilitates gasification of amorphous coke.

Ceria-based materials have received a lot of interest because of their demonstrated catalytic activity in several reactions, such as $\mathrm{CO}$ oxidation and soot oxidation, which can be attributed to the redox property of cerium. ${ }^{12-15}$ Ceria-based materials have been widely used in the Three Way Catalysts (TWC) for the emission control of gasoline cars since the mid-1980s. ${ }^{16-}$ ${ }^{18}$ In addition, the presence of cerium in the catalysts inhibit coke formation during the steam reforming of hydrocarbons. ${ }^{19-22}$ Zhuang et al. investigated the effect of cerium oxide in $\mathrm{MgAlO}_{3}$ supported Ni catalyst for methane steam reforming. ${ }^{19}$ Cerium oxide not only decreased the rate of coke deposition, but also increased the catalytic activity of steam reforming. Natesakhawat et al. reported the beneficial effects of cerium promoter in a $\mathrm{Ni} / \mathrm{Al}_{2} \mathrm{O}_{3}$ catalyst for propane steam reforming by both inhibiting coke formation and improving catalytic activity. ${ }^{20}$ Wang et al. compared the steam reforming rates of methane, ethane, n-butane, n-hexane on a $\mathrm{Pd} / \mathrm{ceria}$ catalyst and a Pd/alumina catalyst. ${ }^{22}$ The $\mathrm{Pd} /$ ceria catalyst had much higher reaction rates than the Pd/alumina catalyst, as well as higher resistance to coke formation. Therefore, ceria-based 
oxides are promising coating materials for steam crackers. Since cerium oxide itself is not stable at high temperature and sinters severely at typical steam cracking conditions, the addition of zirconium is required to increase its thermal stability and improve its redox property. ${ }^{23-29}$ To further increase the activity of ceria-based materials for coke gasification, the doping of alkali and alkaline earth metals to cerium zirconium mixed oxides is desired since they have been shown previously to have high activity for steam gasification of carbon. ${ }^{30}$ However, alkali metals suffer from a relatively high volatility at elevated temperatures in steam wheras the volatility of alkaline earth metals is relatively low at the same conditions. ${ }^{31}$ In this study, alkaline earth metals were added to $\mathrm{Ce}_{0.8} \mathrm{Zr}_{0.2} \mathrm{O}_{2}$ since $\mathrm{Ce}_{0.8} \mathrm{Zr}_{0.2} \mathrm{O}_{2}$ is the most active in coke oxidation of the Ce-Zr mixed oxides..$^{23,32,33}$ As the decoking step during the shutdown of a steam cracker involves both steam and dioxygen, the catalysts in this study were tested in coke gasification with both steam and dioxygen.

\subsection{Experimental methods}

\subsubsection{Catalyst preparation}

Cerium-zirconium mixed oxide $\left(\mathrm{Ce}_{0.8} \mathrm{Zr}_{0.2} \mathrm{O}_{2}\right.$, which is referred as $\left.\mathrm{CZ82}\right)$ was prepared using a controlled precipitation method. First, an aqueous solution of $\mathrm{Ce}\left(\mathrm{NO}_{3}\right)_{3} \cdot 6 \mathrm{H}_{2} \mathrm{O}(99.99 \%$, Sigma Aldrich) and $\mathrm{ZrONO}_{3}(99.99 \%$, Sigma Aldrich) was prepared with a total metal ion concentration of $0.2 \mathrm{M}$. The metal precursor solution was added dropwise to $100 \mathrm{~cm}^{3}$ of distilled deionized water (DDI) at $298 \mathrm{~K}$ while a solution of $15 \mathrm{wt} \%$ aqueous ammonia was added continuously during precipitation to maintain a $\mathrm{pH}$ of 10 . The resulting suspension was stirred for $20 \mathrm{~h}$ at $298 \mathrm{~K}$. The precipitate was recovered by vacuum filtration, washed 3 times with DDI water, dried in air at $400 \mathrm{~K}$ overnight. The samples were then heated to $1173 \mathrm{~K}$ in air at a rate of 
$5 \mathrm{~K} \mathrm{~min}^{-1}$ and held at $1173 \mathrm{~K}$ for $6 \mathrm{~h}$. The obtained CZ82 was mixed with the nitrate salt of alkaline earth metals and ground for $10 \mathrm{~min}$, followed by calcination of the mixture in air at 1173 $\mathrm{K}$ for $2 \mathrm{~h}$. The resulting materials are designated as $\mathrm{xM} / \mathrm{CZ82}$, where $\mathrm{M}$ represents the alkaline earth metals and $\mathrm{x}$ represents the atomic ratio of $\mathrm{M} / \mathrm{Ce}$.

\subsubsection{Characterization of catalyst}

Powder X-ray diffraction (XRD) patterns of the catalysts and coke were obtained on a PANalytical X'Pert Pro MPD Diffractometer with $\mathrm{Cu} \mathrm{K} \alpha$ radiation. Each sample was scanned at a rate of $0.2^{\circ} \mathrm{s}^{-1}$, over a range of $2 \theta$ from $10^{\circ}$ to $90^{\circ}$.

Specific surface area of the catalysts and coke was obtained by $\mathrm{N}_{2}$ adsorption measured at $77 \mathrm{~K}$ using the BET method on a Micromeritics ASAP 2020 automated analyzer.

Raman spectra of the oxide catalysts and coke were recorded with a Renishaw InVia Raman Microscope with an Ar laser (514 nm) and a $3000 \mathrm{~g} \mathrm{~mm}^{-1}$ grating. The Raman scope was calibrated using a silicon wafer.

Scanning transmission electron microscopy (STEM) was performed with a JEOL $2010 \mathrm{~F}$ instrument operating at $200 \mathrm{kV}$ that was equipped with an Oxford Aztec energy dispersive spectrometer (EDS) system. To prepare a sample, $\sim 1 \mathrm{mg}$ of catalyst was suspended in $10 \mathrm{~cm}^{3}$ of ethanol by agitating the mixture for $30 \mathrm{~min}$ in a sonication bath. A copper grid was dipped into the solution to capture the particles, and the ethanol was thoroughly evaporated before microscopy.

The measurement of oxygen storage capacity (OSC) and $\mathrm{H}_{2}$-temperature programmed reduction $\left(\mathrm{H}_{2}-\mathrm{TPR}\right)$ were performed on a Micromeritics Autochem II 2920 equipped with a thermal conductivity detector (TCD) using $0.20 \mathrm{~g}$ of sample. For OSC measurement, the catalyst 
was heated to $673 \mathrm{~K}$ in a 10 vol. $\% \mathrm{O}_{2} / \mathrm{He}$ mixture at a rate of $5 \mathrm{~K} \mathrm{~min}^{-1}$ and held at $673 \mathrm{~K}$ for 30 min, followed by a He purge at $673 \mathrm{~K}$ for $30 \mathrm{~min}$. The gas was then switched to $5 \mathrm{vol} \% \mathrm{H}_{2} / \mathrm{Ar}$ and reduced for $6 \mathrm{~h}$ at $673 \mathrm{~K}$, followed by a He purge at $673 \mathrm{~K}$ for $30 \mathrm{~min}$. The catalyst was then pulsed with $10 \mathrm{vol} . \% \mathrm{O}_{2} / \mathrm{He}$ at $673 \mathrm{~K}$ until saturation was reached. For $\mathrm{H}_{2}$-TPR, the catalyst was heated to $673 \mathrm{~K}$ in a $10 \mathrm{vol} . \% \mathrm{O}_{2} / \mathrm{He}$ at a rate of $5 \mathrm{~K} \mathrm{~min}^{-1}$ and held at $673 \mathrm{~K}$ for $30 \mathrm{~min}$, followed by a He purge at $673 \mathrm{~K}$ for $30 \mathrm{~min}$ prior to cooling to room temperature in He. The catalyst was then heated to $1273 \mathrm{~K}$ in $5 \mathrm{vol} \% \mathrm{H}_{2} / \mathrm{Ar}$ using a rate of $5 \mathrm{~K} \mathrm{~min}^{-1}$.

\subsubsection{Coke gasification by $\mathrm{O}_{2}$ and $\mathrm{H}_{2} \mathrm{O}$}

The samples for coke gasification were prepared in tight contact conditions by grinding the catalyst with the coke using a mortar and pestle for an extensive time (about $70 \mathrm{~min}$ ). The preparation and characterization of the coke used in this study can be found in our previous work. ${ }^{33}$ The coke was obtained by thermal reaction of ethylene at $1150 \mathrm{~K}$ and was a mixture of both graphitic and amorphous carbon. The coke gasification with dioxygen and steam was performed in both temperature-programmed oxidation (TPO) experiments and isothermal reactions. The coke gasification with dioxygen was carried out in a thermogravimetric analyzer (SDT Q600, TA instruments). Approximately $5 \mathrm{mg}$ of sample (coke mixed with catalyst) was placed in a small, flat $\mathrm{Al}_{2} \mathrm{O}_{3}$ sample cup. For TPO experiments, the sample was heated at a ramp rate of $5 \mathrm{~K} \mathrm{~min}^{-1}$ up to $1273 \mathrm{~K}$. For isothermal reactions, samples were heated to the target isothermal temperature at a rate of $20 \mathrm{~K} \mathrm{~min}^{-1}$, then held at the temperature for a specified time. The coke gasification with steam was carried out in a customized thermogravimetric analyzer (STA449F3 Jupiter, NETSCH). Approximately $2 \mathrm{mg}$ of sample (coke mixed with catalyst) was placed in a small, flat $\mathrm{Al}_{2} \mathrm{O}_{3}$ sample cup. For TPO experiments, the sample was heated at a ramp rate of $5 \mathrm{~K} \mathrm{~min}^{-1}$ up to $1273 \mathrm{~K}$ in $100 \mathrm{vol} . \% \mathrm{H}_{2} \mathrm{O}$. For isothermal reactions, samples were heated 
to the target isothermal temperature at a rate of $20 \mathrm{~K} \mathrm{~min}^{-1}$ in protective $\mathrm{N}_{2}$. Once the desired temperature was reached, pure steam was injected into the TGA and the temperature was held for $3 \mathrm{~h}$. Before each measurement, the TGA was evacuated and subsequently purged with $\mathrm{N}_{2}$ to remove oxygen in the system.

\subsection{Results and Discussions}

\subsubsection{Characterization of undoped and alkaline-earth-metal-doped $\mathrm{Ce} 0.8 \mathrm{Zr}_{0.2} \mathrm{O}_{2}$}

Table 3.1 Physical properties of undoped and alkaline-earth-metal-doped Ce-Zr mixed oxides

\begin{tabular}{cccccc}
\hline $\begin{array}{c}\text { Composition } \\
\text { of oxides }\end{array}$ & $\begin{array}{c}\text { BET } \\
\text { surface area } \\
\left(\mathrm{m}^{2} \mathrm{~g}^{-1}\right)\end{array}$ & $\begin{array}{c}\text { Internal } \\
\text { surface area } \\
\left(\mathrm{m}^{2} \mathrm{~g}^{-1}\right)^{\mathrm{a}}\end{array}$ & $\begin{array}{c}\text { External } \\
\text { surface area } \\
\left(\mathrm{m}^{2} \mathrm{~g}^{-1}\right)\end{array}$ & $\begin{array}{c}\text { Pore volume } \\
\left(\mathrm{cm}^{3} \mathrm{~g}^{-1}\right)^{\mathrm{b}}\end{array}$ & $\begin{array}{c}\text { Average pore } \\
\text { diameter } \\
(\AA)^{\mathrm{c}}\end{array}$ \\
\hline $\mathrm{CZ} 82$ & 15 & 3.2 & 12 & 0.10 & 239 \\
$0.1 \mathrm{Mg} / \mathrm{CZ} 82$ & 12 & 2.6 & 9.4 & 0.08 & 264 \\
$0.05 \mathrm{Ca} / \mathrm{CZ} 82$ & 8.8 & 1.3 & 7.5 & 0.07 & 274 \\
$0.1 \mathrm{Ca} / \mathrm{CZ} 82$ & 12 & 1.4 & 11 & 0.08 & 259 \\
$0.2 \mathrm{Ca} / \mathrm{CZ} 82$ & 7.9 & 1.0 & 6.9 & 0.06 & 289 \\
$0.1 \mathrm{Sr} / \mathrm{CZ} 82$ & 12 & 2.8 & 9.2 & 0.07 & 258 \\
$0.1 \mathrm{Ba} / \mathrm{CZ} 82$ & 11 & 2.6 & 8.4 & 0.07 & 240 \\
\hline
\end{tabular}

\footnotetext{
${ }^{a}$ Calculated from t-plot

${ }^{\mathrm{b}} \mathrm{BJH}$ cumulative pore volume

${ }^{\mathrm{c}}$ Calculated by BJH adsorption method
} 
The results from $\mathrm{N}_{2}$ physisorption are summarized in Table 3.1. The internal surface area, calculated from the t-plot method, provides an estimate of the surface area inside of micropores, which is very small compared with the BET surface area. The pore volume of the oxides was calculated by the BJH adsorption method and revealed very low values $\left(<0.1 \mathrm{~cm}^{3} \mathrm{~g}^{-}\right.$ ${ }^{1}$ ), indicating the oxides are essentially non-porous. The pores characterized by diameter between 200-300 A are likely the voids between primary particles present in aggregates. ${ }^{33}$
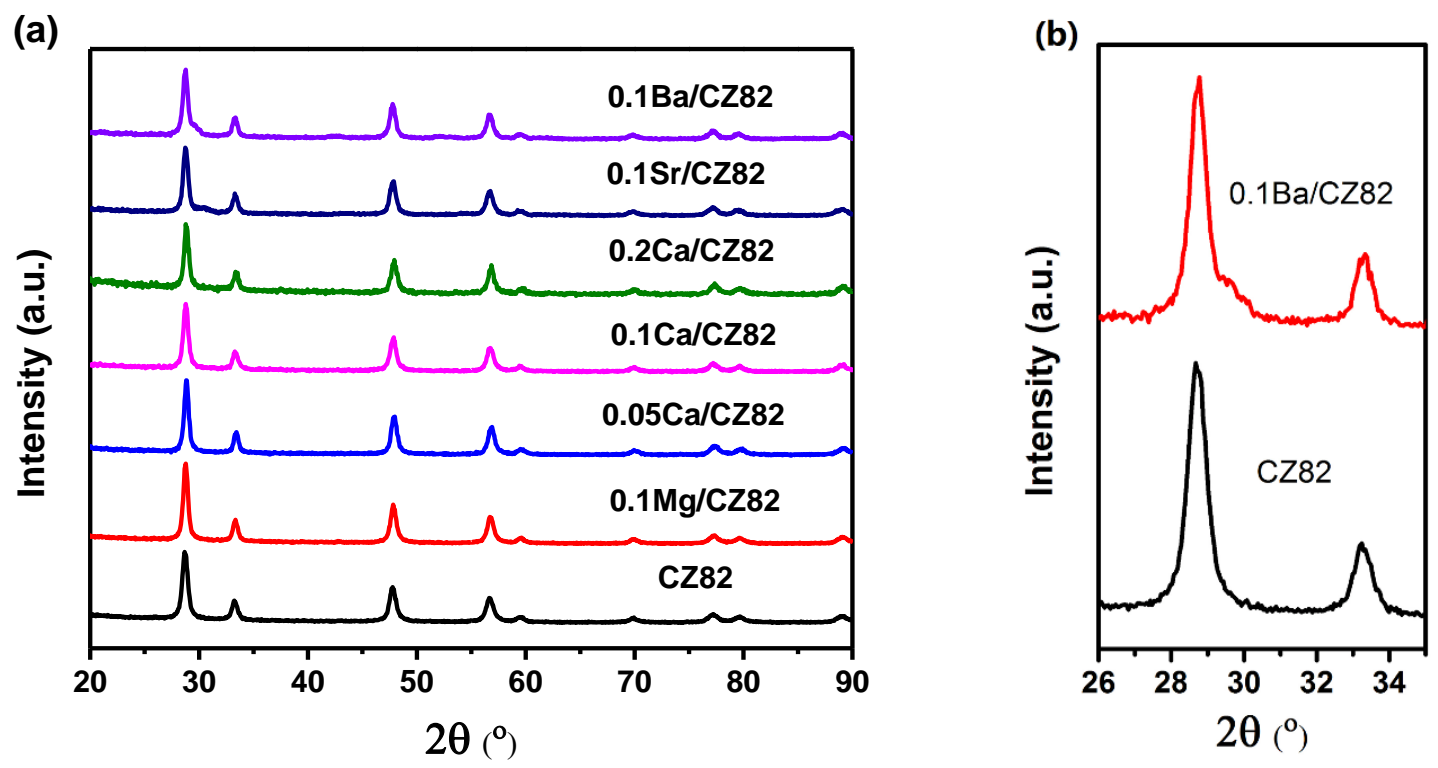

Figure 3.1 X-ray diffraction patterns of undoped and alkaline-earth-metal-doped $\mathrm{Ce}_{0.8} \mathrm{Zr}_{0.2} \mathrm{O}_{2}$.

Figure 3.1 shows the $\mathrm{X}$-ray diffraction patterns of alkaline earth metal doped $\mathrm{Ce}_{0.8} \mathrm{Zr}_{0.2} \mathrm{O}_{2}$ compared to undoped oxide. The Ce- $\mathrm{Zr}$ mixed oxide remained the patterns of cubic structure after the addition of $\mathrm{Mg}, \mathrm{Ca}$ and $\mathrm{Sr}$. The mixed oxide doped with Ba exhibited an additional small reflection near the main peak of $\mathrm{Ce}_{0.8} \mathrm{Zr}_{0.2} \mathrm{O}_{2}$ at $28.8^{\circ}$ (Figure $1 \mathrm{~b}$ ), which may be the 
reflection of $\mathrm{BaCeO}_{3}$ or $\mathrm{BaZrO}_{3}{ }^{34}$ Since there was no shift of the peaks of $\mathrm{Ce}_{0.8} \mathrm{Zr}_{0.2} \mathrm{O}_{2}$, the formation of $\mathrm{BaCeO}_{3}$ or $\mathrm{BaZrO}_{3}$ is must be limited to the surface or subsurface layers instead of the bulk of the mixed oxides.

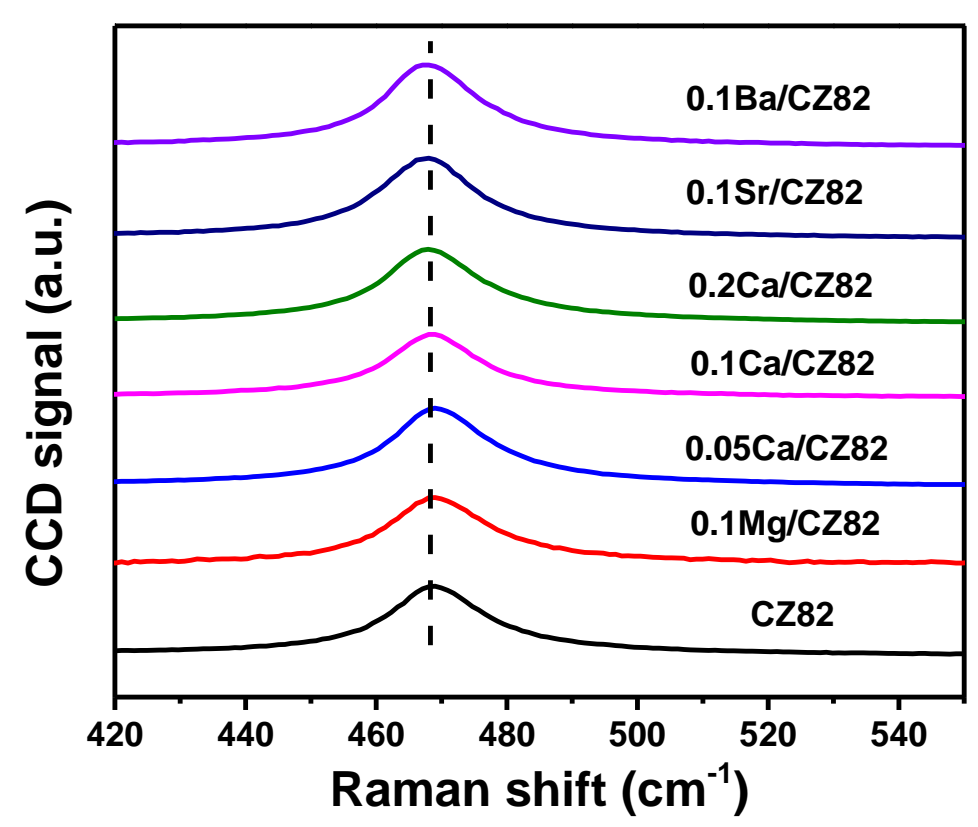

Figure 3.2 Raman spectra of undoped and alkaline-earth-metal-doped $\mathrm{Ce}_{0.8} \mathrm{Zr}_{0.2} \mathrm{O}_{2}$.

The Raman spectra of undoped and alkaline-earth-metal-doped $\mathrm{Ce}_{0.8} \mathrm{Zr}_{0.2} \mathrm{O}_{2}$ are shown in Figure 3.2. The $\mathrm{Ce}_{0.8} \mathrm{Zr}_{0.2} \mathrm{O}_{2}$ sample presented a band positioned at $469 \mathrm{~cm}^{-1}$, which is the $\mathrm{F}_{2 \mathrm{~g}}$ mode of the cubic fluorite structure. ${ }^{35}$ After the addition of alkaline earth metals to $\mathrm{Ce}_{0.8} \mathrm{Zr}_{0.2} \mathrm{O}_{2}$, there were neither any new bands nor any change of the $\mathrm{Ce}_{0.8} \mathrm{Zr}_{0.2} \mathrm{O}_{2}$ band, indicating that the alkaline earth metals remained on the surface of $\mathrm{Ce}_{0.8} \mathrm{Zr}_{0.2} \mathrm{O}_{2}$, which is consistent with the conclusion from the XRD results. The composition of $0.1 \mathrm{Ca} / \mathrm{CZ} 82$ sample was examined by energy-dispersive X-ray spectroscopy (EDS) in the STEM mode (Figure 3.3) and the atomic 
percentage of different elements are listed in Table 3.2. The average atomic percent of Ca was $4.6 \%$ for the regions at the edge of the particle, compared to only $0.8 \%$ for the regions in the middle of the particle. Thus, the results from XRD, Raman spectroscopy and STEM-EDS analysis all point to the conclusion that the alkaline earth metals remained highly dispersed on the surface of $\mathrm{Ce}_{0.8} \mathrm{Zr}_{0.2} \mathrm{O}_{2}$ after calcination at elevated temperature. However, we cannot rule out the possibility that some of alkaline earth metals enter the subsurface lattice of $\mathrm{Ce}_{0.8} \mathrm{Zr}_{0.2} \mathrm{O}_{2}$.

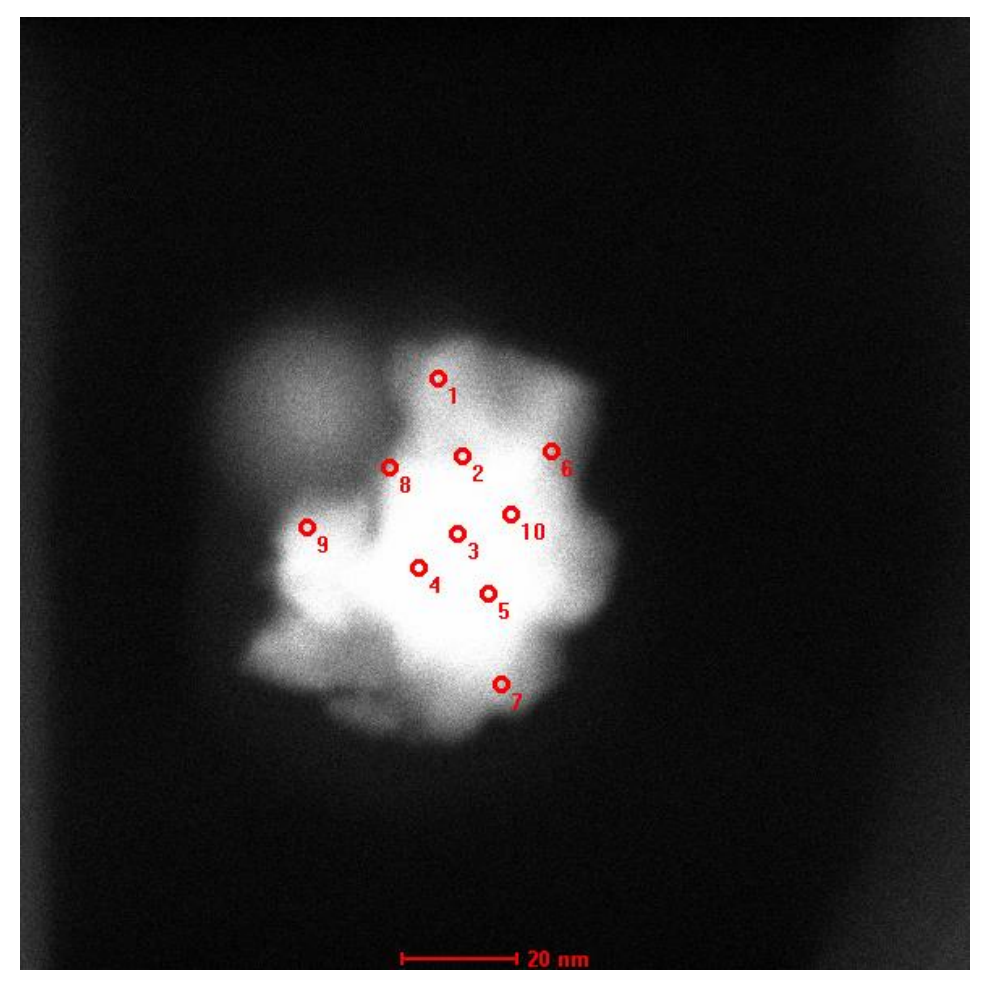

Figure 3.3 Dark-field STEM image of $0.1 \mathrm{Ca} / \mathrm{Ce} 0.8 \mathrm{Zr} 0.2 \mathrm{O} 2$. The corresponding compositions of analysis region are shown in Table 3.2 
Table 3.2 Elemental compositions from EDS of $0.1 \mathrm{Ca} / \mathrm{CZ}^{2} 2^{\mathrm{a}}$

\begin{tabular}{cccc}
\hline Area & Ce (atom\%) & Ca (atom\%) & Zr (atom\%) \\
\hline 1 & 97 & 3 & 0 \\
2 & 94 & 0 & 5 \\
3 & 88 & 0 & 12 \\
4 & 86 & 0 & 14 \\
5 & 92 & 3 & 5 \\
6 & 92 & 8 & 0 \\
7 & 92 & 3 & 5 \\
8 & 84 & 6 & 10 \\
9 & 85 & 3 & 11 \\
10 & 92 & 1 & 7 \\
\hline
\end{tabular}

a: The corresponding regions for EDS analysis are shown in Figure 3.3 


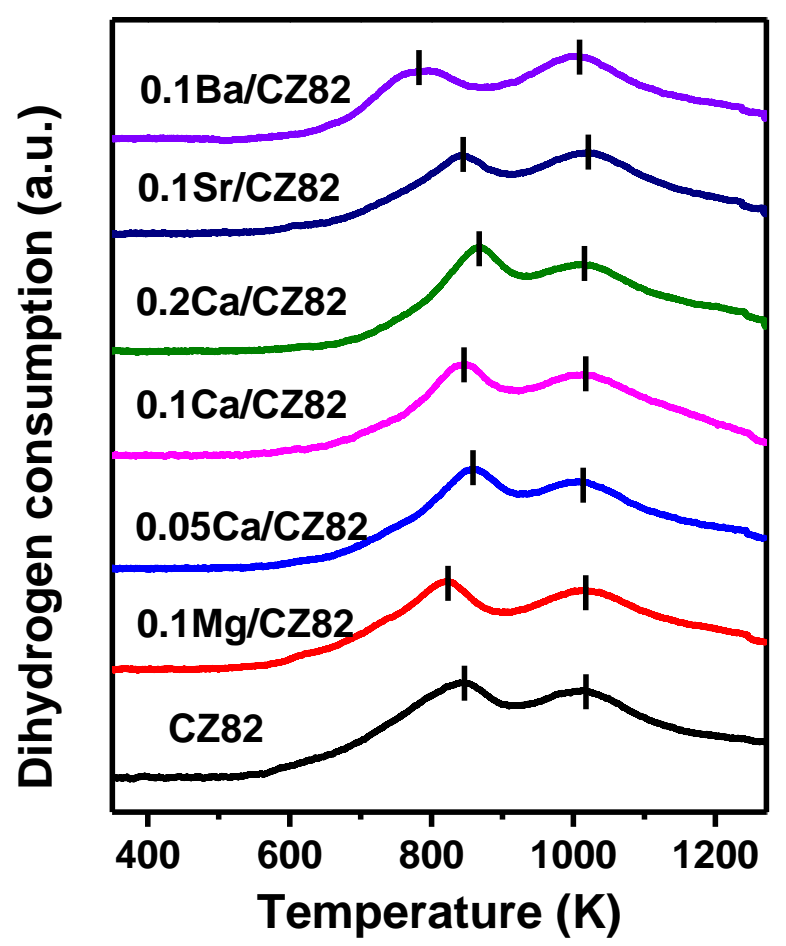

Figure 3.4 Uptake of $\mathrm{H} 2$ during temperature programmed reduction of undoped and alkalineearth-metal-doped $\mathrm{Ce}_{0.8} \mathrm{Zr}_{0.2} \mathrm{O}_{2}$.

The redox property of the samples was characterized by $\mathrm{H}_{2}$-TPR and the results are shown in Figure 3.4. The undoped $\mathrm{Ce}_{0.8} \mathrm{Zr}_{0.2} \mathrm{O}_{2}$ sample exhibited two reduction peaks at about $845 \mathrm{~K}$ and $1015 \mathrm{~K}$. The low temperature peak is assigned to the reduction of surface cerium while the high temperature peak is attributed to the reduction of bulk cerium. ${ }^{36}$ There was little change of the peak temperatures after the addition of $\mathrm{Mg}, \mathrm{Ca}$ or Sr. After the doping of $\mathrm{Ba}$, however, the surface reduction peak shifted to significantly lower temperature by $60 \mathrm{~K}$, which may be the result of the reduction of $\mathrm{BaCeO}_{3}$ formed on the surface. 
Table 3.3 Oxygen storage capacity of undoped and alkaline-earth-metal-doped $\mathrm{Ce}_{0.8} \mathrm{Zr}_{0.2} \mathrm{O}_{2}$.

\begin{tabular}{ccccc}
\hline Oxides & $\begin{array}{c}\text { Surface area } \\
\left(\mathrm{m}^{2} \mathrm{~g}^{-1}\right)\end{array}$ & $\begin{array}{c}\text { Normalized } \\
\text { surface area }\end{array}$ & $\begin{array}{c}\text { OSC } \\
\left.(\mu \mathrm{mol} \mathrm{O} \mathrm{g})^{-1}\right)\end{array}$ & OSC $^{\mathrm{b}}$ \\
\hline $\mathrm{CZ82}$ & 15 & - & 327 & - \\
$0.1 \mathrm{Mg} / \mathrm{CZ} 82$ & 12 & 0.80 & 237 & 0.73 \\
$0.05 \mathrm{Ca} / \mathrm{CZ} 82$ & 8.8 & 0.59 & 172 & 0.52 \\
$0.1 \mathrm{Ca} / \mathrm{CZ} 82$ & 12 & 0.80 & 178 & 0.54 \\
$0.2 \mathrm{Ca} / \mathrm{CZ} 82$ & 7.9 & 0.53 & 125 & 0.38 \\
$0.1 \mathrm{Sr} / \mathrm{CZ} 82$ & 12 & 0.80 & 178 & 0.54 \\
$0.1 \mathrm{Ba} / \mathrm{CZ82}$ & 11 & 0.73 & 278 & 0.85 \\
\hline
\end{tabular}

a: Ratio of surface area of alkaline-earth-metal-doped CZ82 to that of undoped CZ82

b: Ratio of OSC of alkaline-earth-metal-doped CZ82 to that of undoped CZ82

The oxygen storage capacity (OSC) of the oxides was measured by $\mathrm{O}_{2}$ pulse chemisorption at $673 \mathrm{~K}$ after reduction in $\mathrm{H}_{2}$ at $673 \mathrm{~K}$ for $6 \mathrm{~h}$, and the results are listed in Table 3.3. The OSC decreased after the addition of alkaline earth metals, which is attributed to the decrease of surface area after doping, as indicated by the similar values of normalized surface area and normalized OSC relative to undoped $\mathrm{Ce}_{0.8} \mathrm{Zr}_{0.2} \mathrm{O}_{2}$ in Table 3.3. Although bulk reduction of $\mathrm{Ce}$ contributes to the OSC, the $\mathrm{OSC}$ of $\mathrm{Ce}_{0.8} \mathrm{Zr}_{0.2} \mathrm{O}_{2}$ involves primarily the reduction of $\mathrm{Ce}$ in the near surface region of the sample. ${ }^{33}$ The OSC of the doped $\mathrm{Ce}_{0.8} \mathrm{Zr}_{0.2} \mathrm{O}_{2}$ samples is relatively unaffected by the presence of the alkaline earth metals beyond the reduction in surface area because the metals did not enter the bulk structure. 


\subsubsection{Coke gasification with $\mathrm{O}_{2}$ and $\mathrm{H}_{2} \mathrm{O}$ in the presence of undoped and alkaline-earth- metal-doped $\mathrm{Ce}_{.8} \mathrm{Zr}_{0.2} \mathrm{O}_{2}$}

Temperature-programmed oxidation in the presence and absence of catalyst was performed to determine a reasonable isothermal reaction temperature that minimizes the contribution from non-catalytic gasification. The addition of Ce-based catalysts to coke decreased the peak oxidation temperature by $120-170 \mathrm{~K}$, as shown in Figure 3.5. We chose to use $693 \mathrm{~K}$ as the isothermal reaction temperature to ensure the contribution from the uncatalyzed reaction was negligible. The weight loss profile of coke presented a first order decay and a first order equation matched well the weight loss profiles in the presence of undoped and alkalineearth-metal-doped $\mathrm{Ce}_{0.8} \mathrm{Zr}_{0.2} \mathrm{O}_{2}$ (Figure 3.6), which is similar to the results obtained from coke oxidation over a series of $\mathrm{Ce}-\mathrm{Zr}$ mixed oxides. ${ }^{33}$ To obtain reproducible reaction rates, tight contact coke-catalyst samples with different amounts of catalyst were prepared and evaluated in the gasification reaction. Figure 3.7 shows the relationship between rate constant and catalyst loading for those catalysts, which allows the calculation of reaction rates with the method described in our previous work. ${ }^{33}$ 


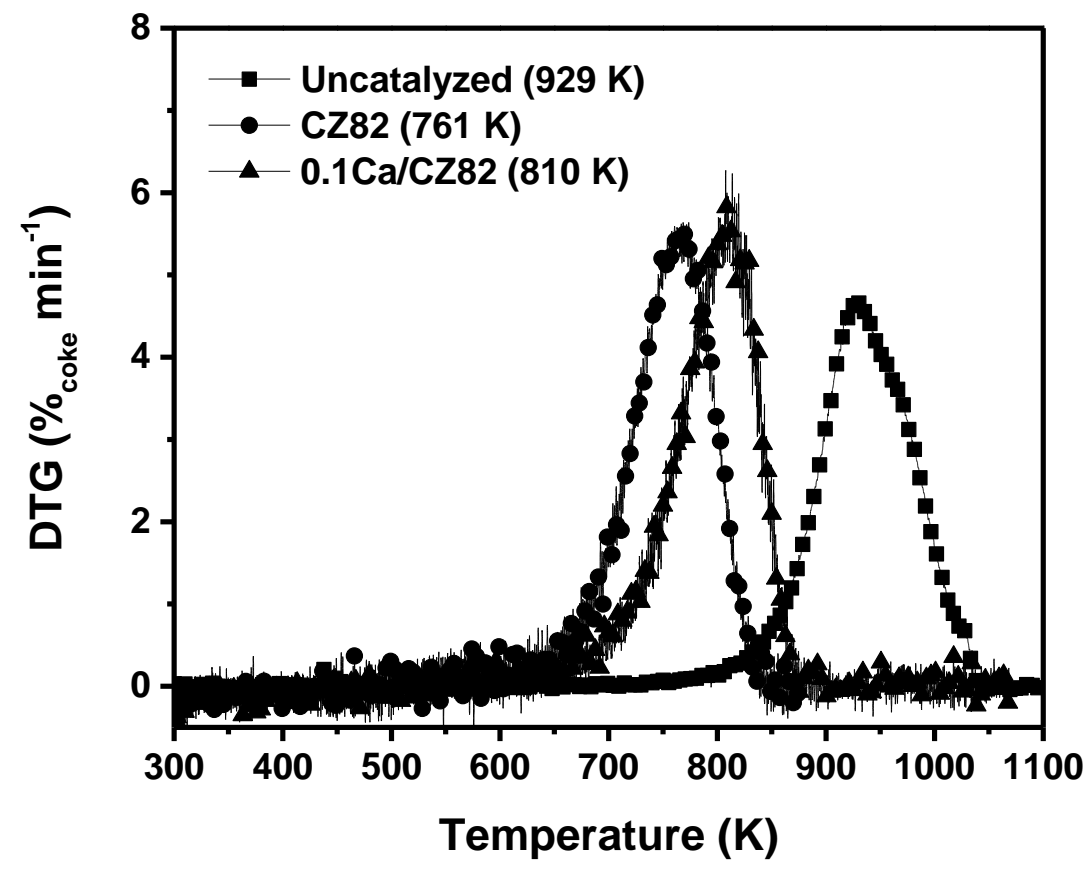

Figure 3.5 Temperature-programmed oxidation of synthetic coke with and without catalyst.

Reaction conditions: $80 \mathrm{wt} . \%$ catalyst in the mixture, $5 \mathrm{~K} \mathrm{~min}^{-1}, 100 \mathrm{~cm}^{3} \mathrm{~min}^{-1} 10 \mathrm{vol} \% \mathrm{O}_{2} / \mathrm{He}$, tight contact sample. The peak oxidation temperature are listed in the parenthes. 


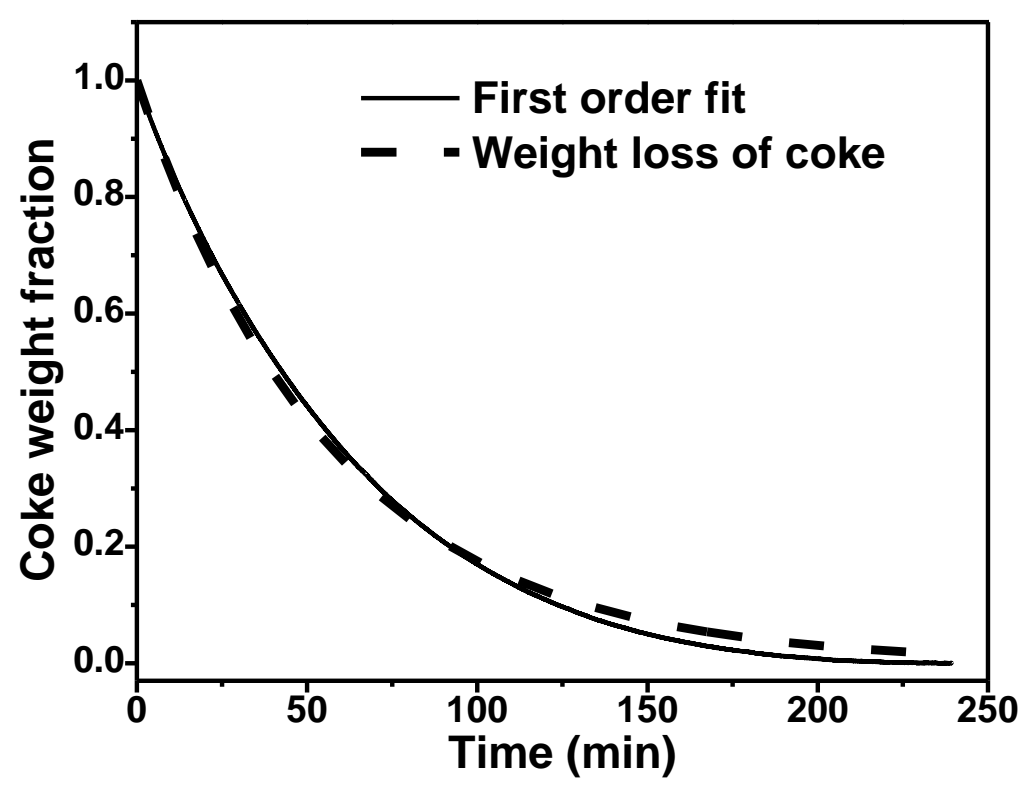

Figure 3.6 Weight loss profile of coke during coke oxidation catalyzed by $\mathrm{Ce}_{0.8} \mathrm{Zr}_{0.2} \mathrm{O}_{2}$ at $693 \mathrm{~K}$. Reaction conditions: 50 wt. $\% \mathrm{Ce}_{0.8} \mathrm{Zr}_{0.2} \mathrm{O}_{2}, 100 \mathrm{~cm}^{3} \mathrm{~min}^{-1} 10$ vol. $\% \mathrm{O}_{2} / \mathrm{He}$, tight contact sample.

For coke gasification with steam, TPO experiments were also performed to determine the isothermal reaction temperature and the results are shown in Figure 3.8. Uncatalyzed steam gasification of coke had a peak temperature of $1182 \mathrm{~K}$, which is much higher than the peak temperature of uncatalyzed coke oxidation at $929 \mathrm{~K}$ and illustrated the low rate of steam gasification. The peak steam gasification temperature in the presence of catalyst decreased by 30-60 K compared to that without catalyst. Isothermal coke gasification with steam over undoped and alkaline-earth-metal-doped $\mathrm{Ce}_{0.8} \mathrm{Zr}_{0.2} \mathrm{O}_{2}$ was then carried out at $993 \mathrm{~K}$ in 100 vol\% steam. Unlike coke gasification with dioxygen, the coke weight loss profile presented a zero order decay with steam (Figure 3.9). A zero order rate equation was used to fit the weight loss profile over the range of conversion of coke from 0 to $20 \%$. 
(a)
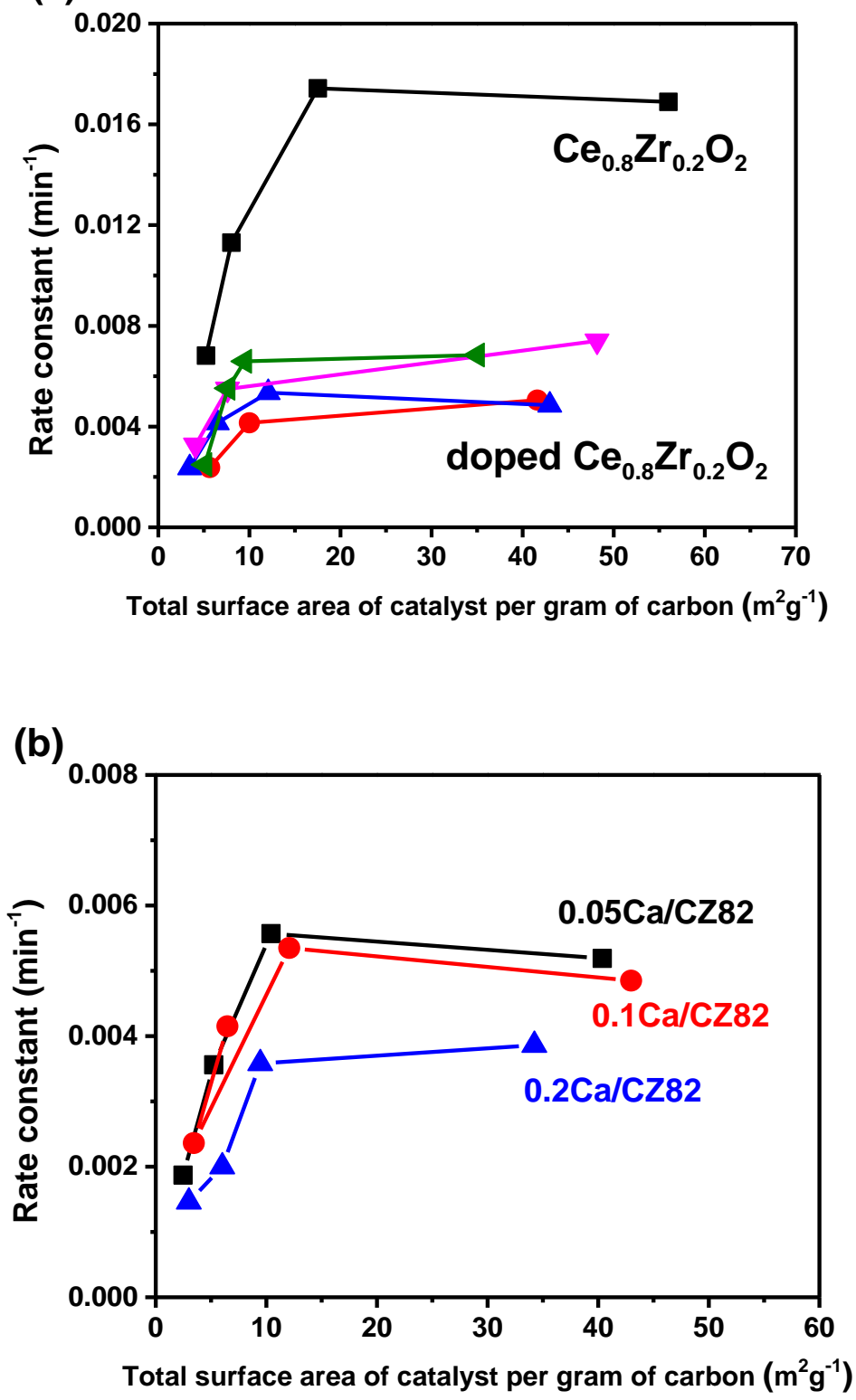

Figure 3.7 Relationship between measured first order rate constant and normalized catalyst loading for (a) $\mathbf{\bullet}: \mathrm{CZ} 82, \bullet: 0.1 \mathrm{Mg} / \mathrm{CZ} 82, \boldsymbol{\Delta}: 0.1 \mathrm{Ca} / \mathrm{CZ} 82, \boldsymbol{\nabla}: 0.1 \mathrm{Sr} / \mathrm{CZ} 82, \boldsymbol{\triangleleft}: 0.1 \mathrm{Ba} / \mathrm{CZ} 82$; and (b) $\mathrm{Ce}_{0.8} \mathrm{Zr}_{0.2} \mathrm{O}_{2}$ doped with different amount of $\mathrm{Ca}$. 


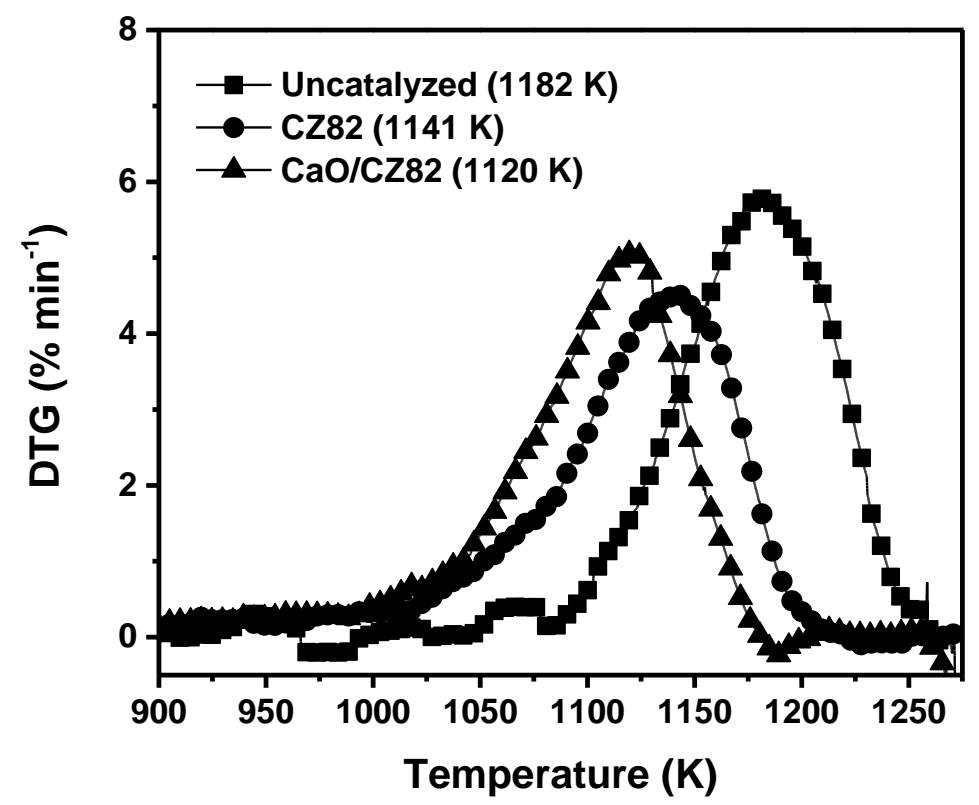

Figure 3.8 Temperature-programmed oxidation of synthetic coke with and without catalyst.

Reaction conditions: $80 \mathrm{wt} . \%$ catalyst in the mixture, $5 \mathrm{~K} \mathrm{~min}^{-1}, 100 \mathrm{~cm}^{3} \mathrm{~min}^{-1} 100 \mathrm{vol} . \% \mathrm{H}_{2} \mathrm{O}$, tight contact sample. The peak gasification temperatures are listed in the parenthesis.

To investigate the effect of catalyst/coke mass ratio, samples with different amounts of catalyst were tested for the coke steam gasification. For all of the catalysts tested, the same trend was observed: at low catalyst loadings (total surface area of catalyst per gram of coke $<20 \mathrm{~m}^{2} \mathrm{~g}^{-}$ ${ }^{1}$ ), the gasification rate was fairly independent of the total surface area of the catalyst (Figure 3.10) whereas at high catalyst loadings (total surface area of catalyst per gram of coke $<20 \mathrm{~m}^{2} \mathrm{~g}^{-}$ ${ }^{1}$ ), the reaction rate was much lower (not shown in Figure 3.10). These results indicate there is an excess of catalyst present at high catalyst loadings and only a portion of the catalyst participates in the reaction, which is quite analogous to the case with coke gasification with dioxygen. To compare the activity of different catalysts, the average reaction rate at low catalyst loadings (total 
surface area of catalyst per gram of coke $<20 \mathrm{~m}^{2} \mathrm{~g}^{-1}$ ) was calculated to represent the intrinsic rate.

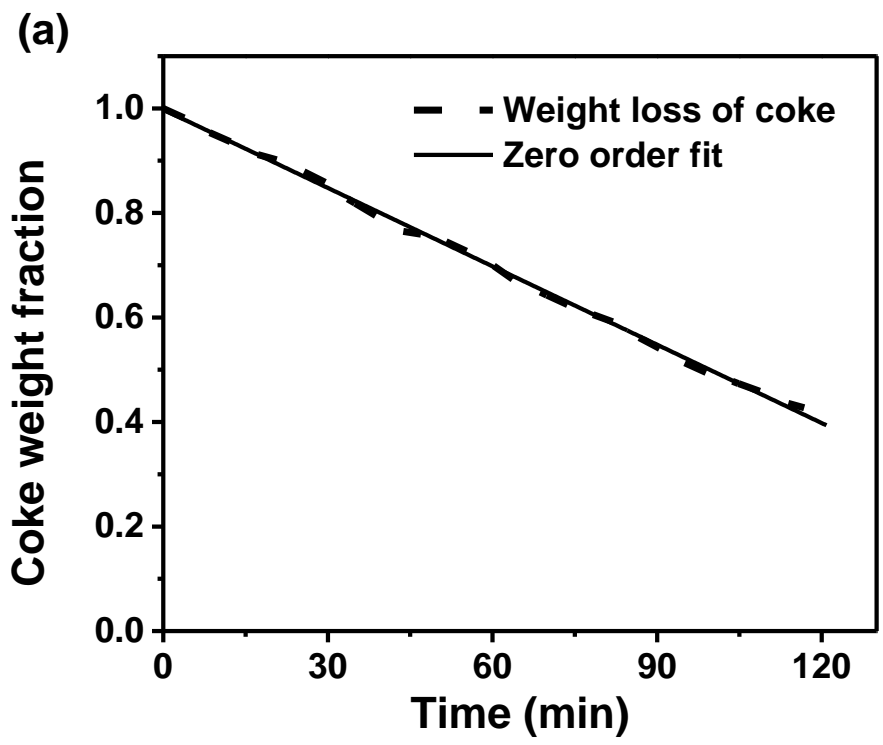

(b)

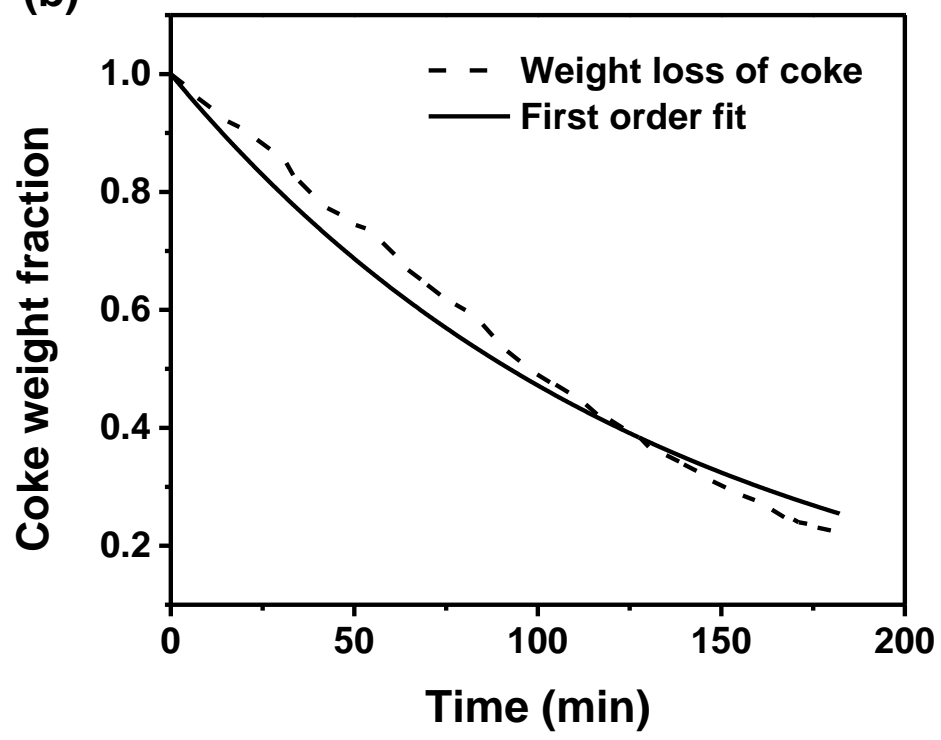

Figure 3.9 Weight loss profile of coke during coke oxidation catalyzed by $0.1 \mathrm{Ba} / \mathrm{Ce}_{0.8} \mathrm{Zr}_{0.2} \mathrm{O}_{2}$ at 993 K. Reaction conditions: 80 wt.\% 0.1Ba/Ce $\mathrm{Ce}_{0.8} \mathrm{Zr}_{0.2} \mathrm{O}_{2}, 100 \mathrm{~cm}^{3} \mathrm{~min}^{-1} 100$ vol.\% $\mathrm{H}_{2} \mathrm{O}$, tight contact samples 


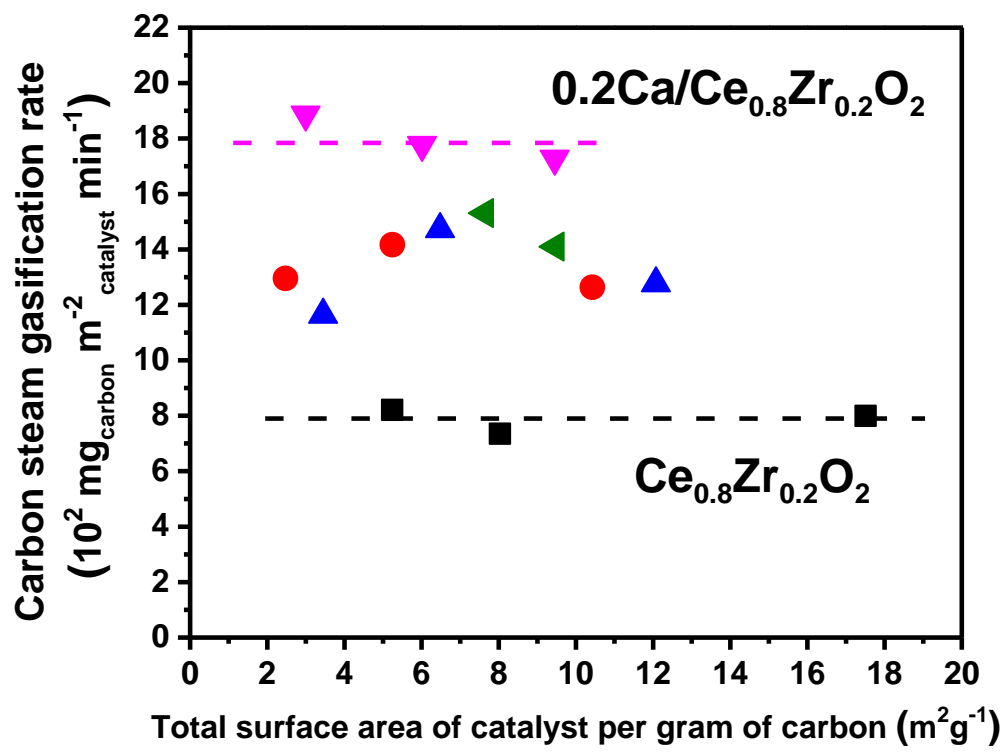

Figure 3.10 Relationship between measured reaction rate and normalized catalyst loading for Undoped and alkaline earth metal doped $\mathrm{Ce}_{0.8} \mathrm{Zr}_{0.2} \mathrm{O}_{2}(\mathbf{m}: \mathrm{CZ} 82, \bullet: 0.05 \mathrm{Ca} / \mathrm{CZ} 82, \boldsymbol{\Delta}$ :

0.1Ca/CZ82, $\boldsymbol{\nabla}: 0.2 \mathrm{Ca} / \mathrm{CZ} 82,4: 0.1 \mathrm{Ba} / \mathrm{CZ82})$. Reaction conditions: $993 \mathrm{~K}, 100 \mathrm{~cm}^{3} \mathrm{~min}^{-1} 100$ vol. $\% \mathrm{H}_{2} \mathrm{O}$, tight contact samples.

Table 3.4 Coke gasification rate with dioxygen and steam over undoped and alkaline-earthmetal-doped $\mathrm{Ce}_{0.8} \mathrm{Zr}_{0.2} \mathrm{O}_{2}$.

\begin{tabular}{ccc}
\hline $\begin{array}{c}\text { Composition } \\
\text { of oxides }\end{array}$ & $\begin{array}{c}\text { Rate of coke gasification } \\
\text { with dioxygen at } 693 \mathrm{~K}\end{array}$ & $\begin{array}{c}\text { Rate of coke gasification with } \\
\left(\times 10^{-3} \mathrm{~g}_{\text {carbon }} \mathrm{m}_{\text {catalys }}^{-2} \mathrm{~min}^{-1}\right)\end{array}$ \\
\hline $\mathrm{CZ82}$ & 1.6 & 7.9 \\
$0.1 \mathrm{Mg} / \mathrm{CZ} 82$ & 0.42 & 9.1 \\
$0.05 \mathrm{Ca} / \mathrm{CZ} 82$ & 0.65 & 13 \\
\hline
\end{tabular}




\begin{tabular}{lll}
\hline $0.1 \mathrm{Ca} / \mathrm{CZ} 82$ & 0.59 & 13 \\
$0.2 \mathrm{Ca} / \mathrm{CZ} 82$ & 0.33 & 18 \\
$0.1 \mathrm{Sr} / \mathrm{CZ} 82$ & 0.72 & 14 \\
$0.1 \mathrm{Ba} / \mathrm{CZ} 82$ & 0.72 & 15 \\
\hline
\end{tabular}

Table 3.4 summarizes the rate of coke gasification with dioxygen and steam over different undped and doped $\mathrm{Ce}_{0.8} \mathrm{Zr}_{0.2} \mathrm{O}_{2}$. After the addition of alkaline earth metals, the rate of coke gasification with dioxygen decreased whereas the rate with steam increased. Moreover, with increasing amount of calcium in the mixed oxide, the coke gasification rate with dioxygen decreased while the gasification rate with steam increased. The opposite effect of alkaline earth metals on the two reactions may result from oxidizing potential of $\mathrm{O}_{2}$ versus $\mathrm{H}_{2} \mathrm{O}$. Coke gasification with dioxygen over Ce-based catalysts involves a redox mechanism. ${ }^{37,38} \mathrm{~A}$ redox mechanism over Ce-based catalysts is also reported to operate during steam gasification of ethanol ${ }^{39}$ and methane. ${ }^{40}$ It is likely that the reaction mechanism of coke steam gasification also includes a redox cycle, in which the lattice oxygen reacts with coke to form $\mathrm{CO}$ or $\mathrm{CO}_{2}$, followed by the replacement of the lattice oxygen vacancy by water. In the presence of alkaline earth metals, a reaction path for steam gasification with dioxygen and steam has been attributed to an oxygen transfer mechanism, ${ }^{41-43}$ with the general reaction sequence as follows:

$$
\begin{aligned}
& \mathrm{C}-\mathrm{C}_{\mathrm{f}}+\mathrm{OM} \rightarrow \mathrm{C}-\mathrm{C}_{\mathrm{f}}(\mathrm{OM}) \\
& \mathrm{C}-\mathrm{C}_{\mathrm{f}}(\mathrm{OM})+\mathrm{OM} \rightarrow \mathrm{C}(\mathrm{OM})-\mathrm{C}_{\mathrm{f}}(\mathrm{OM}) \\
& \mathrm{C}(\mathrm{OM})-\mathrm{C}_{\mathrm{f}}(\mathrm{OM}) \rightarrow \mathrm{CO}+\mathrm{C}-\mathrm{C}_{\mathrm{f}}(\mathrm{OM})+\mathrm{M} \\
& 2 \mathrm{M}+\mathrm{O}_{2} \rightarrow \mathrm{MO} \text { or } \mathrm{M}+\mathrm{H}_{2} \mathrm{O} \rightarrow \mathrm{MO}+\mathrm{H}_{2}
\end{aligned}
$$


where $\mathrm{C}_{\mathrm{f}}$ is the free carbon site, $\mathrm{OM}$ and $\mathrm{M}$ are the non-stoichiometric alkaline earth oxygenated compound and the reduced form, respectively. Since the alkaline earth metals are highly dispersed on the surface of $\mathrm{Ce}_{0.8} \mathrm{Zr}_{0.2} \mathrm{O}_{2}$, the normal redox pathway that is effective for oxidation of coke in the presence of ceria is inhibited by the alkaline earth metals at the surface. At the higher temperature of $993 \mathrm{~K}$, the oxygen transfer mechanism becomes more important, especially in coke gasification with steam.

\subsection{Conclusions}

Calcination of a mixture consisting of $\mathrm{Ce}_{0.8} \mathrm{Zr}_{0.2} \mathrm{O}_{2}$ and a nitrate salt of alkaline earth metals resulted in a high dispersion of alkaline earth metals on the surface of $\mathrm{Ce}_{0.8} \mathrm{Zr}_{0.2} \mathrm{O}_{2}$. The presence of catalyst decreased the peak gasification temperature by $120-170 \mathrm{~K}$ with dioxygen and by $30-60 \mathrm{~K}$ with steam compared to those without catalyst. The normalized reaction rates on a catalysis surface area basis were obtained from the results of isothermal reaction of samples with different amounts of catalyst. The weight loss of coke in catalyzed coke gasification was first order in coke with dioxygen, but was zero order in coke with steam. The rates of alkalineearth-metal doped $\mathrm{Ce}_{0.8} \mathrm{Zr}_{0.2} \mathrm{O}_{2}$ were $20-45 \%$ of that with doped $\mathrm{Ce}_{0.8} \mathrm{Zr}_{0.2} \mathrm{O}_{2}$ in coke gasification

with dioxygen. However, the rates of alkaline-earth-metal doped $\mathrm{Ce}_{0.8} \mathrm{Zr}_{0.2} \mathrm{O}_{2}$ were $115-230 \%$ of that with doped $\mathrm{Ce}_{0.8} \mathrm{Zr}_{0.2} \mathrm{O}_{2}$ in coke gasification with steam. The best catalyst composition among those studied for steam gasification of coke was $0.2 \mathrm{Ca} / \mathrm{Ce}_{0.8} \mathrm{Zr}_{0.2} \mathrm{O}_{2}$. The opposite effect of alkaline earth metal in the two reactions may be caused by different reaction mechanisms: redox mechanism for Ce-based materials and oxygen transfer mechanism for alkaline earth metals.

\section{References for Chapter 3}


(1) Gärtner, C. A.; van Veen, A. C.; Lercher, J. A. Oxidative Dehydrogenation of Ethane: Common Principles and Mechanistic Aspects. ChemCatChem 2013, 5 (11), 3196-3217.

(2) Cai, H.; Krzywicki, A.; Oballa, M. C. Coke Formation in Steam Crackers for Ethylene Production. Chem. Eng. Process. 2002, 41 (3), 199-214.

(3) Ropital, F.; Broutin, P.; Reyniers, M. F.; Froment, G. F. Anticoking Coatings for High Temperature Petrochemical Reactors. Oil Gas Sci. Technol. 1999, 54 (3), 375-385.

(4) Sadrameli, S. M. Thermal/Catalytic Cracking of Hydrocarbons for the Production of Olefins : A State-of-the-Art Review I: Thermal Cracking Review. Fuel 2015, 140, 102115.

(5) Mahamulkar, S.; Yin, K.; Agrawal, P. K.; Davis, R. J.; Jones, C. W.; Malek, A.; Shibata, H. Formation and Oxidation / Gasi Fi Cation of Carbonaceous Deposits : A Review. Ind. Eng. Chem. Res. 2016, 55, 9760-9818.

(6) Grace Chan, K. Y.; Inal, F.; Senkan, S. Suppression of Coke Formation in the Steam Cracking of Alkanes: Ethane and Propane. Ind. Eng. Chem. Res. 1998, 37 (3), 901-907.

(7) Sundaram, K. M.; Van Damme, P. S.; Froment, G. F. Coke Deposition in the Thermal Cracking of Ethane. AIChE J. 1981, 27 (6), 946-951.

(8) Niaei, A.; Salari, D.; Towfighi, J.; Chamandeh, A.; Nabavi R. Aluminized Steel and Zinc Coating for Reduction of Coke Formation in Thermal Cracking of Naphtha. Internatonal J. Chem. React. Eng. 2008, 6, 1-11.

(9) Niaei, A.; Salari, D.; Daneshvar, N.; Chamandeh, A.; Nabavi, R. Effect of Tube Materials and Special Coating on Coke Deposition in the Steam Cracking of Hydrocarbons. World 
Acad. Sci. Eng. Technol. 2007, 5, 15-17.

(10) BASF. CAMOL Catalytic Coatings for Steam Cracker Furnace Tubes; BASF Qtech (Canada), Inc.; Mississauga, Ontario, Canada, 2012.

(11) Petrone, S.; Deuis, R. L.; Kong, F.; Unwin, P. Catalyzed-Assisted Manufacture of Olefins (CAMOL): Year-(4) Update on Commercial Furnace Installations. Presented in AIChE Spring National Meeting; San Antonio, TX, March 21-25, 2010.

(12) Bueno-López, A. Diesel Soot Combustion Ceria Catalysts. Appl. Catal. B Environ. 2014, $146,1-11$.

(13) Hernández-Giménez, A. M.; Castelló, D. L.; Bueno-López, A. Diesel Soot Combustion Catalysts: Review of Active Phases. Chem. Pap. 2013, 68 (9), 1154-1168.

(14) Aneggi, E.; Boaro, M.; De Leitenburg, C.; Dolcetti, G.; Trovarelli, A. Insights into the Redox Properties of Ceria-Based Oxides and Their Implications in Catalysis. J. Alloys Compd. 2006, 408-412, 1096-1102.

(15) Trovarelli, A. Catalytic Properties of Ceria and $\mathrm{CeO}_{2}-$ Containing Materials. Catal. Rev. Sci. Eng. 1996, 38 (4), 439-520.

(16) Trovarelli, A.; de Leitenburg, C.; Boaro, M.; Dolcetti, G. The Utilization of Ceria in Industrial Catalysis. Catal. Today 1999, 50 (2), 353-367.

(17) Kašpar, J.; Fornasiero, P.; Graziani, M. Use of CeO2-Based Oxides in the Three-Way Catalysis. Catal. Today 1999, 50, 285-298.

(18) Gorte, R. J. Ceria in Catalysis: From Automotive Applications to the Water-Gas Shift Reaction. AIChE J. 2010, 56 (5), 1126-1135. 
(19) Zhuang, Q.; Qin, Y.; Chang, L. Promoting Effect of Cerium Oxide in Supported Nickel Catalyst for Hydrocarbon Steam-Reforming. Appl. Catal. 1991, 70 (1), 1-8.

(20) Natesakhawat, S.; Watson, R. B.; Wang, X.; Ozkan, U. S. Deactivation Characteristics of Lanthanide-Promoted Sol-Gel Ni/Al ${ }_{2} \mathrm{O}_{3}$ Catalysts in Propane Steam Reforming. J. Catal. 2005, 234 (2), 496-508.

(21) Navarro, R. M.; Pena, M. A.; Fierro, J. L. G. Hydrogen Production Reactions from Carbon Feedstocks : Fossil Fuels and Biomass. Chem. Rev. 2007, 107, 3952-3991.

(22) Wang, X.; Gorte, R. J. A Study of Steam Reforming of Hydrocarbon Fuels on Pd/Ceria. Appl. Catal. A Gen. 2002, 224 (1-2), 209-218.

(23) Aneggi, E.; de Leitenburg, C.; Trovarelli, A. On the Role of Lattice/surface Oxygen in Ceria-zirconia Catalysts for Diesel Soot Combustion. Catal. Today 2012, 181 (1), 108115.

(24) Reddy, B. M.; Bharali, P.; Thrimurthulu, G.; Saikia, P.; Katta, L.; Park, S.-E. Catalytic Efficiency of Ceria-zirconia and Ceria-hafnia Nanocomposite Oxides for Soot Oxidation. Catal. Letters 2008, 123 (3-4), 327-333.

(25) Atribak, I.; Bueno-López, A.; García-García, A. Thermally Stable Ceria-Zirconia Catalysts for Soot Oxidation by $\mathrm{O}_{2}$. Catal. Commun. 2008, 9, 250-255.

(26) Liu, J.; Zhao, Z.; Liang, P.; Xu, C.; Duan, A.; Jiang, G.; Lin, W.; Wachs, I. E. Study on the Reaction Mechanism for Soot Oxidation over $\mathrm{TiO}_{2}$ or $\mathrm{ZrO}_{2}$-Supported Vanadium Oxide Catalysts by Means of in-Situ UV-Raman. Catal. Letters 2007, 120 (1-2), 148-153.

(27) Katta, L.; Sudarsanam, P.; Thrimurthulu, G.; Reddy, B. M. Doped Nanosized Ceria Solid 
Solutions for Low Temperature Soot Oxidation: Zirconium versus Lanthanum Promoters. Appl. Catal. B Environ. 2010, 101 (1-2), 101-108.

(28) Aneggi, E.; Boaro, M.; De Leitenburg, C.; Dolcetti, G.; Trovarelli, A. Insights into the Dynamics of Oxygen Storage/release Phenomena in Model Ceria-Zirconia Catalysts as Inferred from Transient Studies Using $\mathrm{H}_{2}, \mathrm{CO}$ and Soot as Reductants. Catal. Today 2006, $112(1-4), 94-98$.

(29) Wu, X.; Liu, D.; Li, K.; Li, J.; Weng, D. Role of $\mathrm{CeO}_{2}-\mathrm{ZrO}_{2}$ in Diesel Soot Oxidation and Thermal Stability of Potassium Catalyst. Catal. Commun. 2007, 8 (8), 1274-1278.

(30) Chen, S. G.; Yang, R. T. Mechanism of Alkali and Alkaline Earth Catalyzed Gasification of Graphite by $\mathrm{CO}_{2}$ and $\mathrm{H}_{2} \mathrm{O}$ Studied by Electron Microscopy. J. Catal. 1992, 138 (1), 1223.

(31) Lussier, M. G.; Zhang, Z.; Miller, D. J. Characterizing Rate Inhibition in Steam/hydrogen Gasification via Analysis of Adsorbed Hydrogen. Carbon N. Y. 1998, 36 (9), 1361-1369.

(32) Zhang, G.; Zhao, Z.; Liu, J.; Jiang, G.; Duan, A.; Zheng, J.; Chen, S.; Zhou, R. Three Dimensionally Ordered Macroporous $\mathrm{Ce}_{(1-\mathrm{x})} \mathrm{Zr}_{(\mathrm{x})} \mathrm{O}_{(2)}$ Solid Solutions for Diesel Soot Combustion. Chem. Commun. 2010, 46 (3), 457-459.

(33) Yin, K.; Mahamulkar, S.; Shibata, H.; Malek, A.; Jones, C. W.; Agrawal, P.; Davis, R. J. Catalytic Oxidation of Solid Carbon and Carbon Monoxide over Cerium- Zirconium Mixed Oxides. Submitted to AIChE J.

(34) Yamanaka, S.; Hamaguchi, T.; Oyama, T.; Matsuda, T.; Kobayashi, S.; Kurosaki, K. Heat Capacities and Thermal Conductivities of Perovskite Type $\mathrm{BaZrO}_{3}$ and $\mathrm{BaCeO}_{3}$. J. Alloys Compd. 2003, 359 (1600), 1-4. 
(35) Trovarelli, A.; Zamar, F.; Llorca, J.; Leitenburg, C. de; Dolcetti, G.; Kiss, J. T. Nanophase Fluorite-Structured $\mathrm{CeO}_{2}-\mathrm{ZrO}_{2}$ Catalysts Prepared by High-Energy Mechanical Milling. J. Catal. 1997, 169 (2), 490-502.

(36) Fally, F.; Perrichon, V.; Vidal, H.; Kaspar, J.; Blanco, G.; Pintado, J. M.; Bernal, S.; Colon, G.; Daturi, M.; Lavalley, J. C. Modification of the Oxygen Storage Capacity of $\mathrm{CeO}_{2}-\mathrm{ZrO}_{2}$ Mixed Oxides after Redox Cycling Aging. Catal. Today 2000, 59 (3), 373386.

(37) Machida, M.; Murata, Y.; Kishikawa, K.; Zhang, D.; Ikeue, K. On the Reasons for High Activity of $\mathrm{CeO}_{2}$ Catalyst for Soot Oxidation. Chem. Mater. 2008, No. 20, 4489-4494.

(38) Krishna, K.; Makkee, M.; Moulijn, J. A. Enhanced Soot Oxidation by Lattice Oxygen via $\mathrm{La}^{3+}$-Doped $\mathrm{CeO}_{2}$. J. Catal. 2005, 230, 237-248.

(39) Laosiripojana, N.; Assabumrungrat, S. Catalytic Steam Reforming of Ethanol over High Surface Area $\mathrm{CeO}_{2}$ : The Role of $\mathrm{CeO}_{2}$ as an Internal Pre-Reforming Catalyst. Appl. Catal. B Environ. 2006, 66 (1-2), 29-39.

(40) Ramírez-Cabrera, E.; Atkinson, A.; Chadwick, D. Catalytic Steam Reforming of Methane

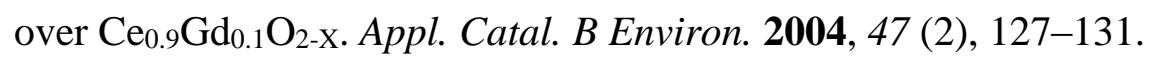

(41) Moulijn, J. A. Towards a Unified Theory of Reactions of Carbon with Oxygen-Containing Molecules. Carbon 1995, 33 (8), 1155-1165.

(42) Chen, S. G.; Yang, R. T. Unified Mechanism of Alkali and Alkaline Earth Catalyzed Gasification Reactions of Carbon by $\mathrm{CO}_{2}$ and $\mathrm{H}_{2} \mathrm{O}$. Energy \& Fuels 1997, 11 (2), 421427. 
(43) Castoldi, L.; Matarrese, R.; Lietti, L.; Forzatti, P. Intrinsic Reactivity of Alkaline and Alkaline-Earth Metal Oxide Catalysts for Oxidation of Soot. Appl. Catal. B Environ. 2009, 90, 278-285. 


\section{Chapter 4. Conclusions and future work}

\subsection{Conclusions}

The coke gasification with dioxygen and steam over ceria-based materials was investigated in this work, as an attempt to explore the possibility of utilizing ceria-based materials for anti-coking coating materials in steam crackers. In Chapter 2, a method was developed to obtain reproducible kinetics for reactions involving coke using coke gasification with dioxygen over cerium-zirconium mixed oxides as a model reaction. In Chapter 3, the method was applied to coke gasification with both dioxygen and steam to obtain the reactions rates over a series of alkaline-earth-metal-doped cerium-zirconium mixed oxides.

Solid coke was prepared by thermal reaction of ethylene at elevated temperature to mimic the coke formation during steam cracking. The results from XRD, Raman spectroscopy and TEM indicated the coke was mixture of both amorphous and graphitic coke. Cerium-zirconium mixed oxides were obtained by co-precipitation method, follows by the calcination at $1073 \mathrm{~K}$. Solid solutions formed for the Ce-Zr mixed oxides with different compositions. The structure changed from cubic to tetragonal with increasing zirconium content in the mixed oxides. Two factors contribute to the OSC of Ce-Zr mixed oxides: the amount of cerium and the oxygen mobility in the oxides. The compromise of these two factors resulted in the highest OSC exhibited by $\mathrm{Ce}_{0.5} \mathrm{Zr}_{0.5} \mathrm{O}_{2}$. Grinding had significant effect on the activity of coke gasification. With increasing grinding time, the rate constant increased first and then kept almost constant. Coke gasification with dioxygen over ceria-based oxides was studied under isothermal tight contact conditions to obtain normalized reaction rates on a catalyst surface area basis. A methodology involving the evaluation of maximum active catalyst surface area has been 
developed. The weight loss of coke in catalyzed coke oxidation was first order in coke, which enabled the straightforward calculation of a first order rate constant. When reaction rates were determined in a regime that was strictly proportional to catalyst loading, then $\mathrm{Ce}_{0.8} \mathrm{Zr}_{0.2} \mathrm{O}_{2}$ was found to be the most active oxidation catalyst. The activation energy over $\mathrm{Ce}-\mathrm{Zr}$ mixed oxides was about $120 \mathrm{~kJ} \mathrm{~mol}^{-1}$ compared to $150 \mathrm{~kJ} \mathrm{~mol}^{-1}$ of uncatalyzed reaction. The order of dioxygen in coke gasification was between $0.20-0.30$. Oxidation of $\mathrm{CO}$ was carried out to confirm the method developed. The activation energy of $\mathrm{CO}$ oxidation over $\mathrm{Ce}-\mathrm{Zr}$ mixed oxides was similar to that of coke gasification. The order of reaction in carbon monoxide was close to unity while the order in dioxygen was zero. The coke oxidation rates were very well correlated with $\mathrm{CO}$ oxidation rates, but not with oxygen storage capacity or reducibility of the catalyst, indicating that $\mathrm{CO}$ oxidation might be a useful probe for the discovery of new coke oxidation catalysts. For coke oxidation, the ratio of catalyst area to coke area in the mixture should be close to unity to maximize rate and catalyst utilization.

The most active catalyst in coke gasification with dioxygen, $\mathrm{Ce}_{0.8} \mathrm{Zr}_{0.2} \mathrm{O}_{2}$, was doped with alkaline earth metals to improve the activity towards coke gasification with steam. The calcination of a mixture consisting of $\mathrm{Ce}_{0.8} \mathrm{Zr}_{0.2} \mathrm{O}_{2}$ and a nitrate salt of alkaline earth metals resulted in a high dispersion of alkaline earth metals on the surface of $\mathrm{Ce}_{0.8} \mathrm{Zr}_{0.2} \mathrm{O}_{2}$. The coke gasification with dioxygen and steam over alkaline-earth-metal-doped $\mathrm{Ce}_{0.8} \mathrm{Zr}_{0.2} \mathrm{O}_{2}$ was performed in both TPO and isothermal reactions. The presence of catalyst decreased the peak gasification temperature by $120-170 \mathrm{~K}$ with dioxygen and by $30-60 \mathrm{~K}$ with steam compared to those without catalyst. The method developed in Chapter 2 was applied to coke gasification with dioxygen to obtain the reaction rates. However, the order of coke was zero for coke gasification with steam. At low catalyst loadings, the rate of coke gasification with steam was relatively 
constant, which could be used to represent the intrinsic rate. The rates of alkaline-earth-metal doped $\mathrm{Ce}_{0.8} \mathrm{Zr}_{0.2} \mathrm{O}_{2}$ were $20-45 \%$ of that with doped $\mathrm{Ce}_{0.8} \mathrm{Zr}_{0.2} \mathrm{O}_{2}$ in coke gasification with dioxygen. However, the rates of alkaline-earth-metal doped $\mathrm{Ce}_{0.8} \mathrm{Zr}_{0.2} \mathrm{O}_{2}$ were $115-230 \%$ of that with doped $\mathrm{Ce}_{0.8} \mathrm{Zr}_{0.2} \mathrm{O}_{2}$ in coke gasification with steam. The best catalyst composition among those studied for steam gasification of coke was $0.2 \mathrm{Ca} / \mathrm{Ce}_{0.8} \mathrm{Zr}_{0.2} \mathrm{O}_{2}$.

In summary, a method to obtain reproducible kinetics was developed for reactions involving coke. The alkaline-earth-metal-doped cerium-zirconium mixed oxide exhibited high activity for coke gasification with steam, demonstrating its potential to be used as an anti-coking coating materials for steam crackers.

\subsection{Future work}

\subsubsection{In-situ coke deposition and gasification over catalysts}

As mentioned in Chapter 2, the contact conditions of coke and catalysts have a significant effect on reactivity of coke. During steam cracking, coke is formed on the surface of cracker tube. The contact conditions are different from either tight contact or loose contact conditions. It is desirable to deposit coke on catalyst surface and study its steam gasification activity.

Our collaborators at the Georgia Institute of Technology purchased a customized thermogravimetric analyzer (TGA, NETZSCH, STA449F3 Jupiter®), which enables the feed of hydrocarbon gases, allowing in-situ deposition of coke on catalyst and support samples with

excellent coke-catalyst contact ${ }^{1}$. The coke deposition on the catalysts and supports, which occurs via a gas phase radical mechanism, depends on the reaction time, temperature, hydrocarbon concentration and sample external surface area but not on the chemical composition of the support under the conditions used. The in-situ generated coke can be compared with ex-situ 
formed coke by characterization of Raman spectra and temperature programmed oxidation (TPO) analyses. Thermal aging of coke is shown to be effective in increasing the hardness of the coke samples. Coke deposited in-situ is shown to oxidize similarly to catalyst-coke samples prepared by grinding (tight contact conditions), suggesting that in-situ coke deposition in the TGA can be used to generate samples with realistic coke-catalyst contacting, as might be found in an industrial reactor or catalyst bed.

In-situ coke deposition experiments can be carried out at Georgia Tech with our best catalysts. The kinetics of steam gasification can be studied and compared with tight contact samples prepared by grinding. The stability and sustained decoking performance of the lead catalyst formulations can be tested by consecutive decoking operations with steam in TGA over many cycles. In addition, our collaborators at Georgia Tech are exploring methods to prepare coating with ceria-based materials over metal coupons with similar compositions as the industrial cracker tubes. Once the method is developed, our best catalyst can be coated on the coupon, which will be tested for the inhibition of coke formation during steam cracking conditions.

\subsubsection{Water gas shift reaction: A possible probe reaction for steam gasification of coke}

In Chapter 2, it was shown that the coke gasification rates with dioxygen correlated well with the $\mathrm{CO}$ oxidation rates over cerium-zirconium mixed oxides. It is possible that there is a similar relationship between coke gasification with steam and the water gas shift reaction. If that is the case, the water gas shift reaction could be used as a probe for the screening of coke gasification catalysts.

The water gas shift reaction has been used widely in the manufacturing of ammonia, hydrocarbons, methanol and hydrogen ${ }^{2}$. There are four general types of water gas shift catalysts. 
The first one is chromium-iron oxide catalyst used at temperature range of $623 \mathrm{~K}$ to $723 \mathrm{~K}$, which was termed as the high temperature shift catalyst. The second one is low temperature shift catalyst used between $463 \mathrm{~K}$ and $523 \mathrm{~K}$, which is a copper-zinc oxide catalyst. The third type of catalyst is a medium temperature shift catalyst used between $548 \mathrm{~K}$ and $623 \mathrm{~K}$, which is a copper-zinc catalyst modified with iron oxide. The fourth type is precious metal-based catalyst used at temperatures lower than $523 \mathrm{~K}$. There are few studies on the water gas shift reaction over ceria-based materials or alkaline earth metals, especially at elevated temperature. Boisen et al. studied the water gas shift reaction over 12 transition metals $(\mathrm{Fe}, \mathrm{Co}, \mathrm{Ni}, \mathrm{Cu}, \mathrm{Ru}, \mathrm{Rh}, \mathrm{Pd}, \mathrm{Ag}, \mathrm{Re}$, Ir, $\mathrm{Pt}$ and $\mathrm{Au}$ ) supported on $\mathrm{MgAl}_{2} \mathrm{O}_{4}$ and $\mathrm{Ce}_{0.75} \mathrm{Zr}_{0.25} \mathrm{O}_{2}{ }^{3}$. They observed much higher activity over the $\mathrm{Ce}_{0.75} \mathrm{Zr}_{0.25} \mathrm{O}_{2}$ supported catalysts except for $\mathrm{Cu}$ and $\mathrm{Au}$. Alkaline earth metals are typically used as promoters for water gas shift catalysts. Whether or not the alkaline earth metals survive in steam at elevated temperature remains a question. The water gas shift reaction rates evaluated over alkaline-earth-metal-doped cerium-zirconium mixed oxides at elevated temperature can be compared with the rates of coke steam gasification and possibly address the question about the stability of the catalysts.

\section{Reference for Chapter 4}

(1) Mahamulkar, S.; Yin, K.; Davis, R. J.; Shibata, H.; Malek, A.; Jones, C. W.; Agrawal, P. K. In Situ Generation of Radical Coke and the Role of Coke-Catalyst Contact on Coke Oxidation. Ind. Eng. Chem. Res. 2016, 55 (18), 5271-5278.

(2) Ratnasamy, C.; Wagner, J. P. Water Gas Shift Catalysis. Cat. Rev. 2009, 51 (3), 325-440.

(3) Boisen, A.; Janssens, T. V. W.; Schumacher, N.; Chorkendorff, I.; Dahl, S. Support Effects and Catalytic Trends for Water Gas Shift Activity of Transition Metals. J. Mol. 
Catal. A Chem. 2010, 315 (2), 163-170. 


\section{Appendix A. List of Publications at University of Virginia}

(1) Yin, K. $;^{[+]}$Shou, H. ${ }^{[+]}$Ferrari, D.; Jones, C. W.; Davis, R. J. Influence of Cobalt on Rubidium-Promoted Alumina-Supported Molybdenum Carbide Catalysts for Higher Alcohol Synthesis from Syngas. Top. Catal. 2013, 56 (18-20), 1740-1751. ${ }^{[+]}$Equal Contribution.

(2) Mahamulkar, S.; Yin, K.; Davis, R. J.; Shibata, H.; Malek, A.; Jones, C. W.; Agrawal, P. K. In Situ Generation of Radical Coke and the Role of Coke-Catalyst Contact on Coke Oxidation. Ind. Eng. Chem. Res. 2016, 55 (18), 5271-5278.

(3) Mahamulkar, S. $;^{[+]}$Yin, K.; ${ }^{[+]}$Agrawal, P. K.; Davis, R. J.; Jones, C. W.; Malek, A.; Shibata, H. Formation and Oxidation/Gasification of Carbonaceous Deposits : A Review. Ind. Eng. Chem. Res. 2016, 55, 9760-9818. ${ }^{[+]}$Equal Contribution.

(4) Xie, J.; Huang, B.; Yin, K.; Pham, H. N.; Unocic, R. R.; Datye, A. K.; Davis, R. J. Influence of Dioxygen on the Promotional Effect of Bi during Pt-Catalyzed Oxidation of 1,6-Hexanediol. ACS Catal. 2016, 6, 4206-4217.

(5) Yin, K.; Mahamulkar, S.; Shibata, H.; Malek, A.; Jones, C. W.; Agrawal, P.; Davis, R. J. Catalytic Oxidation of Solid Carbon and Carbon Monoxide over Cerium- Zirconium Mixed Oxides. AIChE J. (Accepted)

(6) Xie, J.; Yin, K.; Serov, A.; Artyushkova, K.; Pham, H. N.; Sang, X.; Unocic, R. R.; Atanassov, P; Datye, A. K.; Davis, R. J. Selective Aerobic Oxidation of Alcohols over Atomocally-dispersed Non-Precious Metal Catalysts. ChemSusChem. (Accepted) 